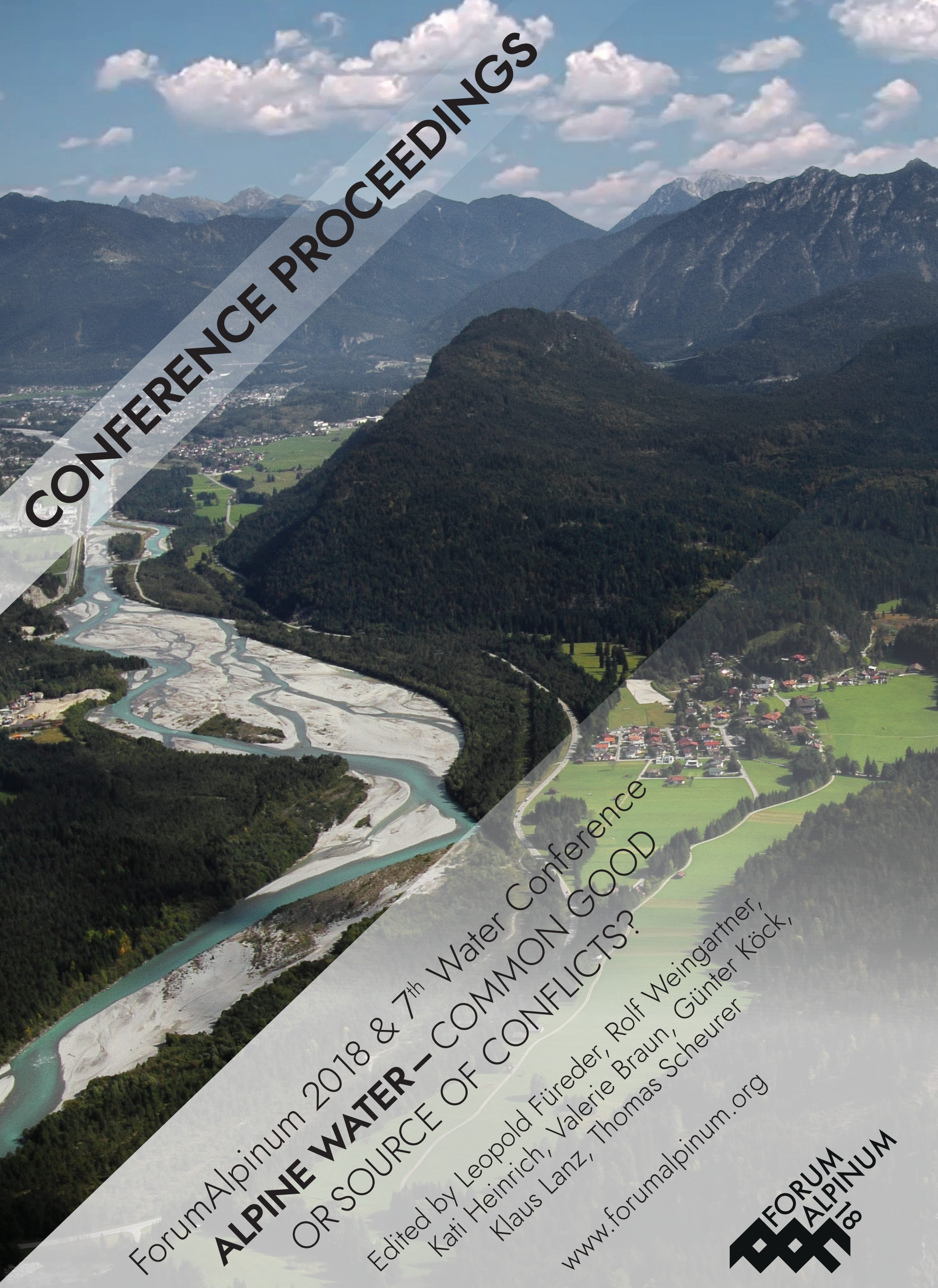




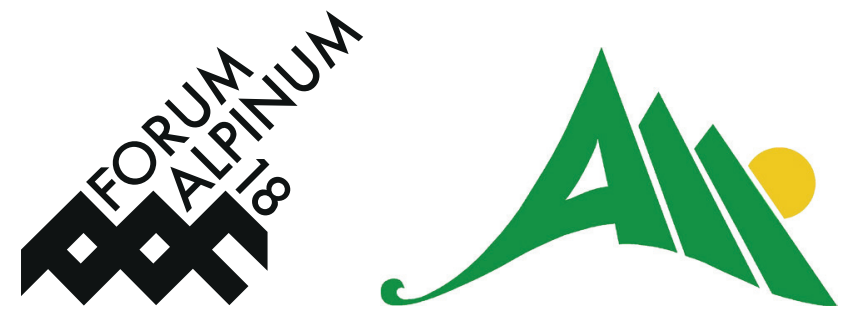

\title{
ALPINE WATER - COMMON GOOD OR SOURCE OF CONFLICTS?
}

\author{
Proceedings of the ForumAlpinum 2018 \\ and the $7^{\text {th }}$ Water Confernce
}

Breitenwang, Tyrol, Austria

June 4-6, 2018 


\section{Organisation}

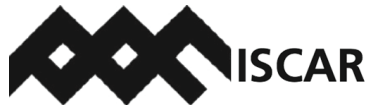

International Scientific Committee on Research in the Alps

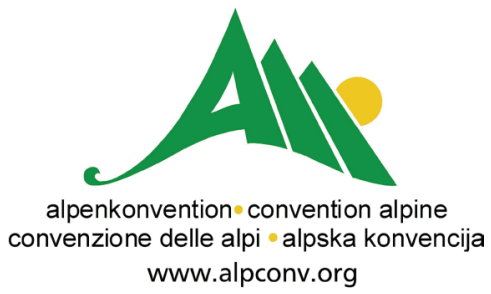

www.alpconv.org

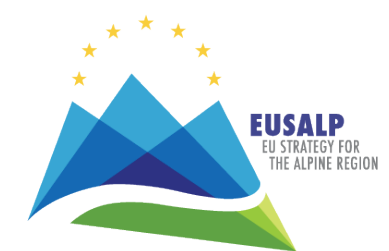

Financial support \& sponsoring

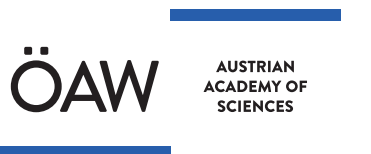

- Bundesministerium Nachhaltigkeit und Tourismus

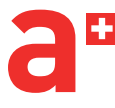

Akademien der Wissenschaften Schweiz Académies suisses des sciences Accademie svizzere delle scienze Academias svizras da las scienzas Swiss Academies of Arts and Sciences

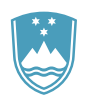

REPUBLIC OF SLOVENIA MINISTRY OF THE ENVIRONMENT AND SPATIAL PLANNING

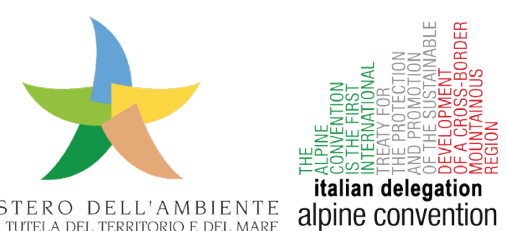

MINISTERO DELL'AMBIENTE

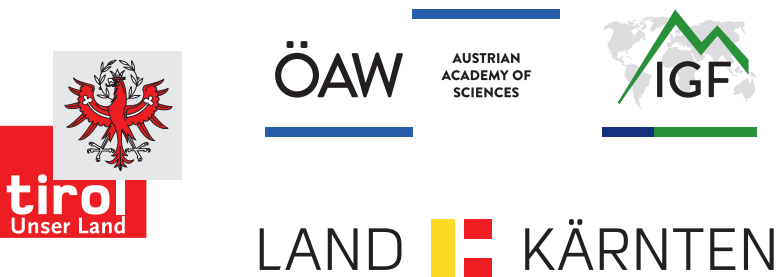

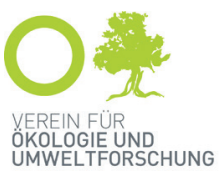
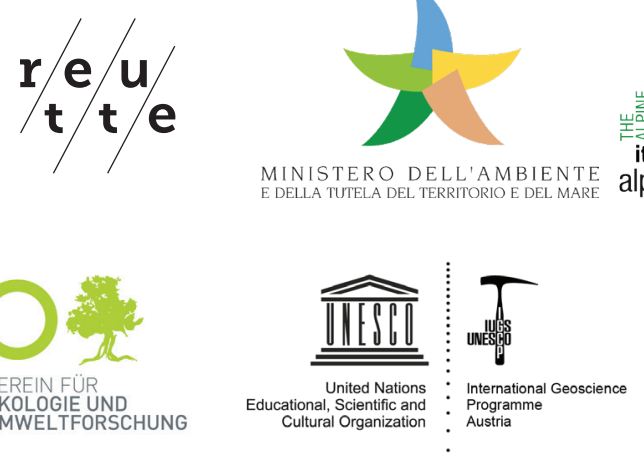

PLANSEE

The Plansee Group
National committee for "Global Change" of the ÖAW National committee for "Geo/Hydro-Sciences" of the ÖAW

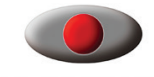

POLSCH TV TIION

\section{science} vision

\section{Impressum}

Editors: Leopold Füreder, Rolf Weingartner, Kati Heinrich, Valerie Braun, Günter Köck, Klaus Lanz, Thomas Scheurer

Coordination: Heidi Humer-Gruber, Valerie Braun, Thomas Scheurer

Layout: Kati Heinrich \& Valerie Braun

Proofreading: Brigitte Scott

Cover photo: Charly Winkler

Cover layout: Benjamin Scheurer \& Kati Heinrich

ISBN-Online: 978-3-7001-8353-2

DOI: 10.1553/forumalpinum2018

Citation: Füreder L., R. Weingartner, K. Heinrich, V. Braun, G. Köck, K. Lanz, T. Scheurer (eds.) (2018) Alpine Water - Common Good Or Source Of Conflicts? Proceedings of the ForumAlpinum 2018 and the $7^{\text {th }}$ Water Conference, 4.-6. June 2018, Breitenwang (Tyrol). Austrian Academy of Sciences Press. ISBN-Online: 978-3-7001-8353-2. DOI: 10.1553/forumalpinum2018

(C) 2018 Austrian Academy of Sciences Press

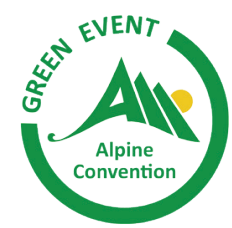




\section{ALPINE WATER - COMMON GOOD OR SOURCE OF CONFLICTS?}

Changing environmental and climatic conditions as well as growing demand is likely to lead to conflicts in water use and water management in the Alps. This ForumAlpinum will identify hot spots of water use and management in the Alps, will analyse target conflicts, assess their relevance in a regional, national or international context, and discuss possible solutions.

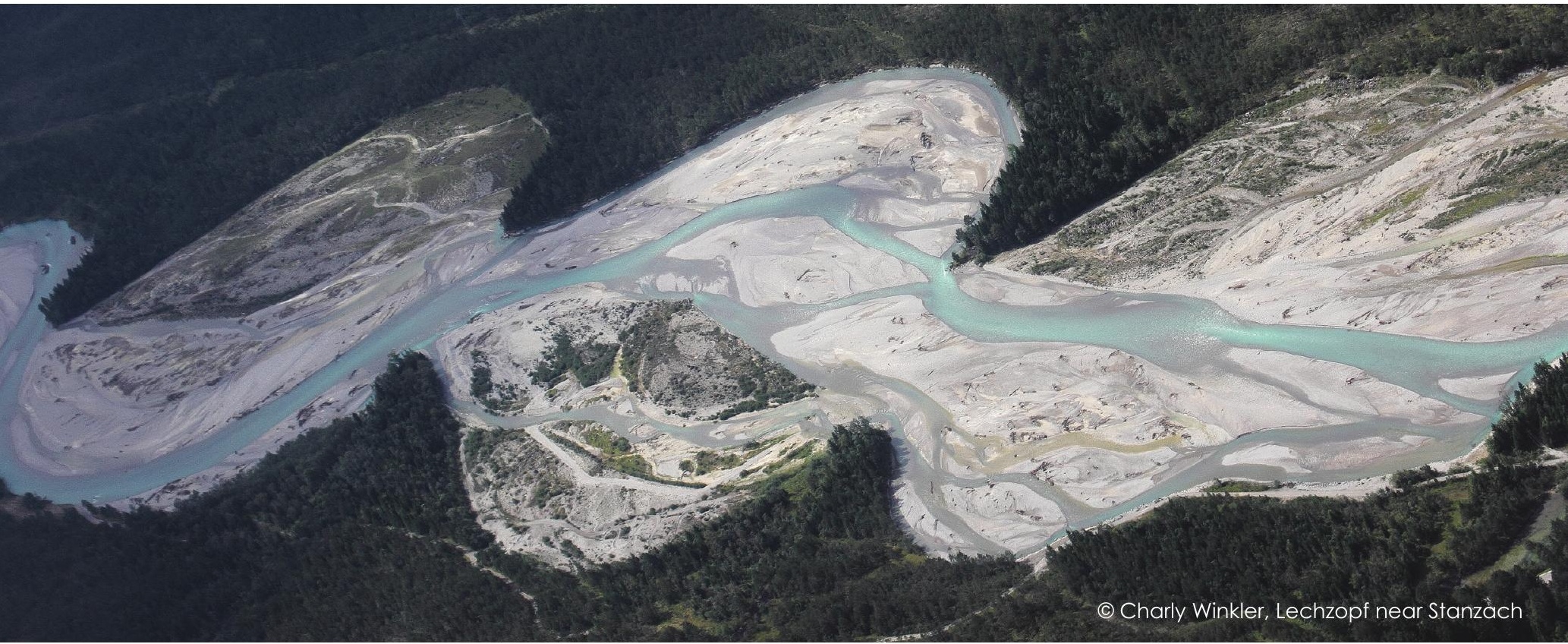

\section{CONTENT}

\section{Foreword by the editors}

The Tyrolian Lech valley - living with a wild river Policy Brief

Action needed to prevent future conflict over the use and management of water in the Alpine region in times of climate change and growing demand

Mapping of Hydrological and water-driven hotspots in the Alps

Water-related hotspots in the Alps

Changing resources and seasonality

Emerging water-related hotspots and hazards from climate change

Emerging water-related hotspots and hazards from socio-economic changes

Springs under pressure

Monitoring and managing European Union species and habitats of Alpine rivers

\section{$7^{\text {th }}$ Water Conference}

Findings from the $7^{\text {th }}$ Water ConfereNce

The impacts of and response to droughts in the Alpine region
Green infrastructure for an integrated and sustainable water management

Common guidelines for the use of small hydropower in the Alpine region

Conflicting water use in the Alps

Local water use: water supply, agriculture, tourism

Tourism

Ecological integrity of rivers

Managing conflicting water use

Learning from the past for the management of present and future water-related conflicts: Dealing with floods and flood risk in historical Alpine societies

Mitigating future water conflicts

Alpine multi-purpose reservoirs: Future potential and relevance

Poster session: Abstracts

\section{Programme}

Participants

48

58

61

65 74 7

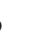





\section{FOREWORD BY THE EDITORS}

The focus of the ForumAlpinum 2018 entitled "Alpine Water - common good or source of conflicts?" lay upon upcoming conflicts in water use and water management in the Alps, mainly against the background of changing environmental and climatic conditions as well as growing demand for water and riverine space. During the well attended conference, the following questions were discussed: What will be the hotspots of conflicting water use and water management in future and where will they occur? To what extent will water use and management have to be adapted to the expected changes in availability or demand? Are there any conflicts in water use emerging already? Do we have appropriate instruments for avoiding or solving water management conflicts?

The proceedings summarize the different aspects presented and discussed during the ForumAlpinum. Three contributions stand out that synthesize important issues of the Forum:

- Action needed in policies concerning water use and management in the Alps: The challenges and the need for action to overcome or mitigate future conflicts in the use of water and riverine space are anticipated in a Policy Brief addressed to the Water Platform of the Alpine Convention and to responsible authorities in water-related policies (page 9)

- Mapping water hotspots in the Alps: A specific method for identifying existing and future water-related hotspots of water use in the Alps has been developed for the ForumAlpinum. The method and the result of the mapping process are presented and discussed on page 14.

- $7^{\text {th }}$ Water Conference of the Alpine Convention: ISCAR especially welcomed the idea to integrate the ForumAlpinum with this conference on water topics treated by the Water Platform of the Alpine Convention and EUSALP. The main results of the $7^{\text {th }}$ Water Conference are presented on page 38.

The ForumAlpinum 2018 - the $13^{\text {th }}$ Forum since 1994 - and the $7^{\text {th }}$ Water Conference were organized by the International Scientific Committee on Alpine Research (ISCAR) in cooperation with the platform Water Management in the Alps of the Alpine Convention and Subgroup 3, Integrated and sustainable water management, of Action Group 6 of the EU Strategy for the Alpine Region (EUSALP). Our sincere thanks go to the Alpine Convention and EUSALP, especially to Paolo Angelini, Luca Stravs, Christian Schilling, Andrea Bianchini and Taja Ferančič, for enabling and preparing this joint conference.

The ForumAlpinum 2018 was organized in Austria on the occasion of the Austrian Presidency of the Alpine Convention (2017-2018), with the financial support of the Austrian Academy of Sciences, the Swiss Academies of Arts and Sciences, the Federal Province of Tyrol, the Austrian Federal Ministry for Sustainability and Tourism, and the Italian Ministry for the Environment, Land and Sea. We are very grateful for these important financial contributions, also to the sponsors listed in the proceedings.

Finally, our gratitude extends to all speakers and session chairs, the scientific board and organization staff and the Conference Centre in Breitenwang, and, last but not least, to all participants for their contributions to an inspiring ForumAlpinum 2018.

Univ.-Prof. Dr. Leopold Füreder, University of Innsbruck

Prof. Rolf Weingartner, University of Berne

Dipl.-Ing. Kati Heinrich, MSc, Austrian Academy of Sciences, Innsbruck

Dr. Valerie Braun, Austrian Academy of Sciences, Innsbruck

Dr. Günter Köck, Austrian Academy of Sciences, Vienna

Dr. Klaus Lanz, International Water Affairs, Evilard

Dr. Thomas Scheurer, Swiss Academy of Sciences, Berne 



\section{THE TYROLIAN LECH VALLEY - LIVING WITH A WILD RIVER}

The Tyrolean Lech in northwestern Austria is one of the last wild rivers in the Alps and the flagship of the Tyrolean Lech Nature Park and the Natura 2000 site. A unique mixture of nature, culture and crafts shapes the communities in the Lechtal, including the old market town of Reutte and the conference venue of Breitenwang. Breitenwang is the starting point for mountain sports and exploration of the unique wild river landscape.

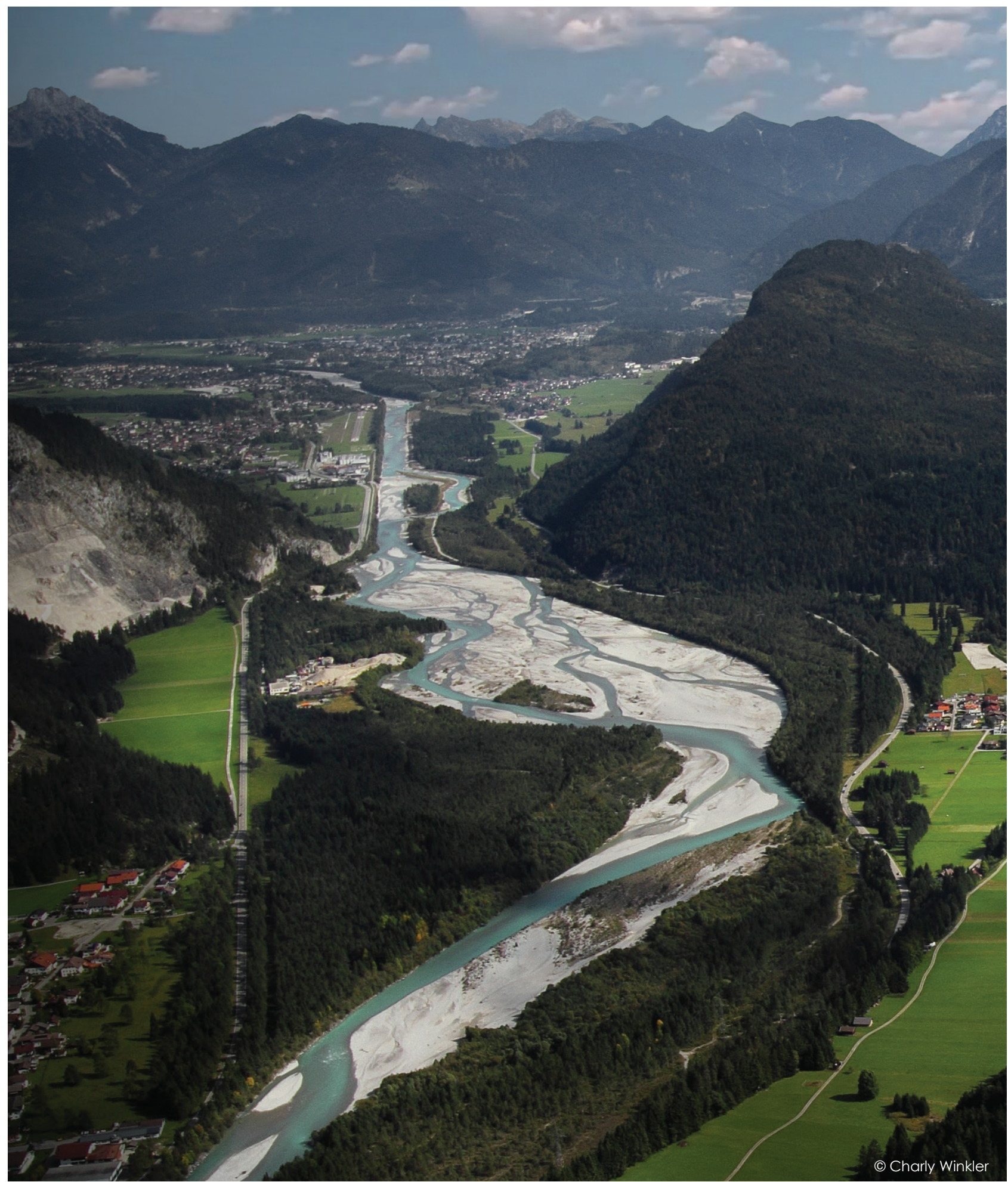





\title{
ACTION NEEDED TO PREVENT FUTURE CONFLICT OVER THE USE AND MANAGEMENT OF WATER IN THE ALPINE REGION IN TIMES OF CLIMATE CHANGE AND GROWING DEMAND
}

\author{
Key messages from the ForumAlpinum 2018 \& the $7^{\text {th }}$ Water Conference \\ (June 4-6, Breitenwang, Austria)
}

THOMAS SCHEURER, ROLF WEINGARTNER, KLAUS LANZ

Expected future changes in climatic conditions as well as the availability of and demand for water in the Alpine region will result in novel stakeholder constellations in water use and lead to new social and legal requirements for water management. This policy brief highlights the major challenges for the use and management of water from local to macro-regional scale. Many of these challenges concern areas and regions throughout the entire Alpine space, and solutions are best sought through international coordination and cooperation, e.g. within the framework of the Alpine Convention or the Alpine macro-region. Therefore this policy brief addresses especially the water-related bodies of the Alpine Convention and EUSALP, including national and regional authorities.

\section{DRIVERS OF FUTURE WATER AVAILA- BILITY AND WATER DEMAND IN THE ALPINE REGION}

A changing climate, manifested in higher temperatures, changing precipitation patterns, higher evaporation rates and novel atmospheric patterns, will alter water availability and regional water balances, particularly in the second half of this century. In the Alps, the increase in temperature is expected to exceed the global average considerably. It will significantly alter the role of snow and ice in the water balance: Less winter precipitation will be retained as snow and run off directly, reducing snow and snow cover in winter as well as spring and summer snowmelt and thus water availability in summer. Retreating glaciers will further decrease summer runoff. Precipitation is expected to increase during winter and decrease during summer. As a consequence, reduced summer runoff and a higher likelihood of drought periods in summertime are expected.

Natural hazard regimes will also change. Melting permafrost, together with the predicted rise of extreme precipitation events, will destabilise slopes and lead to increased accumulation of debris. This will increase the likelihood of debris flows and flood events. An adaption of risk management to these new challenges is urgently needed.

Alpine rivers and landscapes will change markedly as a result of climate change. In summer, white perennially snow-covered mountains will change to pebblegrey. Floodplains and new lakes will emerge where glaciers dominate today.

Socio-economic change will generally increase the pressure on water systems through greater demand for water (hydropower, public supply, irrigation, heating / cooling, snow making) and for riverine space (settlements, infrastructures, flood protection). Demand will also rise in adjacent downstream regions (water supply, irrigation, cooling water), underlining the transregional importance of the Alpine region and its change. Water demand is in part seasonal or time-specific (e.g. irrigation during summer, cooling during heat waves, water for artificial snow or electricity in winter) and often not in tune with natural availability. To accommodate seasonally fluctuating water demand, artificial water storages could be extended (e.g. enlarging existing or building new reservoirs or artificial lakes). 
Further socio-economic pressures on water resources come from water pollution and the impacts on hydromorphology of dams, embankments etc.

In view of these trends, competition for the use and management of water resources in the Alpine region is likely to intensify, and additional situations of competition and even conflict are likely to arise. To prevent an increase of conflict over water use, water quality, and riverine space, new cooperative approaches are required in water policy and management. It is time to act now to prevent such conflicts in the future.

\section{CURRENT AND EMERGING COMPETI- TION AND CONFLICT OVER THE USE AND MANAGEMENT OF WATER}

Given the expected changes in water availability and demand, conflict over water use and management in the Alpine region will emerge or intensify in four dimensions: amount of water, water quality, spatial demands and landscape.

\section{(1) Conflicts over the amount of water}

Potential conflicts regarding the available amount of water will increase in future: With water becoming more scarce in the summer season, competition will increase between consumers such as agriculture / forestry (irrigation), hydropower, industry and tourism (golf, water sports, etc.). Intensive irrigation agriculture will be affected first. In winter, competing demands between tourism, water supply and hydropower occur mainly locally in areas with high water consumption by tourism (technical snow making, drinking water, water supply, wellness). With energy policies focusing on renewable $\mathrm{CO}_{2}$-free sources, hydropower production will remain an important option for producing electricity. Conflicts that have existed for decades in the transitional area between ecology and economy will continue to exist and could even intensify.

\section{(2) Conflicts over water quality}

Water quality remains an important element of management despite enormous improvements in reducing nutrient intake in the past 60 years. Various sources will continue to affect water quality and restrict the use of water and fishery : a) persistent pollutants from industry and households, which are not satisfactorily removed by wastewater treatment, a situation exacerbated in rivers during low flow or cold periods and in sediment traps; b) agricultural input of pesticides and nutrients into ground- water, rivers, and lakes; c) the thermal use of water for heating and cooling as a new and growing issue; d) pollutants from contaminated constructions or sites (i.e. PCB). Such conflicts will concentrate in urbanised and intensively cultivated valleys.

\section{(3) Conflicts over spatial demands}

... arise, where sprawling urbanization, industrial development, and transport infrastructures are expected to expand further, mainly on valley floors and in areas attractive for tourism. An increase in intensively used or even sealed surfaces will conflict with space required for the regeneration and protection of groundwater as well as for rainwater and flood retention. No new construction should occur in areas threatened by floods and debris flow.

\section{(4) Conflicts over hydro-morphology and landscape}

Areas with little or no human impact have become rare in the Alps. But the natural integrity and ecological connectivity of aquatic ecosystems and habitats (rivers, springs, wetlands, floodplains, lakes) is essential to the longterm vitality of the entire Alpine water system, as well as for aquatic biodiversity and attractive landscapes. Any relenting to further socio-economic demands that change the natural water regime is likely to increase pressure on the remaining and even on protected nearnatural aquatic ecosystems, wetlands, and water resources.

Hotspots of current and future conflict over the use and management of water in the Alpine region have been identified mainly in these (partly overlapping) areas:

- Urbanised and intensively used valley plains (e.g. Inn valley) (Conflicts 1, 2, 3)

- Tourism areas (e.g. Crans Montana) (Conflicts 1, $2,3,4)$

- Areas periodically suffering from water scarcity or drought (e.g. Trento) (Conflicts 1, 3)

- Alpine rivers \& river basins (e.g. Isar or Isère catchment) (Conflicts 1, 2, 3, 4)

- Aquatic habitats of high ecological integrity (e.g. wetlands, moors) (Conflicts 1, 2, 3, 4)

- Areas with destabilization (e.g. slopes in permafrost areas, bedload) (Conflict 3, 4)

Hotspots of conflicting use and management of water share these common characteristics:

- Conflicts are often cross-border and multi-level (local to regional to national to international)

- Conflicts are trans-sectoral, i.e. different stakeholders, public service sectors and scientific disciplines are involved and in need of cooperation 
- Usually numerous (natural and/or social) drivers and interests are involved.

The prevention of conflicts over the use and management of water will require new approaches in cooperation and coordination that involve all aspects mentioned and all interests at stake.

\section{ACTION NEEDED TO PREVENT CON- FLICT OVER THE USE AND MANAGE- MENT OF WATER}

Five fields of action have been identified as most urgent for the Alpine region:

\section{(1) Balance water availability and water use}

Demand and availability of water can be balanced either by demand control, by efficiency measures or by an improvement in water supply systems. A balanced water management also ensures sufficient residual water in Alpine rivers.

Demand side: Numerous options are available to reduce water consumption or to make it more efficient, particularly in agriculture (e.g. drip irrigation), industry (e.g. reuse wastewater), energy production (e.g. more efficient turbination), and tourism (e.g. concentration of snow making at higher altitudes).

Action is needed to improve the efficiency of water use in Alpine regions.

Supply side: A concerted large-scale assessment of future water demands and storage options can lead the way to adequate water availability at times of seasonal or drought-induced water scarcity. Storage options need to consider both multifunctional management of conventional dams (mainly at high altitude) and decentralised interlinked smaller units (e.g. ponds, underground storage, artificial groundwater recharge). Ideally, future water storages will be multifunctional, supplying water for energy production, irrigation, snow-making and wastewater dilution, sustain ecological flow and sediment transport in rivers, and retain floodwaters. Where appropriate, they ought to be combined with existing storage units. Compared to traditional storage, adapted or new multifunctional storage systems need to fulfil highest landscape and environmental standards and contribute to the attractiveness of Alpine areas.

Action is needed for (cross-border / macro-regional) planning of storage networks and their operation, integrating all stakeholders and parties concerned.
It is also necessary - where applicable from a cross-border perspective - to develop operative priorities in times of water scarcity and emergency plans to deal with droughts.

\section{(2) Reduce water pollution}

The concentration of micro-pollutants in many rivers, lakes and groundwater bodies is still on the increase and jeopardises aquatic ecology as well as the supply of clean drinking water. While pollutant discharge from wastewater treatment plants can be reduced by further treatment steps, inputs from non-point sources, such as agriculture, urban areas and atmospheric deposition, pollutants from older constructions (e. g. PCB in dams, military buildings), mining, shooting ranges and waste deposition require legal action.

Action is needed to optimise agricultural and industrial technologies and production systems in order to reduce micro-pollutants at source.

Further action should be taken and to improve wastewater treatment as periods of low flow and hence low effluent dilution are becoming more frequent.

Restoration of polluted sites or contaminated constructions (especially PCB in dams) remains an important focus.

\section{(3) Prevent conflict along rivers and in riverine plains}

Rivers and their plains are essential landscape elements of Alpine valleys and attract a wide range of interests. Promising methods for balancing interests have been developed in several countries (e.g. river dialogue in Austria, Network of River Contracts in Italy, River Watch by WWF, space reserved for water (Gewässerraum) in the Swiss federal law for water protection). They are being further elaborated in projects like SPARE. River dialogues have to take in the entire river basin, including tributaries, lakes, groundwater and riverine zones. This includes setting aside areas needed for risk prevention: zones potentially exposed to high risks of extreme events, such as flooding, debris flow or avalanches, need to be kept free of settlements and valuable assets. Also, ever more frequent periods of low flow in rivers and springs need to be taken into account.

Action is needed to implement insights of existing approaches in local and cross-border dialogue efforts along river basins and to further develop and strengthen them.

Special attention must be paid to the encourage natural water retention measures and develop environmentally sound low-flow management practices for residual water sections, in low-flow sections with treated wastewater, and in case of water scarcity. 


\section{(4) Preserve remaining near-natural aquatic ecosystems and landscapes}

Growing societal demands for water, water storage and land will add pressure on the remaining natural lakes, ponds, rivers, springs and wetlands. In an increasingly overused landscape, these aquatic elements and their surroundings are pivotal reservoirs of biodiversity and deserve the highest degree of protection. Not to forget their role as important assets for tourism, wellbeing and recreation.

Action is needed to fully enforce existing conservation legislation on aquatic ecosystems and to ensure their ecological connectivity and biodiversity.

Protection must be improved for endangered pristine springs, based on an action plan and monitoring across the entire Alps.

Protected areas In particular need to take on full care of pristine aquatic ecosystems.

\section{(5) Provide useful data and develop appropriate procedures}

Presently, there is a general lack of water consumption data in all sectors. Such data are a prerequisite for any water management and holistic planning. Similar to the above-mentioned river dialogues, new dialogue models should be developed for regional and cross-border water management. Such dialogues will help to balance public and private ownership, as well as upstream and downstream interests, prioritise water use in times of scarcity and coordinate cooperation.

Action is needed, first, to monitor water use by individual actors, specified by time of demand. This should be compared to and balanced with actually available water resources.

Second, short and mid-term forecast systems for soil bumidity, river run-off and groundwater levels need to be established to help predict availability and demand, ensure adequate water allocation and avoid overexploitation of resources, particularly in times of drought and scarcity.

Third, novel approaches should be established to ensure cooperation and coordination in complex water management issues. 


\title{
MAPPING OF HYDROLOGICAL AND WATER-DRIVEN HOTSPOTS IN THE ALPS
}

\author{
CHAIR: ROLF WEINGARTNER, UNIVERSITY OF BERN
}

\begin{abstract}
Although there is sufficient water in the Alpine region, seasonal and regional scarcity of supply must be expected in the future. In addition, global warming will lead to a destabilization of high mountain areas and change the landscape. These developments are overlaid by the socio-economic dynamics and the increasing water demand of existing and new user groups. Module 1 aims to identify, describe and locate current and future conflicts of use in the Alpine region. To this end, the participants work out an exemplary overview of water-related conflicts (hotspots). The results form the basis for the discussion in the ensuing modules.
\end{abstract}

\section{Keynotes}

\section{Analysing Alpine water-related hotspots: setting the ground}

\author{
Rolf Weingartner, University of Bern
}

Despite the abundance of water in the European Alps, conflicts over the utilization and protection of water resources have a long history. Water conflicts are commonly regarded as competition for water use, for instance, when hydropower production is limiting residual water flows in downstream river stretches. However, conflict of interest in the water sector is going far beyond questions of water distribution. The quality of water resources, the hydromorphological state of rivers and lakes, and issues of space are further important causes of water management conflict. In a changing climate, expanding our perception and understanding of water management conflicts is ever more crucial.

\section{Introduction to the workshops: What is a water-related hotspot and how can we map it?}

\section{Klaus Lanz, International Water Affairs}

\begin{abstract}
Water-related hotspots are situations in which a societal demand in the water sector can no longer be met. In order to understand the causes of such water management conflicts and to work on solutions, it is crucial to identify the societal or stakeholder interests involved and the underlying nature of the conflict. The proposed mapping exercise aims at a systematical characterization of water-related conflicts of interest in the Alps. Its objective is to gain a comprehensive perception of the extent of conflict in the water sector. The focus will be both on existing situations and on conflicts of interest expected to develop in the future, either caused by climate or by societal change.
\end{abstract}




\section{WATER-RELATED HOTSPOTS IN THE ALPS}

\section{KLAUS LANZ, KATI HEINRICH \& ROLF WEINGARTNER}

\section{INTRODUCTION}

Water in the Alps is usually associated with abundance, and with danger. For ages, human civilization has concentrated on harnessing it - be it to make use of its powers, be it to protect society from flood waters. Alpine countries profit markedly from the abundance of electricity and cool freshwater. Apart from hydropower and drinking water supply, they are making use of the element for industry, cooling, heating, irrigation and snow-making. At the same time, ambitious goals have been established regarding biological quality and hydromorphology of rivers and lakes. Alpine waters have thus become the subject of a large number of expectations and demands.

Considering the large number of potential demands, conflict is inevitable. However, public perception of water-related conflict is limited. Media seldom pick up water issues, unless drought or flooding directly affect a large number of people. In reality, water-related conflict situations occur much more frequently. Some are dealt with in the daily workings of public authorities, others remain to be assessed and resolved.

Water policy centres on four main goals:

1. to balance water utilization with water availability, i. e. river flow, lake and groundwater storages,

2. to protect water quality,

3. to protect and restore a hydromorphology that ensures the ecological and hydrological functioning of rivers and lakes,

4. to set aside sufficient space for revitalization as well as flood and pollution control.

In recent decades, attention has focused on water utilization issues (such as ensuring residual flows in the management of hydropower, irrigation and snowmaking), and on quality issues (wastewater treatment, prevention of agricultural pollution).
In the past 25 years, however, triggered by the more holistic perspective on rivers and lakes established by the 2000 EU Water Framework Directive, it became clear that the ecology of water bodies is not just governed by flow and chemical quality, but also by hydromorphology. The subsequent assessment of European waters revealed severe deficits regarding hydromorphological status, specifically in mountain regions, and mitigating measures are being planned.

The role of space in water management only becomes clear in a comprehensive analysis of all water-related societal demands. Space needs to be reserved for flood retention areas, to protect drinking water wells from pollution and, above all, to allow rivers to flow more freely and to ecologically connect with the surrounding landscape. In the valley floors of Alpine rivers, space is particularly scarce and demands are numerous. In most places, society has failed to reserve sufficient space for water management and flood control. While these appear to be mere land-use and land-ownership issues, they are also water-related conflicts. Overlooking them means omitting a crucial element of comprehensive water management.

\section{A MAPPING EXERCISE}

A mapping exercise was carried out on the occasion of ForumAlpinum 2018 in Breitenwang, Austria. The objective was three-fold: first, to collect and analyse as many typical water-related conflict situations (hotspots) in the Alps as possible; secondly, to increase awareness among participants for water-related conflicts beyond water utilization; thirdly, to gain a common understanding and definition of a water-related conflict. To this end, we asked participants to name and characterize water-related conflicts of interest in the Alps. A mapping form with detailed instructions for characterization was provided online and in print. 


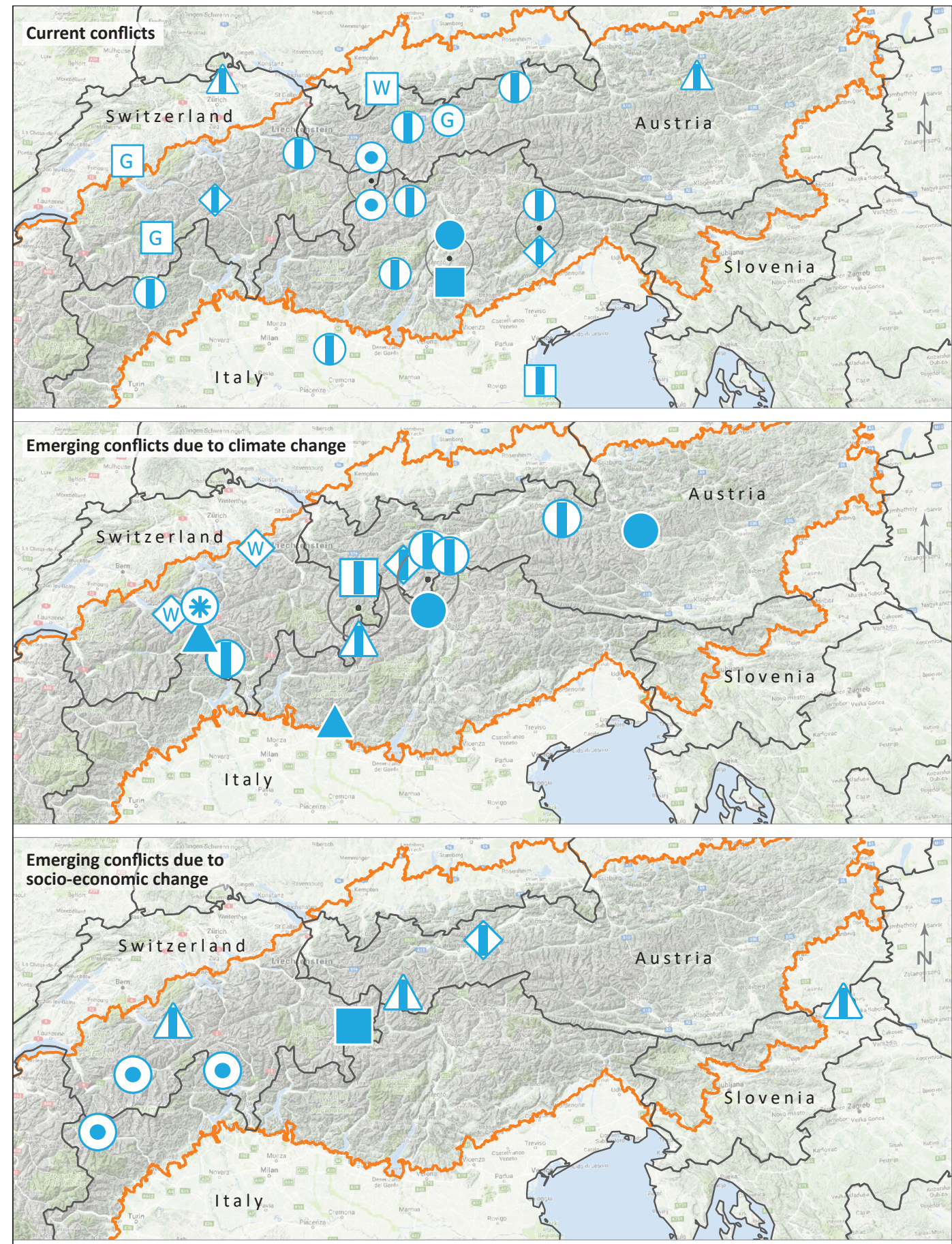

Hydrological and water-driven hotspots in the Alps mapped during the Forum Alpinum 2018

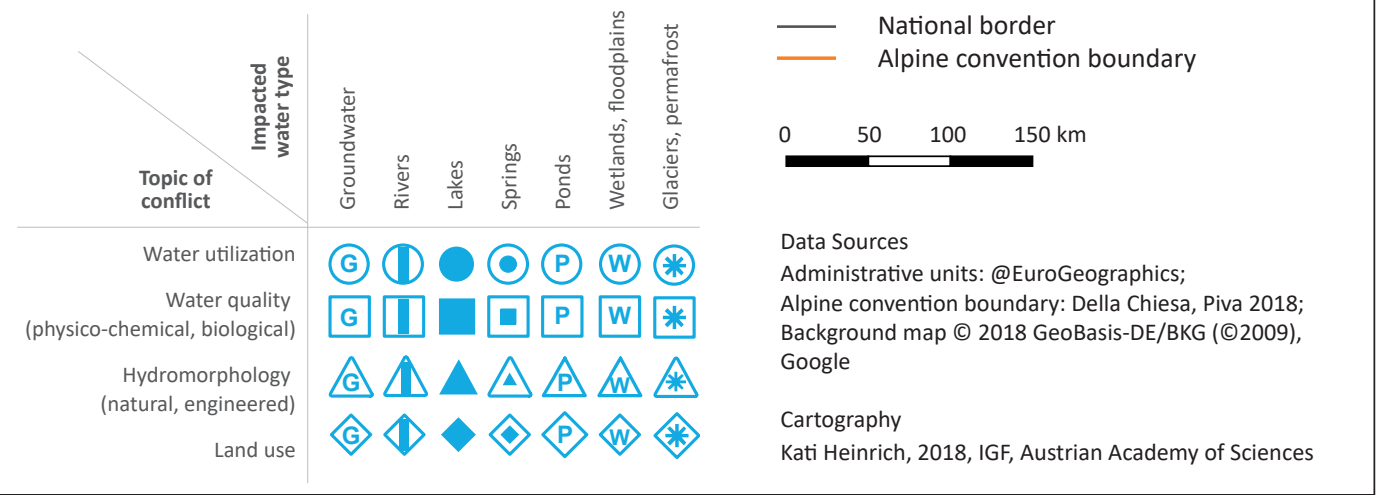

Fig. 1: Mapping 
The characterization of each hotspot followed a sixstep procedure:

A. Geographical localization: hotspots could be marked on the map as point (e.g. a spring), line (e. g. a river), or area (e.g. a lake or wetland)

B. Occurrence of conflict: occurring today, expected to occur in the future (caused by socio-economic change), expected to occur in the future (caused by climate change)

C. Identification of the water body involved: groundwater, river, lake, spring, pond, wetland/floodplain, glacier/permafrost

D. Identification of conflict type: water utilization, water quality (physico-chemical, biological), hydromorphology (natural, engineered), land use/landscape

E. Identification of the societal demands (or stakeholder groups) involved: energy, tourism/leisure, agriculture/forestry, municipal water supply, flood control, aquatic ecology and landscape, fisheries, industry/trade, transport (road, rail), land owners

F. Most promising solution approaches: stakeholder cooperation, mediated compromise, extended planning perimeter, improved implementation of law, adaptation of legislation, participatory planning to avoid conflict, others.

Finally, participants could supply additional information on the conflict hotspot. In total, 43 hotspots were submitted and analysed.

\section{ANALYSIS OF MAPPING HOTSPOTS}

- Map of conflicts occurring today

- Map of emerging conflicts due to climate change

- Map of emerging conflicts due to socio-economic change

\section{Mapping results}

43 cases were submitted during the mapping procedure. Fig. 2 shows the relative importance of the water bodies involved, with rivers in the majority. Cases involving lakes and springs were named much less frequently, while only a few conflicts over groundwater, wetlands and glaciers were submitted by participants.

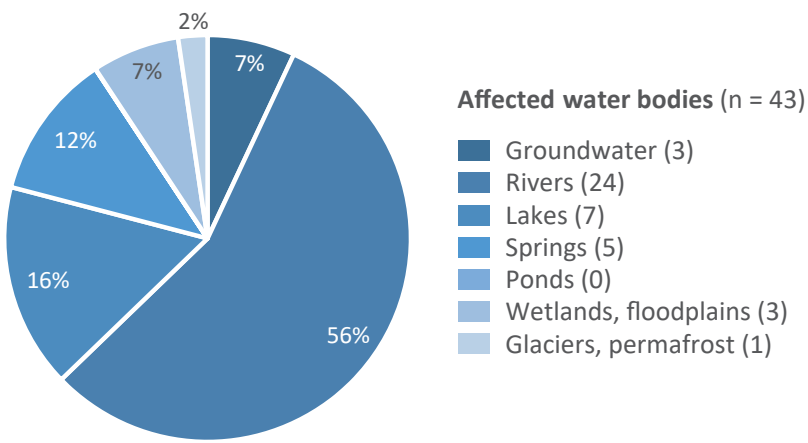

Fig. 2: Breakdown of water bodies

\section{Mapping tool}

The mapping algorithm consists of three steps:

- Locating the hotspots in Google Earth

- Filling in an analogue or web form with detailed information about the conflict at each hotspot

- $\quad$ Processing the data in a geographic information system (i.e. QGIS) for analysis and interpretation.

The aim was to develop an easy to use method to document hydrological and water-driven hotspots during the conference and afterwards. In a first step, the hotspots were mapped with Google Earth. Each point was characterized by its coordinates (longitude, latitude) and an identification number (clear ID). The data were exported as a $\mathrm{kmz}$ file which is a compressed $\mathrm{kml}$ (keyhole mark-up language) file and includes a set of features (e.g. place marks, images, textual descriptions etc.). For the purpose of gathering detailed information about the conflict point, Breezingforms ${ }^{1}$ for Joomla!@ was used and included in a temporary project website run by the Institute for Interdisciplinary Mountain Research at Innsbruck. Thematic information about the impacted water type, the topic of conflict, the stakeholders involved and promising solutions were recorded, as well as details of when conflicts would occur, location description and contacts. As a result, a csv file with all data was exported.

Finally, the Google Earth kmz file was imported into a geographic information system (GIS, i.e. QGIS), with each data point linked to the thematic information from the returned forms using the clear ID. The geographical information system allowed further analyses, data preparation and interpretation, and the creation of maps.

https://crosstec.org/en/downloads/breezingformsfor-joomla.html 
In terms of the societal demands at stake in the conflict cases, energy production, tourism and agriculture/ forestry are the most frequently mentioned economic activities, with concerns over aquatic ecology and landscape involved in similar numbers (Fig. 3). Flood control, municipal water supply and fisheries come second, and the importance of spatial water-related conflicts is reflected by the occurrence of land owners as stakeholders.

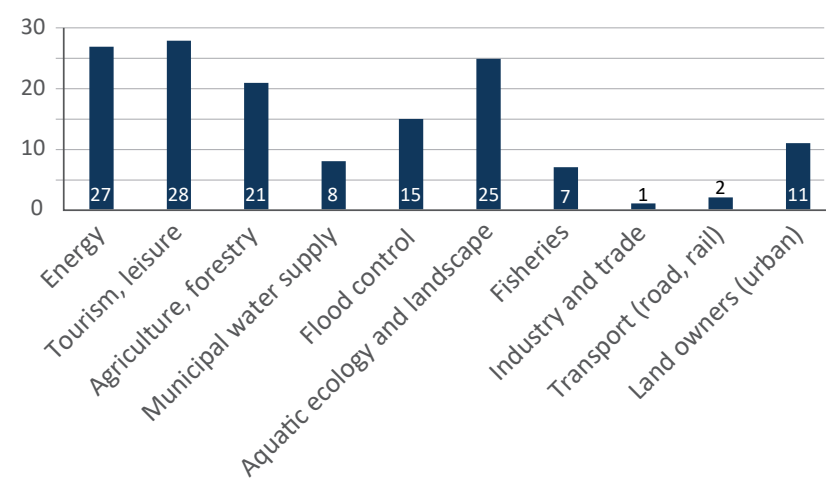

Fig. 3: Breakdown of societal demands

Hotspots concerning water utilization were named more than twice as often as other types of conflict (Fig. 4). A much smaller number of quality, hydromorphology and land-use issues were submitted. This relative weighting could be a result of participants' professional background: hydrologists might be more likely to identify water quantity issues and less familiar with quality and land-use issues which are not central to their everyday work.

The submitted cases also show a higher incidence of quality issues for groundwater ( 2 of 3 ) and lakes ( 2 of 7 ) than for rivers (2 of 24). No quality conflicts were mentioned for springs (Fig. 5).

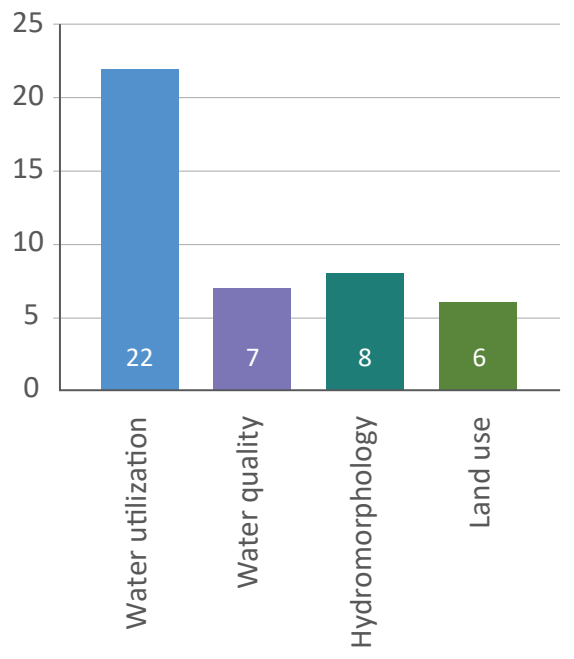

Fig. 4: Types of conflict

\section{PATTERNS OF CONFLICT}

Thorough analysis of the 43 hotspot submissions revealed a pattern of pronounced altitudinal differentiation. While at high altitudes the impact of socioeconomic activities is low, their influence increases with decreasing elevation and reaches its maximum in Alpine river valleys. Climate change mainly expresses itself via the hydrological system, here the altitudinal dependence runs in the opposite direction: most pronounced climate change impact at high altitudes, decreasing with elevation.

To support and underpin this interpretation, we are using six concrete examples illustrating specific conflict situations typically occurring at various altitudinal regions (see Fig. 6).

Fig. 5: Impacted water bodies by type of conflict

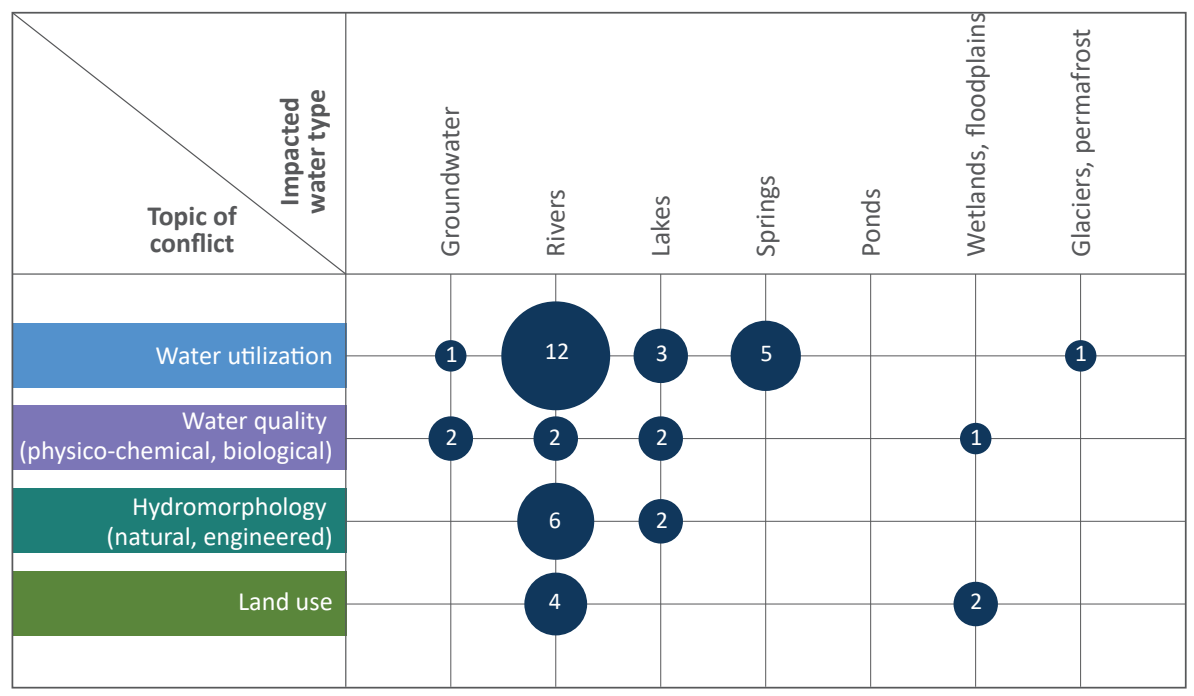




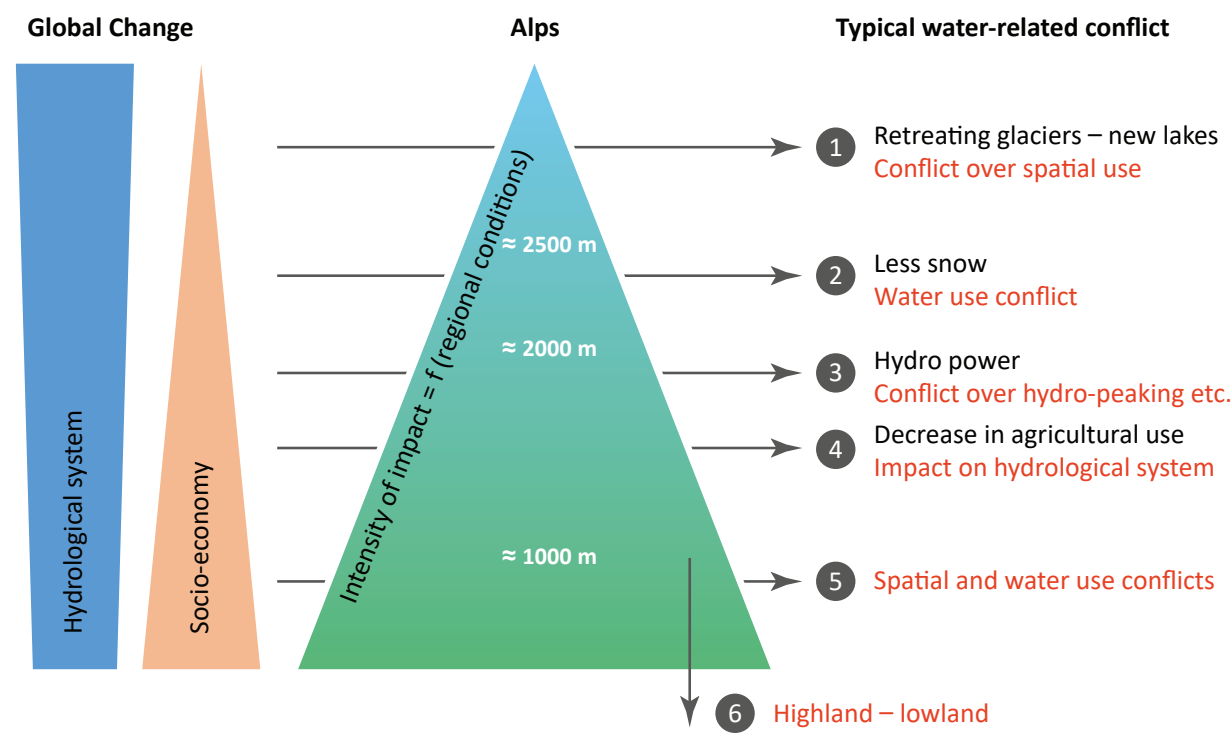

Fig. 6: Patterns of conflict (Source: Rolf Weingartner)

\section{Trift Project}

At the highest altitude range, above $2500 \mathrm{~m}$, the retreat of glaciers is expected to be an important cause of water-related conflict of interest. Entirely new landscapes will emerge, including a substantial number of new lakes in depressions left by glaciers, and society will have to decide how to deal with them. These new lakes could either be left to themselves and - where appropriate and possible - develop into tourist attractions, or they could be enlarged by new dams to be used as reservoirs for hydropower or other uses.

One such case is the lake formed by the retreat of the Trift glacier in the Bernese Alps of Switzerland. The topography of the valley below the lake, a narrow gorge, allows the construction of a high dam at moderate cost. This would result in a major new reservoir in the once ice-filled valley and in a considerable extension of hydropower production. A broad participatory process started in 2012 and discussions focused on nature and landscape protection. Besides hydropower, the main uses planned will be flood control and energy-system services (Kellner et al. 2018) The draft concession was submitted by the local hydropower company (Kraftwerke Oberhasli, KWO) to the Bernese authorities for approval in 2017.

The Trift glacier is just the first example of numerous potential hydropower opportunities in the landscapes left by retreating glaciers. The discussions around the Trift project will therefore frame the political process and the societal perspective for the development of former glacial valleys. One important aspect is the increased likelihood of landslides faced at such highaltitude lakes, as the surrounding mountainsides may become increasingly unstable with retreating permafrost (Haeberli et al. 2013). Hence, landscape protection, economic exploitation and hazard management will have to be balanced in future management plans.
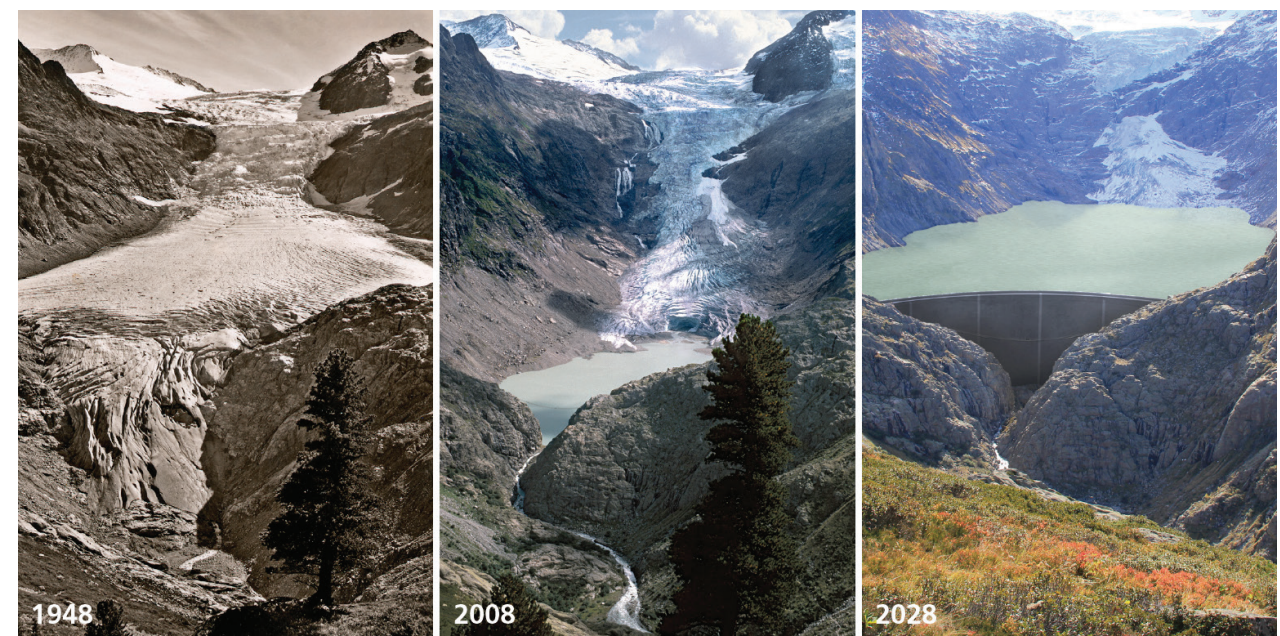

Fig. 7: Trift Glacier 1948, 2008 and potential dam and reservoir (Graphics @ Kraftwerke Oberhasli AG) 
Fig. 8: Rivers affected by hydropeaking in Switzerland (BAFU

2015, p. 6)

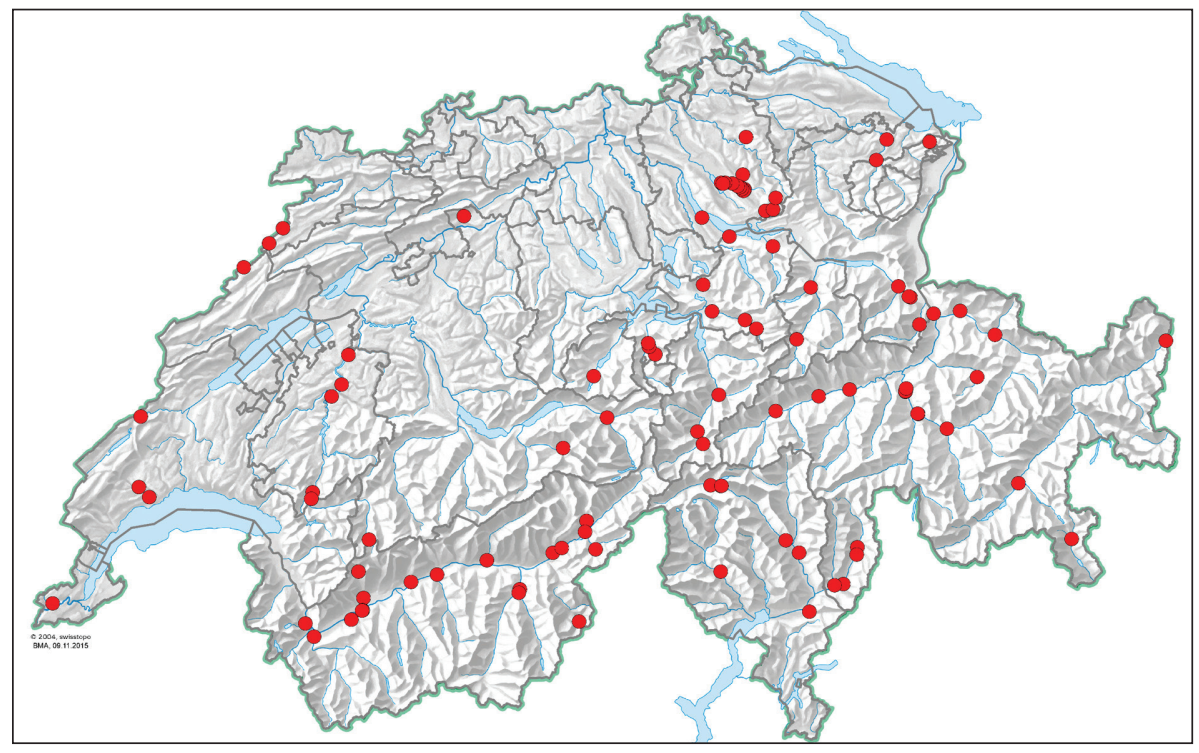

\section{Artificial snow-making}

The next lower range of altitude - between approx. 1800 and $2500 \mathrm{~m}$ - is also heavily influenced by climate change, resulting in a shorter winter season with decreasing snow depth (Beniston et al. 2018). For mountain resorts, this implies less reliable snow cover for skiing. In order to adjust, many ski resorts have invested in extensive infrastructure for artificial snowmaking to secure the skiability of their slopes.

Artificial snow-making requires pumping energy and distribution infrastructure, but also substantial amounts of water. Yet, water availability may be low at the end of a dry autumn and generally, flow in Alpine streams and springs is low during winter. To guarantee adequate water supplies, the most obvious solution is to build reservoirs to store water in times of excess. There are, however, limitations in terms of preservation of the natural high-mountain landscape. As, for practical reasons, snow-making reservoirs are usually built at high altitudes, filling them still requires substantial pumping energy.

Water use conflicts occur between snow-making on the one hand and drinking-water supply and residual flow, on the other. For instance, direct conflict between drinking-water supply and snow-making has been reported for Scuol in Engadine valley in Switzerland. At Scuol, up to $80 \%$ of the water used for snow-making is extracted from public drinking-water springs (WSL 2007). During peak season at Christmas and in January/February, water demand for technical snow production coincides with maximum water consumption by tourists, resulting in an obvious conflict.

To avoid such competition for water, the distribution systems for public supply and snow-making should be kept separate, physically and also in terms of financing. In the longer run, snow-making will have to be limited to slopes at higher altitudes. In the face of rising temperatures and snow lines, a concentration of ski tourism at higher altitudes seems inevitable. Thus, spatial planning over larger Alpine regions is urgently needed.

Hence, in the altitude range of 1800 to $2500 \mathrm{~m}$, both climate change and socio-economic change play a role, with climate change being the dominant factor.

\section{Hydropower and hydro-peaking}

One level down, below $2000 \mathrm{~m}$, human influence increases markedly, mainly because of the ubiquitous exploitation of water courses for hydropower (in Switzerland, 14 times the annual national run-off is put through the turbines of power plants) (Björnsen Gurung et al. 2014). Apart from the lack of residual water in many affected streams, the ecological and morphological effects of hydro-peaking dominate.

In Austria, large stretches of Alpine rivers are affected by hydro-peaking (Seebacher \& Zeiringer 2011). As Fig. 8 shows, some 110 hydropower facilities are causing significant artificial run-off fluctuations in Switzerland (SFV 2014). As an example, Fig. 9 shows runoff in the Vispa in the Swiss canton of Valais. Within minutes, run-off fluctuates from almost zero to more than $20 \mathrm{~m}^{3} / \mathrm{s}$ and back (Bruder et al. 2012). Thus, fish and other fauna are exposed to potentially damaging currents and get caught in dry places when the water level drops quickly. Also, the temperature changes very quickly as cold water from reservoirs suddenly reaches the rivers downstream. Not even algae are able to survive these harsh conditions (Schmutz et al. 2016). However, technical solutions such as stilling basins are available (see Fig. 10). In Switzerland, hydropower companies are required by law to alleviate the negative effects of hydro-peaking by 2031. The cost for the 


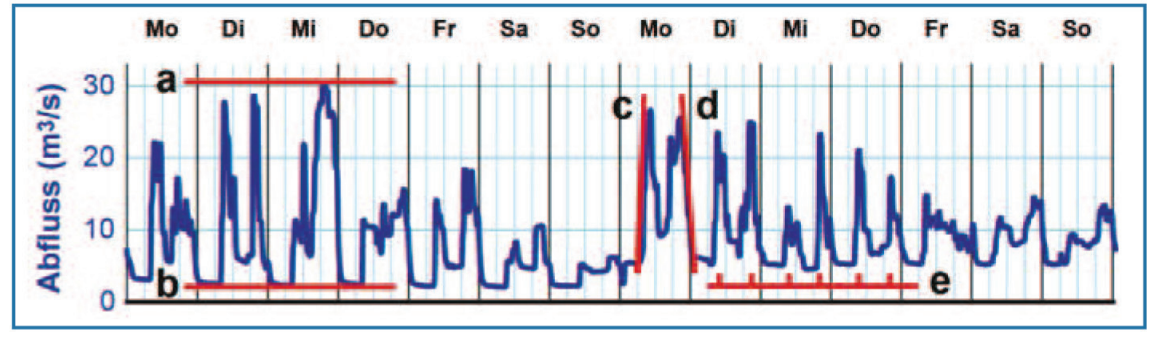

Fig. 9: Typical flow fluctuations in the river Vispa (Valais, Switzerland) as a result of demand-driven electricity generation (Bruder et al. 2012, p. 257)

necessary measures is borne by consumers via a levy on electricity.

Hydro-peaking in the Alps is a widespread water-related conflict between power production and ecological quality of rivers. This area of conflict is dominated by the competing societal demands for electricity and intact rivers, while climate change plays a minor role.

\section{Potential hydrological consequences of human retreat}

In the altitudinal range of 1000 to $2000 \mathrm{~m}$, alpine meadows are a dominant feature of the Alpine landscape. During the summer months, grazing cattle, sheep and goats on elevated pastures is a traditionally important activity of Alpine agriculture. However, some of the pastures are remote and awkward to reach. Such areas are becoming increasingly unattractive from an economic point of view in the course of the increasing intensification of agriculture. There is a tendency to abandon the most difficult locations or to reduce the number of grazing animals. As a consequence, major tracts of former meadows are becoming overgrown with low bushes and trees.

This change in vegetation is potentially influencing run-off generation. Generally, tree and bush vegetation tends to reduce direct run-off and alter the local water balance as larger plants evapotranspirate more water than grass. The exact extent depends on local conditions. However, it should be noted that the effects of land-use changes must always be assessed in the context of soil properties. Germann (1994) stated: "Forest soils are more likely to control run-off than soils under any other land use. However, not all the soils under forest bear the characteristics [to reduce direct runoff] and soils under various vegetation covers may show well developed properties to effectively mitigate peak run-off'.

\section{Flood control and intensity of use in river valleys}

River valleys, the lowest part of the Alpine landscape, are dominated by socio-economic pressures much more than by climate change. Offering the only even surfaces in mountainous areas, river valleys are central to many uses: settlement, industry, road and rail traffic infrastructures as well as agriculture. Over decades, human appropriation of river valleys has been excessive in many cases, leaving little or no space for the rivers that once shaped and dominated the valley floors.

Societal over-exploitation of valley floors is causing water management problems in at least three respects:

- lack of space for revitalization of rivers

- lack of space for groundwater protection zones for public drinking water supply

- lack of space for flood control (retention zones)

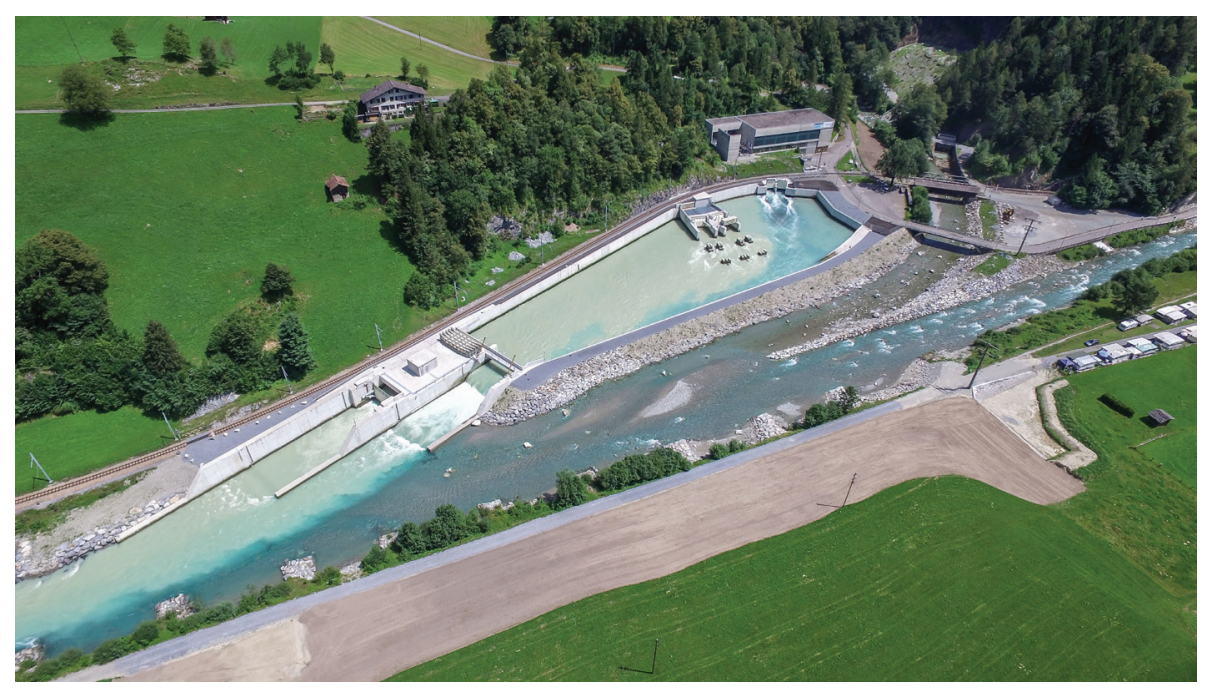

Fig. 10: Hydro-peaking stilling basin at Innertkirchen Switzerland (Photograph (C) Kraftwerke Oberhasli AG) 


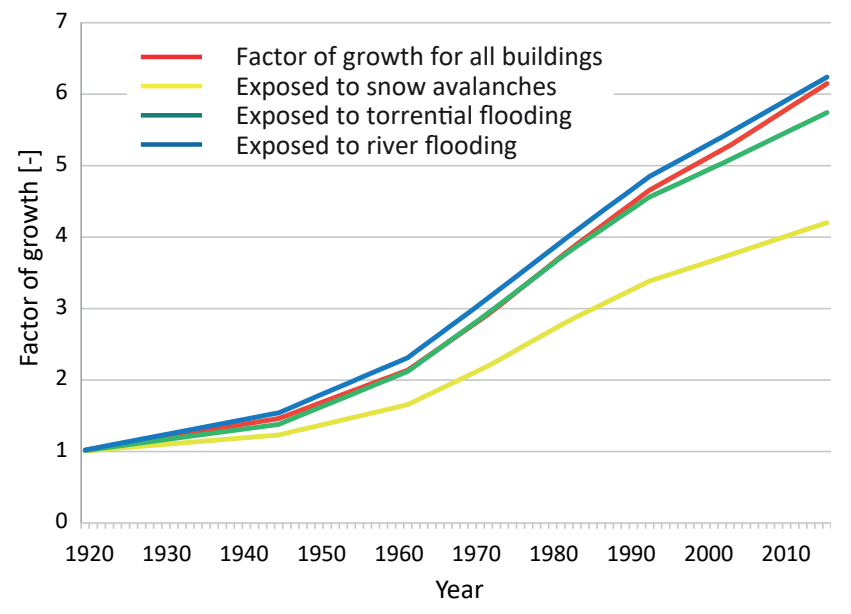

Fig. 11: Growth rates for all buildings and buildings in hazard zones (Fuchs et al. 2015, p. 2137, modified,).

Many Alpine river valleys are striking examples of misguided spatial development. Although flooding hazards are well known and understood, rising land prices have caused residential and industrial areas to be established in flood-prone areas. Where once wetlands or seasonal pastures provided retention room for flood water, expensive and vulnerable assets now need to be protected from flooding (Zischg et al. 2018). As figures from Austria show, this trend is still continuing (Fig. 11).

As shown in Fig. 11, during the past 100 years and until today, the number of buildings on land exposed to river flooding has been growing at the same rate as the total number of buildings in Austria. With respect to avalanches, however, society and planners seem to have been a lot more cautious. While construction has continued in avalanche-prone areas as well, the growth rate is markedly lower than in flood-prone areas. Partly this difference can be explained by the perceived safety from flooding once flood controls such as embankments have been established. Yet, in case of a more extreme flood, many more buildings and assets are exposed now than 30 years ago.

The simple visual comparison of two valley floors (cf. Fig. 12) reveals the consequences of 'unplanned planning': it is obvious that the river has lost its ecological functions and stability, also in terms of finding enough space to accommodate flood waters. How to solve this spatial crisis in over-used valley floors is a difficult issue. At the very least, the remaining pockets of free space need to be protected from further construction. But how to regain river space if that proves necessary to prevent disastrous flooding?

\section{Alpine water to resolve lowland water shortages}

Finally, the Alps are not hydrologically isolated, but serve as suppliers of fresh water to the underlying regions (Viviroli and Weingartner 2004). Demands for water are rising, especially in times of heat and drought, but also because of increasingly intensive use of irrigation in agriculture.

In April 2017, hydropower companies in the Adige catchment were ordered to release water in large quantities from their reservoirs in Alto Adige, in the Italian Alps, to maintain minimal flow in the underlying river (Regione di Veneto 2017). This helped to mitigate shortages of drinking water and also reduced the in-
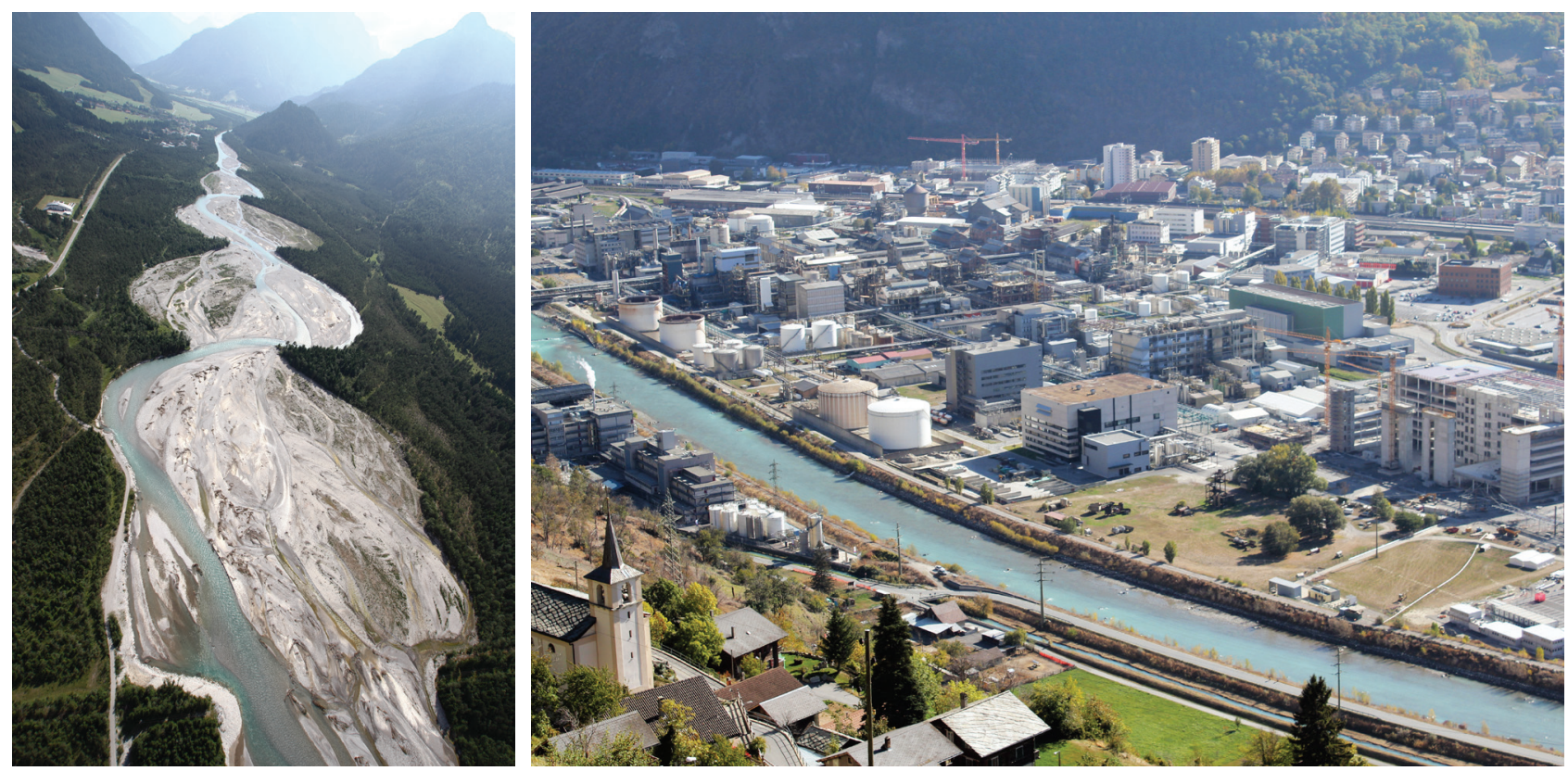

Fig. 12: Lech valley, Austria (left; photograph @ Charly Winkler) and Rhone valley, Valais, Switzerland (right; photograph: (C) Klaus Lanz) 
trusion of seawater at the Adige estuary. At the same time, hydropower companies were unable to produce electricity according to demand and so lost revenues.

Forced release of stored water from hydropower reservoirs is regarded as a last resort of water management. Hydropower operators stress that large quantities of water are being used for irrigation and that irrigation efficiency needs to increase to reduce demand. Also, of all 28 EU countries, water abstraction for drinkable use is highest in Italy, indicating major losses from distribution networks (Istat 2018). It can be argued that while meteorological drought played the major role in the 2017 water crises, irrigation farmers and leaking public water infrastructures also contributed to water scarcity.

The 2017 Adige water crisis is a stark reminder of the importance of prospective, precautionary water management, taking into account all water uses in a catchment. This includes consumptive uses, such as irrigation, industrial and drinking-water supply, but also hydromorphological and chemical stressors (Chiogna et al. 2016). Similar problems exist in many other catchments and increasing demands for water are voiced by downstream stakeholders. Under climate change conditions, managing and sharing water resources with people downstream will become an increasingly important aspect of Alpine water policy.

\section{GOOD WATER MANAGEMENT}

Water-related conflicts only become severe if we fail to act. Any action requires all relevant actors to be involved in decision-making and enough time to be allowed for mutual understanding of problems and to elaborate a joint vision for the future of our waters (Kellner et al. 2018). This is also reflected by the preferred solution options proposed by ForumAlpinum participants in the mapping exercise (Fig. 13).

Generally, four steps can be identified towards better water management:

\section{Perception}

Step one in preventing future water problems is to identify all potential causes of water-related conflict. This was also the purpose of the mapping procedure described above. Often, water-related conflicts not directly linked to water use are overlooked, especially issues of space.

\section{Understanding}

Step two is to succeed in a common, shared vision of the causes of conflict and the societal demands involved. Although problems may manifest locally, their analysis has to be undertaken on an appropriate regional scale. To gain a full picture and to lay the foundation for sustainable solutions, a thorough analysis is required bridging the gap between scientific disciplines. Finally, where more than one department of public administration is involved, adequate cooperation has to be ensured.

\section{Negotiation}

Once water-related conflict situations are assessed fully, the underlying societal demands need to be balanced. This crucial step is often the most difficult, as in many cases it is necessary to reduce demands for the benefit of the greater good. This implies that stakeholders have to accept limits: limits of water availability, of pollution, of space. Usually solutions can be found in a larger perimeter (regional or catchment scale) and, particularly, if enough time is allowed for adaptation. In some cases, the necessary conversion may take more than one generation.

\section{Effectuation}

Of course, negotiated solutions need to be put in law and enforced on the ground. This involves monitoring the outcome of the agreed measures and possibly adjusting them.

\section{Stakeholddeerdedplanningerimeter ImprovedImplementation OfLaw ParticipatoryPlanningToAvoidConflict Others}

Fig. 13: Relative frequency of solution options mentioned by participants of ForumAlpinum who submitted examples of hotspots of water-related conflict. 


\section{REFERENCES}

BAFU (2015): Renaturierung der Schweizer Gewässer: Die Sanierungspläne der Kantone ab 2015. Bundesamt für Umwelt, Berne, Switzerland. Available at: https://www.bafu.admin.ch/dam/bafu/ de/dokumente/wasser/fachinfo-daten/die_ sanierungsplaenederkantoneab2015.pdf.download. pdf/die_sanierungsplaenederkantoneab2015.pdf (accessed 28.08.2018).

Beniston, M. et al. (2018): The European mountain cryosphere: A review of past, current and future issues. In: The Cryosphere 12: 759-794. doi: 10.5194/tc12-759-2018

Björnsen Gurung, A. \& M. Stähli (2014): Wasserressourcen der Schweiz: Dargebot und Nutzung - beute und morgen. Thematische Synthese $1 \mathrm{im}$ Rabmen des Nationalen Forschungsprogramms NFP 61 "Nachbaltige Wassernutzung". Available at: http://www.nfp61. ch/SiteCollectionDocuments/nfp61_thematische_ synthese_1_d.pdf (accessed: 28.08.2018).

Bruder. A., S. Schweizer, S. Vollenweider, D. Tonolla \& T. Meile (2012): Schwall und Sunk: Auswirkungen auf die Gewässerökologie und mögliche Sanierungsmassnahmen. In: Wasser Energie Luft 4: 257-264. Available at: https:// grimselhydro.ch/wp-content/uploads/Bruder-et-al2012a-Auswikrungen-Schwall-Sunk.pdf (accessed: 28.08.2018).

Chiogna, G., B. Majone, K. Cano Paoli, E. Diamantini, E. Stella, S. Mallucci, V. Lencioni, F. Zandonai \& A. Bellin (2016): A review of hydrological and chemical stressors in the Adige catchment and its ecological status. In: Science of The Total Environment 540: 429443. doi: $10.1016 /$ j.scitotenv.2015.06.149

Fuchs S., M. Keiler \& A.P. Zischg (2015): A spatiotemporal multi-hazard exposure assessment based on property data. In: Natural Hazards and Earth System Sciences 15(9): 2127-2142. doi: 10.5194/ nhess-15-2127-2015

Germann, P.F. (1994): Do forests control run-off? In: Beiträge zur Hydrologie der Schweiz 35: 105-110.

Haeberli, W., M. Bütler, C. Huggel, H. Müller \& A. Schleiss (2013): Neue Seen als Folge des Gletscherschwundes im Hochgebirge. Nationales Forschungsprogramm "Nachhaltige Wassernutzung" NFP 61. Available at: https://vdf.ch/index. php? route $=$ product $/$ product\&product_id $=1717$ (accessed 28.08.2018).
Istat (2018): Giornate mondiale dell'acqua. Le statistiche dell'Istat. Available at: https://www.istat.it/it/ files//2018/03/Focus-acque-2018.pdf (accessed at: 28.08.2018).

Kellner, E., C. Oberlack, J.-D. Gerber (2018, submitted): Polycentric governance compensates for incoherence of resource regimes: The case of water uses under climate change in Oberhasli, Switzerland. Environmental Science and Policy.

Kellner, E. \& R. Weingartner (2018): Chancen und Herausforderungen von Mehrzweckspeichern als Anpassung an den Klimawandel. W asser Energie Luft 2: 101-107.

Körner, C. et al. (2012): VALUrsern - The ecological and socio-economic consequences of land transformation in alpine regions: an interdisciplinary assessment and valuation of current changes in the Ursern Valley, key region in the Swiss central Alps. Val Ursern Final Report, SNF, Bern.

Regione di Veneto (2017): Siccità. Dichiarato lo stato di crisi in Veneto. In: Comunicato stampa 573 del 18/04/2017. Available at: https://www.regione. veneto.it/web/guest/comunicati-stampa/dettagliocomunicati?_spp_detailld $=3109469 \quad$ (accessed 28.08.2018).

Seebacher, M. \& B. Zeiringer (2011): Schwallproblematik. und das Projekt. Available at: http://hydropeaking. boku.ac.at/summary.htm (accessed: 21.08.2018).

Schmutz, S. et al. (2016): Assessing ecological impacts of bydropeaking in Austrian rivers. Presentation at the WA21 conference „Auswirkungen von Schwall und Sunk“, Interlaken. Available at: https://wa21.ch/wp-content/uploads /2017/10/16-Hydropeaking-10-Schmutz.pdf (accessed: 28.08.2018).

SFV (2014): Der tägliche Tsunami in den Schweizer Gewässern - Kraftwerke töten mit Schwall-Sunk Fische und gefährden Menschen. Positionspapier, 5. Juni 2014. Available at: https://www.sfv-fsp.ch/fileadmin/user_upload/ Herausforderungen/Schwall-Sunk-Betrieb/Positionspapier_2014_de.pdf (accessed: 28.08.2018).

Viviroli, D. \& R. Weingartner (2004): Hydrologische Bedeutung des europäischen Alpenraums. Hydrological Atlas of Switzerland, plate 6.4, Bern.

Zischg, A.P., P. Hofer, M. Mosimann, V. Röthlisberger, J.A. Ramirez, M. Keiler \& R. Weingartner (2018): Flood risk (d)evolution: Disentangling key drivers of flood risk change with a retro-model experiment. In: Science of The Total Environment 639: 195-207. doi: 10.1016/j.scitotenv.2018.05.056 


\title{
Workshops
}

\section{CHANGING RESOURCES AND SEASONALITY}

\author{
CHAIR: ANDREAS SCHAFFHAUSER, ZAMG \\ MAPPING SUPPORT: KATI HEINRICH, IGF, ÖAW
}

\section{CONCLUSION}

Andreas Schaffhauser

Any change or seasonal reduction in the available water resources can cause serious management challenges and downstream conflicts in the Alpine region. The results of hydro-climatological models with different RCP scenarios will give a very valuable quantification of climate change effects on the availability of water resources.

The Copernicus programme and Earth Observation in general can contribute to a continuous and area-wide monitoring of water resources in the Alps. The use of remote sensing methods supports the identification of water-related hotspots and can contribute to the mapping and the systematic characterization of water-related conflicts of interest in the Alps. Such monitoring will increase not only the understanding of hydrological processes under a changing climate, but also support sustainable water management for drought periods, irrigation, energy production or technical snow production.

The above-mentioned results were endorsed in the input talks. Marc Zebitsch (Eurac research, Institute for Earth Observation) demonstrated the potential of EO application for a continuous and full coverage monitoring of the Alpine water resources. Ulrich Strasser (University of Innsbruck) presented the quantification of future climate change effects on the availability of water resources, as well as the associated consequences for various stakeholders for the Ötztal Alps (Tyrol, Austria), using hydro-climatological models driven with the relevant RCP scenarios.

Existing water-related hotspots and hazards were identified by the workshop participants. The relevant hotspots were discussed in small groups and mapped according to the guidelines for a systematical characterization of water-related conflicts of interest in the Alps.

\section{INPUTS}

Hydrological scenarios in the Austrian Alps for the next century - first results of the HydroGeM3 project

Ulrich Strasser \& Thomas Marke

University of Innsbruck, Institute of Geography

Supply and demand of water in Alpine head watersheds are expected to undergo significant changes in the coming decades. Glaciers are retreating, seasonal snow cover duration is shortening, and streamflow will decrease after peak water. A seasonal reduction of the available water resources can cause serious management challenges and downstream conflicts. In the HydroGeM3 project, we quantify future climate change effects on the availability of water resources in the Ötztal Alps (Tyrol, Austria) by forcing the hydro-climatological AMUNDSEN model with scenario data along the RCP2.6, RCP4.5, and RCP8.5 paths until 2100. Indicators for hydropower generation and winter tourism have been assessed in an inter- and transdisciplinary stakeholder process. Quality assessment of the model results is supported by means of multilevel spatio-temporal validation, and time series of stable isotopes for the streamflow components are analysed and compared to respective model results. Water demand is quantified by means of a new agent-based model to simulate water fluxes at the human-environment interface. Results indicate considerable decreases in the amounts of snow up to $80 \%$ in low to medium elevations in the future and strongly retreating glaciers with less than $20 \%$ of their present-day volume still left by 2100 . Runoff volumes will decrease by almost $40 \%$ on the annual scale, and peak flows will shift from July to June, and the average natural length of the skiing season will decrease by up to 50 days. 


\section{The Alps water tower - an earth observation perspective \\ Marc Zebisch, Claudia Notarnicola, Carlo Marin Mattia Callegari \& Felix Greifeneder \\ Eurac research, Institute for Earth Observation}

The Alps (and mountains in general) are known to be water towers for large downstream regions, which heavily depend on water from the Alps for irrigation, river navigation, energy production and industry. Climate change and climate extremes are already challenging this relationship. In this talk we argue that, particularly with the latest fleet of ESA satellites from the Copernicus program, Earth Observation can significantly contribute to continuous and area-wide monitoring of water resources in the Alps. Such a monitoring will increase not only the understanding of hydrological processes under a changing climate, but also support sustainable water management for irrigation, energy production or technical snow production. We present hydrological applications of Earth Observation for the EUREGIO region of Tyrol, South Tyrol, Trentino as well as for the entire Alps. In particular, we show how snow cover and its contribution to runoff can be monitored and how runoff can be forecast over a period of weeks to months. Furthermore, we show how the integration of remote sensing with hydrological models can improve the understanding of key hydrological processes. Finally, we demonstrate how soil moisture and soil moisture anomalies can be tracked with radar satellite data. 


\title{
EMERGING WATER-RELATED HOTSPOTS AND HAZARDS FROM CLIMATE CHANGE
}

\author{
CHAIR: ANDREA FISCHER, IGF, ÖAW \\ MAPPING SUPPORT: VALERIE BRAUN, IGF, ÖAW
}

\section{CONCLUSION}

Andrea Fischer

Alpine landscapes can be read as the imprints of formative forces, including frozen and liquid water. On various time scales, natural processes, such as drifting continents, formation and disappearance of seas, erosion and deposition, as well as climate changes, influence topography and conditions for life. After the last glacial maximum, human activities changed the landscape through land use and cultural practices. The workshop aimed at tackling various aspects of water as a geomorphological parameter influencing the landscape, as well as modern anthropogenic aspects and views on water availability and management.

Two input talks presented research results from glacier monitoring: Marco di Tullio presented $S A R$ Big Data and Google Earth Engine: key tools for glacier health monitoring, by Andrea Nascetti, Marco di Tullio, N. Emanuelli, F. Nocchi, A. Camplani and Mattia Crespi (University of Rome La Sapienza, Geodesy and Geomatics Division). They presented a method to retrieve glacier surface velocity from Sentinel SAR imagery by exploiting the potential of Google Earth Engine. JanChristoph Otto gave a talk on Future lakes - future potentials. New lakes in Austria following glacier retreat, by him and Markus Keuschnig.

After the input talks, water-related hotspots were discussed in groups of three participants (see also Lanz, Heinrich \& Weingartner page 12).

\section{INPUTS}

\author{
SAR Big Data and Google Earth Engine: key \\ tools for glaciers health monitoring \\ Andrea Nascetti',2, Marco Di Tullio', N. Emanuelli', \\ F. Nocchi', A. Camplanil \& Mattia Crespil \\ ' Geodesy and Geomatics Division, DICEA, University of \\ Rome "La Sapienza", Italy \\ ${ }^{2}$ Geoinformatics, KTH Royal Institute of Technology, \\ Stockholm, Sweden
}

The glaciers are a natural global resource and one of the principal climate change indicators on global and local scales, being influenced by temperature and changes in snow precipitation. Of the parameters used for glacier monitoring, surface velocity is an important element, since it is influenced by events connected to glacier changes (mass balance, hydro-balance, glacier stability, landscape erosion). The main idea of this work is to continuously retrieve glacier surface velocity using free ESA Sentinel-1 SAR imagery and to exploit the potential of the Google Earth Engine (GEE). GEE was recently released by Google as a platform for petabytescale scientific analysis and visualization of geospatial datasets. The algorithm of SAR offset tracking, developed at the Geodesy and Geomatics Division of the University of Rome La Sapienza, has been integrated in a cloud-based platform that automatically processes large stacks of Sentinel-1 data to retrieve glacier surface velocity field time series. Several results related to relevant glaciers (i.e. Baltoro (Karakoram), San Rafael and San Quintin (Chile), Aletsch (Switzerland)), also validated with respect to already available and accepted software (i. e. ESA SNAP, CIAS), highlight the potential of the big data analysis to automatically monitor glacier surface velocity fields on a global scale, exploiting the synergy between GEE and Sentinel-1 imagery. 
Future lakes - future potentials. New lakes in Austria following glacier melt

Jan-Christoph Otto' \& Markus Keuschnig ${ }^{2}$

'University of Salzburg, Research Group Geomorphology ${ }^{2}$ Georesearch, Salzburg

Glacier melt is the most apparent consequence of temperature rise in the $20^{\text {th }}$ and $21^{\text {st }}$ century in the European Alps. The space released by the disappearing ice is frequently filled by new glacial lakes that form in the highest parts of the mountains (Fig. 14). In Austria, more than 260 new lakes have formed in glacier forefields since the Little Ice Age. Their formation dynamics are consistent with observed increasing temperature trends with rising number and increasing size of new glacial lakes since the 1980s. This trend is assumed to continue in the near future. Glacial lakes constitute an important environmental and socio-economic impact on high mountain systems, including water resource management, sediment delivery, natural hazards, energy production and tourism. Their development significantly modifies the landscape configuration as well as the visual appearance of high mountain areas. Knowledge of the location, number and size of future lakes can be used to assess potential impacts on high mountain geo-ecosystems and upland-lowland interactions. We trace the formation of glacial lakes since the mid-19 $9^{\text {th }}$ century and estimate the future formation of glacial lakes in Austria. These lakes potentially develop when the current glacier extent continues to decrease. We will discuss benefits, potentials and threats to hydrological, geomorphological and economic systems in mountain environments.

Fig. 14: A proglacial lakes formed at the Hochjochferner, Ötztaler Alps. Photograph by Jan-

Christoph Otto

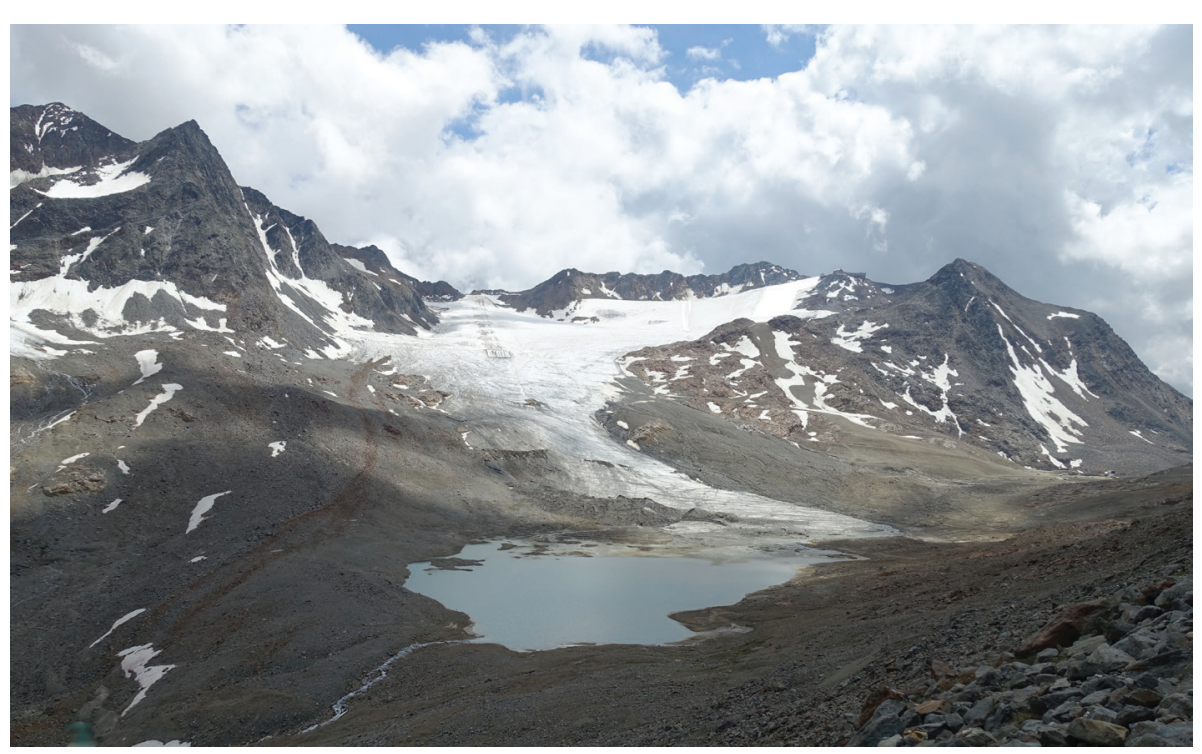




\title{
EMERGING WATER-RELATED HOTSPOTS AND HAZARDS FROM SOCIO-ECONOMIC CHANGES
}

\author{
CHAIR: ELISABETH SÖTZ, WWF AUSTRIA \\ MAPPING SUPPORT: ANNA SCHÖPFER, UNIVERSITY OF INNSBRUCK, \\ INSTITUTE OF ECOLOGY
}

\begin{abstract}
Human land uses have shaped the Alps for millennia, just as human living patterns have been influenced by the natural environment. In the course of climate change, hazard hotspots might shift - in the wake of glacier retreat, permafrost melting, or changing precipitation. In other cases, it is the human activity, or the sudden abandonment of human activity, which involuntarily trigger destabilization which leads to new hazards. Apart from the occurrence of hazards, exposure and vulnerability play an equally important role in the risk of disaster. The present workshop will highlight some aspects of this reciprocal impact of nature and human activity, and in conclusion seek to emphasize key factors to take into account when we have to deal with socio-economic development in an environment of increasing destabilization.
\end{abstract}

\section{CONCLUSIONS}

Elisabeth Sötz

Contributions and discussion highlighted the following existing conflicts regarding water use and hydrological risks:

- Construction of buildings in natural hazard zones; sometimes because the plots are cheaper, but even rich fancy resorts do not take the hazard risk into account.

- Construction of buildings and ski lifts which do not take into account water supply aqueducts.

- Water use conflicts between neighbouring municipalities - e.g. a municipality which has fewer permanent habitants, but many more tourists than the neighbouring ones.
- Tourism tries to adapt to climate change by shifting ski resorts uphill, or investing in (water- and electricity-demanding) snow-making - but this is only a bridging solution, not a permanent one.

The following required actions have been identified:

- Inclusive spatial and land-use planning, taking into account all use interests (and also reaching out to remote, decentralized buildings or settlements)

- Paradigm shift in tourism - studies already show that the most successful tourist destinations are those who offer diverse, four-season activities for tourists. 


\section{INPUTS}

Fair distribution of risks and benefits - the challenges of social justice in mountain hazard management

Thomas Thaler', Andreas Zischg², Maria PapathomaKöhle', Margreth Keiler² \& Sven Fuchs'

'University of Natural Resources and Life Sciences, Vienna, Institute of Mountain Risk Engineering

2 University of Bern, Institute of Geography

As financing protection against mountain hazards becomes more difficult and investments have to be prioritized, dilemmas of justice emerge: some local governments and individuals benefit from natural hazard protection schemes whereas others lose. Decisions on whom to protect often caused contradicting concepts of political understanding, which differ in their interpretations of fair resource allocation and distribution. This presentation explores questions of social justice and injustices in the Austrian natural hazards debate. A spatially explicit object-based temporal assessment of elements of risk to mountain hazards (avalanches, river floods, torrential floods and debris flows) in Austria is presented for the period 1919-2012. The assessment is based on two different datasets, a) hazard information using legally binding land use planning restrictions, and $\mathrm{b}$ ) information on the building stock and citizens combined from different spatial data available at national level. We found that, depending on the respective political direction, various local governments gain and others lose within the actual distributional system of mitigation strategies. These findings highlight the distributional consequences of future mountain hazard management strategies and point to the crucial selection of policy direction in navigating the selection of various adaptation schemes.
The construction of a landscape for tourism. The role of water in the creation of high-altitude ski resorts in the French-Italian Alps (1950-1980)

\section{Caterina Franco}

Laboratoire MHAevt, ENSAG, Université Grenoble Alpes \& Department ABC, Politecnico di Milano

The proposed contribution is part of the research for a $\mathrm{PhD}$ thesis in Architecture, still in preparation. It deals with the role of water in the construction of high-altitude ski resorts in the French-Italian Alps after the Second World War. Indeed, when new tourist centres were designed and built on virgin soil, new strategies had to be found and new infrastructure had to be built to provide water for the new settlements, located sometimes higher than the sources or far from them, and generally in areas that had been uninhabited before. We explore water as an element that played a role in the construction of new tourist centres along two hypotheses. On one side, the hydrographic assets of the site influenced the planning of new infrastructure; on the other, the design and construction of the new settlements turned out to be a process of modification of a landscape in its natural and anthropic components. We focus on the case studies of Chamrousse, in the French Alps, and Pila, in the Italian Alps. Through archival research and using cartography and drawing as tools, we will retrace the trajectory of the construction and modification of water infrastructure, from the creation of the new settlements until recent years, when the demand for water rose because of the need to make technical snow. Finally, understanding the historical process is seen as a fundamental step to assessing the current assets of a territory, and to identifying its potentials and vulnerabilities. 


\title{
SPRINGS UNDER PRESSURE
}

\section{CHAIR: STEFANIE VON FUMETTI, UNIVERSITY OF BASEL, DEPARTMENT OF ENVIRONMENTAL SCIENCES}

\begin{abstract}
Alpine springs provide ecosystem services such as the supply of drinking-water. Ecologically they are important aquatic habitats under pressure. They suffer from cattle trampling, capturing or relocation, etc.. In addition, changes in land use and climatic changes threaten springs further. Headwaters in Alpine regions will be affected strongly by climatic changes, such as higher water temperatures or altered discharge regimes. In this workshop, we will discuss conflicts of interests and threats to natural springs and how we can monitor them effectively. The development of conservation strategies should be a focus of future efforts in order to sustain important ecosystem services of springs in the Alps.
\end{abstract}

\section{CONCLUSIONS}

Stefanie von Fumetti

Springs in the Alps will be faced with intensified conflicts of interest in future. They are used for drinking water supply for humans and cattle. Demand for water is increasing under a rising pressure of touristic infrastructure, such as hotels and chalets. Especially in regions where chalets traditionally used for transhumance farming are restored for tourism, the pressure on still natural springs will be high. As climate change is altering the hydrology of captured springs used for drinking water, the pressure of still natural springs will increase further.

As important biodiversity hotspots, valuable natural springs in the Alps especially need better protection in future. To this end, pan-Alpine action plans should be developed. Nature parks, biosphere reserves and national parks are ideal model regions for implementing such conservation strategies. First efforts have been made during the Workshop at the Forum Alpinum to start an Alps-wide spring initiative; this process will be intensified in the upcoming months.

Fig. 15: Park Beverin. Photograph: Micha Näf

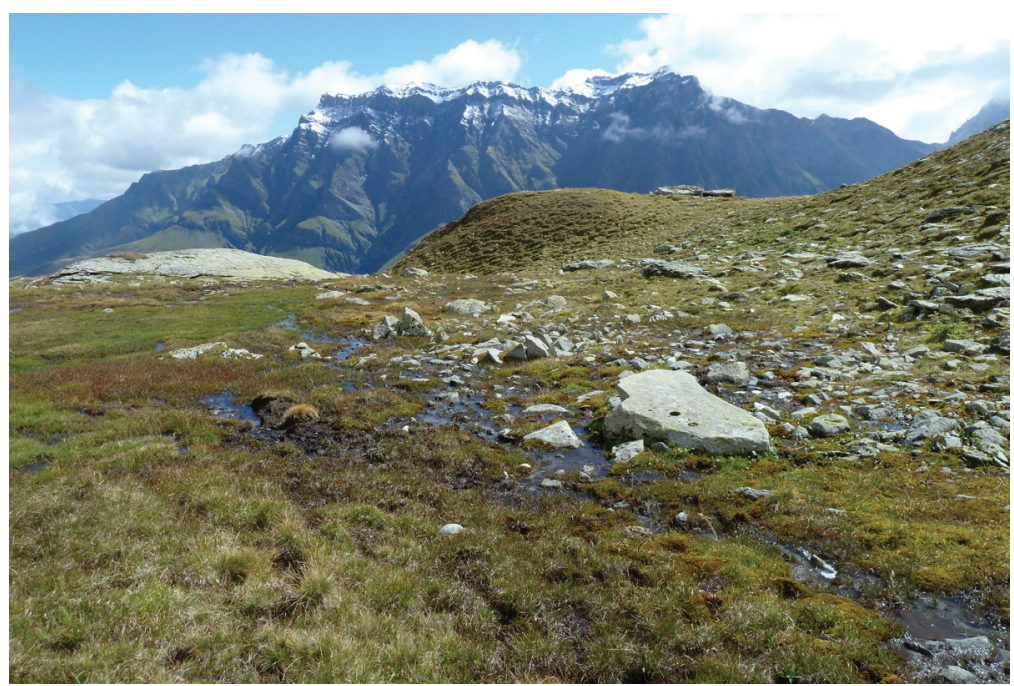


For investigating the impact of climate change on natural springs, long-term monitoring programmes are urgently needed. At the Forum Alpinum, important methodological aspects were discussed to standardize the methodological procedure of long-term spring monitoring projects in the Alps. A handbook will be written in the upcoming months to summarize the proposed procedure. A coordinated methodological approach will enable us to compare the future development of Alpine springs in different geographically regions.

\section{INPUTS}

Alpine springs under pressure: will Global Change increase present conflicts of interest?

\section{Stefanie von Fumetti' \& Daniel Küry² \\ 'University of Basel, Department of Environmental Sciences ${ }^{2}$ Life Science $A G$, Basel}

Springs are a small, but very central part of the aquatic cycle. Since ancient times they have provided ecosystem services, such as the supply of drinkingwater, crop irrigation and health promotion. Almost contrary to this anthropocentric perception, they are, from the ecological point of view, important aquatic habitats under pressure. By providing unique prerequisites for the meio- and macro-fauna as well as algae and mosses, they are inhabited by especially adapted species, which are threatened by the severe utilization pressure. Global Change, i.e. land-use changes as well as climatic changes, is threatening springs further. The IPCC report clearly states that Alpine regions will be affected more strongly by climatic changes than lowlands. It can easily be imagined that Alpine springs will experience higher water temperatures or a shift in their discharge regime. There is an urgent need to investigate how Alpine spring systems could react to climatic as well as land-use changes in order to develop conservation plans for protecting ecologically valuable springs and to sustain a very important ecosystem service in the Alps, namely drinking water.

\section{Ecological evaluation, conservation and restoration of spring habitats in the Swiss Alps}

Daniel Küry

Life Science AG, Basel

In Switzerland springs are considered endangered habitats, not only at lower altitudes but also in the Alps. In three nature parks of the Canton Graubünden, the ecological state of 232 spring habitats was assessed by investigating their structure, flora and fauna by means of a newly created field protocol. Between 30 and $75 \%$ of the crenic habitats were classified as natural or nearnatural. Based on the structural state and the richness of plant and animal taxa, 21 springs were shown to have a high restoration priority and 26 a high restoration importance, respectively. A total of 160 springs were considered of medium priority and 140 objects had a medium importance. The main disturbance of the springs was trampling by cattle and the diversion of water for chalets or lodges. For damaged or threatened spring habitats restoration measures were developed for future programmes to support the ecological infrastructure of the nature parks. An action plan of the Federal Office for Environment will help to implement measures for the conservation of springs in Switzerland.

\section{Long-term monitoring of Alpine springs to determine climate change impact}

\section{Gabriele Leonhardt}

Nationalparkverwaltung Berchtesgaden, Forschung und Informationssysteme

Springs are spatially limited transition zones that affect the water balance and the biological diversity in a given watershed. If the quantity and seasonality of precipitation and snowmelt will change in the future due to rising temperatures, or storms lead to more sun exposure, spring habitats may subsequently change. This may lead to a shift in species composition, possibly accompanied by invasions or losses. Such effects can only be documented by applying a standardized methodology as currently being developed in Berchtesgaden National Park (BNP) and also in Bavarian Forest National Park in Germany. This study combines the revision of data from former monitoring projects in BNP with standardized new field work concentrating on a selected set of springs in both parks. Morphological habitat description is based on standards proposed by the Landesbund für Vogelschutz, in Bayern e.V.. Main components of physicochemical water analysis are $\mathrm{pH}$, oxygen saturation, electric conductivity and temperature. The study of zoological diversity focuses on crustaceans, molluscs, mites, and particular insect orders and combines traditional taxonomic methods with (meta)barcoding techniques. The resulting guideline will suggest criteria for choosing best suitable reference sites and indicator species, but also recommendations for monitoring intervals and a proposal for sustainable data storage. 


\section{Collecting biota in spring habitats: A proposal for a sustainable methodology in long-term monitoring studies}

\section{Reinhard Gereckel \& Marco Cantonati2}

' University of Tübingen, Department of Evolution and Ecology

${ }^{2}$ Museo delle Scienze, Trento, Limnology and Phycology Section

Given the generally small size of springs and their often extreme microhabitat diversification, a representative documentation of species composition encounters considerable difficulties in these habitats. A balance must be found between safeguarding the sensitive habitat and gaining representative quantitative data. We propose a minimal-invasive collecting method for benthic invertebrates and diatoms (+ dominant macroalgae). A summarizing sample is taken along a transect of the whole area from the transition eu-/hypocrenal to the spring mouth. Collection is done in a mosaic way, leaving extended parts of the spring area untouched (Fig. 16), but covering all representative habitat types and reflecting their relative cover by varying collection intensity. For algae, we propose an approach focusing on diatoms, integrated by limited, strictly target-oriented, dominant benthic macroscopic algae analyses. This technique has been evolved, discussed and applied in the course of more than 20 years of field work, in the Berchtesgaden and Adamello-Brenta Nature Parks, involving more than 50 specialists from seven countries. The resulting sample can be studied with traditional zoomorphological techniques or molecular sequencing, or a combination of both. The technique is proposed as a uncomplicated tool that can be easily applied under highly differing environmental conditions.

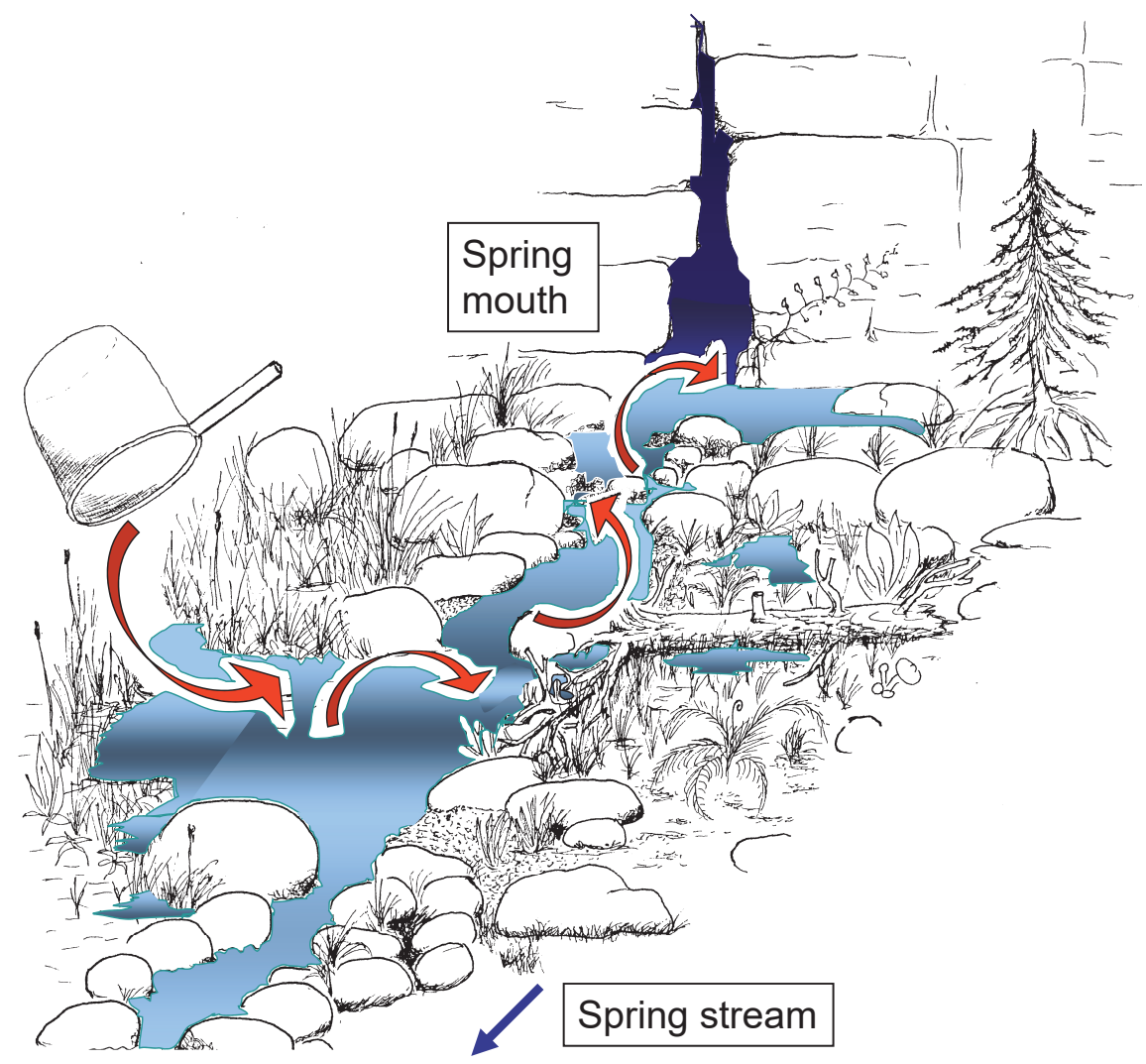

Fig. 16: Schematic view of a spring; collecting is done at several patches along a transect between the lower end and the spring mouth. Graphics: () Reinhard Gerecke 


\title{
MONITORING AND MANAGING EUROPEAN UNION SPECIES AND HABITATS OF ALPINE RIVERS
}

\author{
CHAIR: NORBERT MÜLLER, UNIVERSITY OF APPLIED SCIENCES, ERFURT \& \\ HELMUT KUDRNOVSKY, FREELANCER, KEMATEN
}

\begin{abstract}
The EU Habitats Directive demands monitoring and managing its Annex species and habitats. In this session, we will discuss this subject area for Alpine rivers. The special focus will be on key species and their habitat types 3220, 3230, 3240 "Alpine rivers" and 7240* and 91EO. Within the last EU Habitats Directive, Article 17 Reporting, the conservation status of these habitats ranged from unfavourable to inadequate to bad. Therefore, examples of management and reintroduction of key species will be part of this workshop alongside methods of monitoring. This workshop is also part of the $16^{\text {th }}$ International Alpine Workshop, an annual meeting of scientists, practitioners and advanced students working in Alpine rivers (see www.fh-erfurt.de/la/tagliamento).
\end{abstract}

\section{CONCLUSIONS}

Norbert Müller \& Helmut Kudrnovsky

With the Water Framework, Bird, and Habitats Directives, the European Union has established three important instruments for the conservation, sustainable and wise use, and restoration of its Alpine water ecosystems. In the implementation process of these directives, the EU demands the preservation and restoration of a favourable conservation status, as well as monitoring and managing their Annex species and habitats. For Alpine rivers, a special focus within the Habitats Directive is on key species and their habitat types of "Alpine rivers" with herbaceous vegetation (3220), false tamarisk (3230), rosemary willow (3240), dwarf bulrush communities at sand and silt rich sites $(7240 *)$, and softwood alluvial forests (91E0*).

Natural river dynamics are the key requirements for a favourable conservation status of these habitats. Rivers and riverine landscapes are ecosystems significantly shaped by recurrent natural disturbances. These dynamic processes initiate a complex mosaic of habitats that is home to a remarkably high diversity of aquatic, amphibious and terrestrial organisms linked to these aquatic systems.
What are and will be increasing or upcoming conflicts in water use in the Alps (and beyond) related to socio-economic or climate change?

River ecosystems are connected on large spatial scales, have varied drivers, strong, and often conflicting, societal interests, and interacting management processes. Nowadays Alpine rivers with near-natural morphology and dynamics, along with their natural riparian vegetation, have become rare and are highly endangered.

The key components of hydro-morphological pressure are changes in hydrological regime / runoff, interruption of river and habitat continuity, disconnection from adjacent wetlands / floodplains, and changes in erosion and sediment transport.

Climate change may change spatial and temporal patterns of precipitation in and around the Alps, with a possible increase in the demand for water for irrigation. Abandoning the use of fossil and nuclear energy calls for a greater use of renewable energy like hydropower.

Within our annual workshop ${ }^{1}$ at the Forum Alpinum, we discussed current main challenges in implementing the EU Environmental Directives, followed by a weeklong excursion to two main references ecosystems for

1 https://www.fh-erfurt.de/lgf/la/lehrende/prof-dr-norbertmueller/tagliamento/ 
the Alpine rivers in Austria - the Tyrolean river Lech and the river Isel, including their tributaries.

Although enormous efforts were made in the last ten years within two Life projects at the Tyrolean Lech, it is uncertain if a favourable conservation status in the river course, which is impacted by hydroelectric power plants, will be achieved. At the river Isel and its tributaries, there is ongoing great pressure to use these ecosystem or parts thereof for hydroelectric power plants.

What are needed actions and available tools to face or mitigate such conflicts?

At European Union level, the Habitats Directive and the Water Framework Directive establish legal frameworks and set out action plans to maintain or restore a favourable conservation status of Alpine rivers and associated habitats and species of community interest.

An intensified and entangled implementation of both these directives helps raising awareness of Alpine rivers as lifelines for humans as well as for species and habitats of European interest and finding a sustainable and balanced way to ensure all social and ecological functionalities of such ecosystems.

Only strict conservation and restoration actions will save these two river reference ecosystems, Lech and Isel and tributaries, and will meet the requirements of the EU Environmental Directives.

\section{INPUTS}

3230 "Alpine rivers and their ligneous vegetation with Myricaria germanica" - recent observations along the river Lech

Helmut Kudrnovsky

Freelancer, Kematen

According to the Interpretation Manual of the European Union, habitat 3230, "Alpine rivers and their ligneous vegetation with Myricaria germanica" is described as: communities of low shrubby pioneers invading the herbaceous formations on gravel deposits rich in fine silt, of mountain and northern boreal streams with an Alpine, summer-high, flow regime. Myricaria germanica and Salix spp. are characteristic (Salici-Myricarietum; Fig. 17).

Next to the river system of Isar/Rissbach, the Tyrolean Lech is one of two hotspots for this specific habitat type in the northern parts of the Eastern Alps. Additionally, both river sections are part of Natura 2000, the Europe-wide network of protected areas (Tiroler Lech - SiteCode: AT3309000; Karwendel mit Isar - SiteCode: DE8433301, Karwendel - SiteCode: AT3304000) and challenge conflicts of landscape use like hydropower plants or gravel mining.

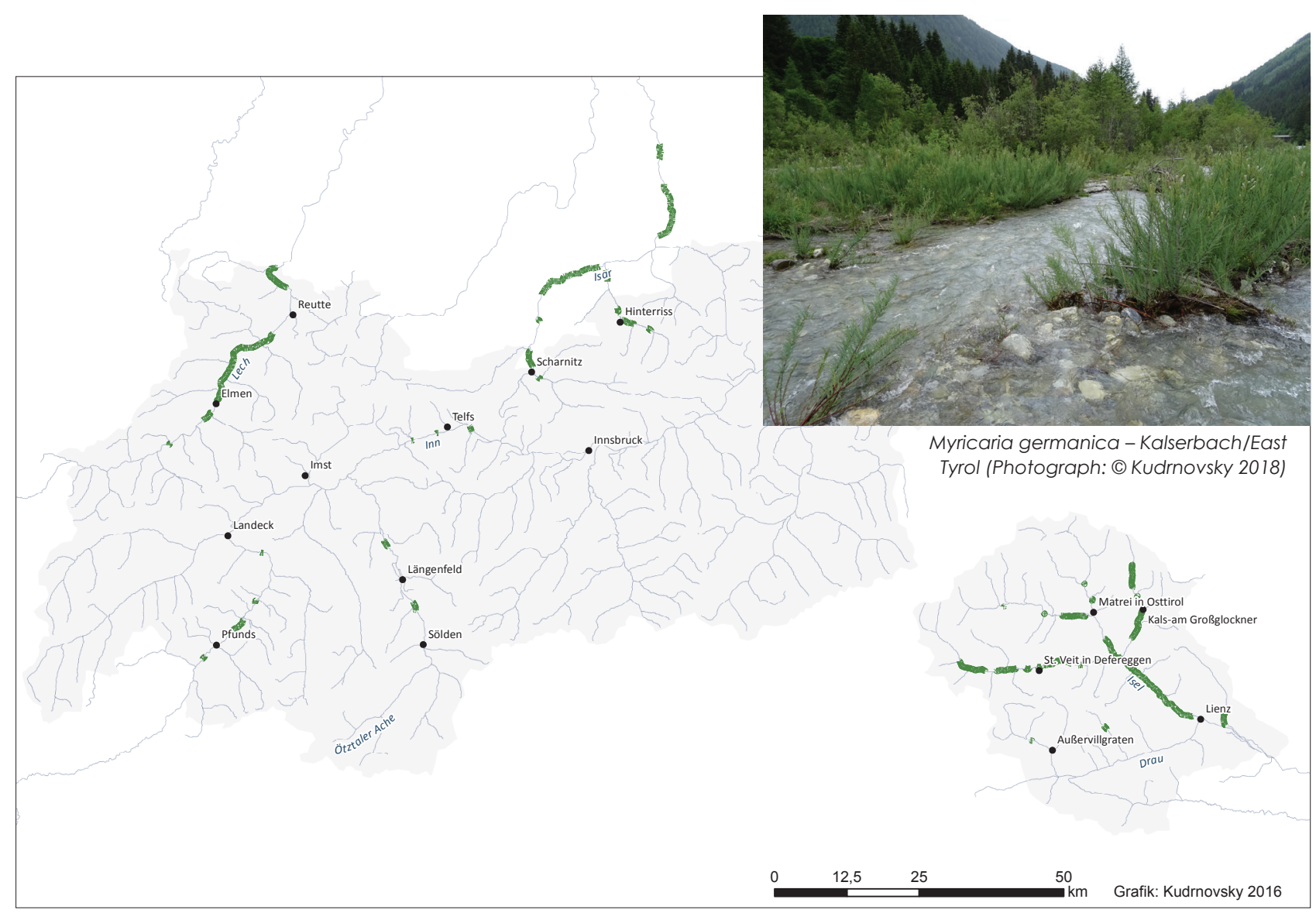

Fig. 17: Myricaria germanica - species distribution in Tyrol. Graphics: @ Naturpark Tiroler Lech 2016 
In recent years, the author visited the Tyrolean part of the river Lech several times. Based upon the comparison of historic and current documents (e.g. aerial photos, landscapes pictures and results of habitat mapping over the years), recent observations of trends, e.g. in spatial distribution or population characteristics, will be presented and discussed with the audience.

\section{Reintroduction of Myricaria germanica in Italy - an overview}

\section{Michielon Bruno \& Tommaso Sitzia}

University of Padova, Department of Land, Environment, Agriculture and Forestry

Myricaria germanica (L.) Desv (German tamarisk), a pioneer shrub of natural Alpine and pre-Alpine rivers, is declining in Europe as a result of human disturbance, which has reduced the spontaneous river dynamics, the input of sediments and the river corridor width. Since all the Italian rivers are subject to some form of human disturbance, conservation of $M$. germanica should be ensured by river restoration, active management of riparian habitats or reintroductions. The reintroduction of M. germanica has recently been the subject of projects of national and international interest. $M$. germanica can reproduce easily by cuttings or seeds, but translocations have a variable success rate. Some reintroduction projects have also been performed in Italy. For example, the Emilia-Romagna region coordinated the Life project Taro-Requalification of Taro fluvial habitats vital to avifauna (LIFE 98NAT/IT/5138) in which thousands of new M. germanica plants, grown in nurseries, were produced and planted. The plant nursery of the Veneto region produced hundreds of plants of $M$. germanica in the last 20 years.In South Tyrol a wide range of river enhancement programmes have been carried out since 1999. In many river sites, the Office for Mountain Basins of the Civil Protection Agency of the Autonomous Province of Bozen / Bolzano has planted thousands of rooted cuttings of $M$. germanica, which have generated some new vital populations. We confirm that $M$. germanica is a good indicator of natural riverine conditions. Therefore a successful reintroduction of $M$. germanica can be used to assess the environmental success of a river enhancement work.

\section{0 years monitoring and managing Typha minima at the Tyrolean river Lech - a key species of Alpine rivers

\author{
Norbert Müller
}

University of Applied Sciences Erfurt, Department Landscape Management \& Restoration Ecology

Typha minima Funck ex Hoppe (Dwarf Bulrush; Fig. 18) is the outstanding key species for braided rivers of the Alps and their foreland. Within the European Habitats Directive, the species is assigned to the priority habitat $7240^{*}$, Alpine pioneer formations of Caricion bicoloris-atrofuscae. This habitat is defined as Alpine, peri-Alpine and northern British communities colonizing neutral to slightly acid gravelly, sandy, stony, sometimes somewhat argilous or peaty substrates soaked by cold water, in moraines and on edges of springs, rivulets, glacial torrents of the alpine or sub-alpine levels, or on alluvial sands of pure, cold, slow-flowing rivers and calm backwaters. Recent mapping guidelines for this habitat distinguish between four pioneer formations in the alpine zone and one pioneer formation in the subalpine to montane zone, including Typha minima. Due to river regulation and the construction of power plants, the species, and its habitat has declined rapidly in the $20^{\text {th }}$ century in the Alps and it is today extinct or highly endangered in most European countries. At the river Lech a last large Typha minima population was discovered in 1988 in a gravel pit in Tyrol, next to the Bavarian border. After traditional conservation actions in the first years, a species action programme started in 2003. This programme is including ex situ and in situ cultivation of the species, the management of the last isolated populations and trials for the reintroduction of the species by seeds and young plants to create new populations during river restoration. Within a wider scientific collaboration some research was done on population biology and genetics. In this contribution, we will present a) results from monitoring the actions mentioned above, b) conclusions for the reintroduction of plant species during river restauration, and c) recommendations on monitoring and managing of dynamic habitats of Alpine rivers within the EU Habitats Directive. 


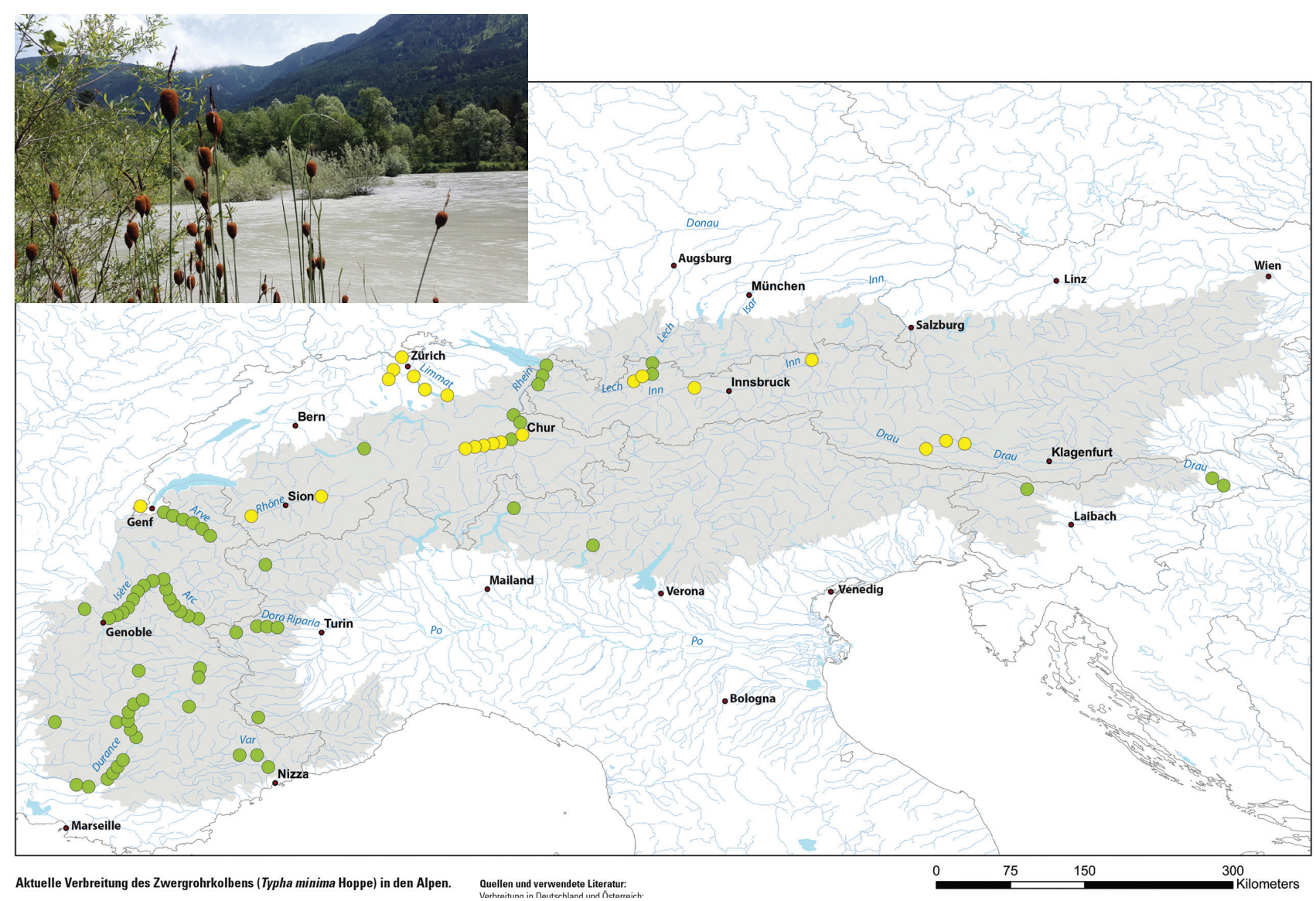

Fig. 18: Typha minima - species distribution (O natural and O reintroduced) in the Alps. For natural braided rivers in the Alps, the most vulnerable plant indicator is Dwarf Bulrush (Typha minima Hoppe). Today the species is restricted to the last near natural rivers courses. It is extinct in Germany and threatened with extinction in all other alpine member states. Its European Union habitat 7240 * is a priority habitat, that means specials efforts should be done to protect and restore this habitat. Since 20 years, reintroduction efforts are combined with river restoration measures along rivers in Switzerland and Austria. Graphics: (c) Norbert Müller 2016, photograph: Norbert Müller 2018 Typha minima, Drau).

\section{Monitoring Bryodemella tuberculata - a key species of the habitats 3220,3230 and 3240 Alpine rivers}

\section{Michael Reich}

Leibniz University of Hannover, Institute of Environmental Planning

In Central Europe, the grasshopper Bryodemella tuberculata is restricted to sparsely vegetated gravel bars of rivers and streams of the Bavarian and Tyrolian Alps. These populations have probably been isolated from Northern and Eastern European populations for several thousand years. The species is classified as threatened by extinction in the Red Lists of Bavaria and Germany. Many local populations became extinct during the first half of the $20^{\text {th }}$ century along the headwater streams of the Iller, the Lech in Bavaria, or the Inn in Switzerland. The local populations at the Isar downstream of Bad Tölz disappeared during the second half of the $20^{\text {th }}$ century. Today the Tyrolian Lech and the Isar upstream of the Sylvenstein reservoir harbour the two most important meta-populations in Central Eu- rope. Smaller populations can be found at the headwaters of the Ammer and Loisach catchments, as wells as along streams feeding lakes Heiterwang and Plansee.

B. tuberculata is a key species of several habitat types protected by the EU Habitats Directive. It occurs in and is restricted to - the habitat types: Alpine rivers and the herbaceous vegetation along their banks (3220), Alpine rivers and their ligneous vegetation with Myricaria germanica (3230), and Alpine rivers and their ligneous vegetation with Salix elaeagnos (3240). The long-term persistence of $B$. tuberculata is characterized by metapopulation dynamics. Local populations may become extinct by flooding or succession, but can be recolonized or colonized from neighbouring local populations. Population dynamics of the single local populations are therefore often not correlated or even show opposing trends. Monitoring single local populations (like single gravel bars), or a monitoring scheme using permanent observation plots, will not lead to significant results. Therefore, monitoring of the population viability, or the conservation status, requires monitoring of entire meta-populations. A simple and fast field method can be carried out using groups of 4-8 people 
and counting individuals visually during the period of maximum abundance. Results from several small and large meta-populations reveal that population sizes remain stable along some river reaches, while others are characterized by decreasing populations or even local extinction.

\section{A standardized selection of species and habitats for protection measures}

Anna Schöpfer \& Leopold Füreder

University of Innsbruck, Institute of Ecology

European directives and international programmes provide a framework for a sustainable and effective improvement of habitats and the conservation of endangered species. Nature protection measures are thus an integrated component of restoration projects. Nevertheless, action plans often lack a scientific rationale as well as a multidimensional approach, since managers must operate within time and budget constraints. This circumstance calls for simple but efficient mechanisms, which bridge the gap between science and practice by translating scientific knowledge to management policy. The authors developed a standardized method for the evidence-based selection of target species within the

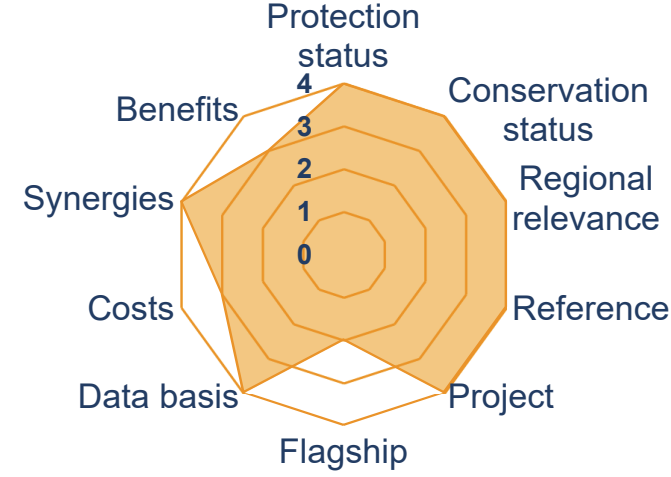

Fig. 19: Multidimensional evaluation of the importance of Typha minima for protection measures in the Natura 2000 site Tiroler Lech. Graphics: from Schöpfer and Füreder 2018.

framework of the river restoration project LIFE Lech - Dynamic river system Lech. The species of the protected area Tiroler Lech were evaluated on multimetric scales. The index score of the species generates the priority ranking for measures. The standardized selection method was tested on already finalized LIFE projects to examine its applicability and to identify deviations between the standardized approach and the status quo. The standardized selection method is a first step towards a science based Decision Support System (DSS) for LIFE projects. 


\title{
$7^{\text {TH }}$ WATER CONFERENCE
}

\author{
OF THE WATER PLATFORM OF THE ALPINE CONVENTION IN DIALOGUE \\ WITH EUSALP AG 6 SUBGROUP WATER
}

\author{
FINDINGS FROM THE $7^{\text {TH }}$ WATER CONFERENCE* \\ JOŽE PAPEŽ JOINTLY WITH THE WATER MANAGEMENT IN THE ALPS \\ PLATFORM OF THE ALPINE CONVENTION
}

\section{Impacts and responses to droughts in the Alpine region}

Drought is recognized as a major risk in agriculture and is of critical importance in large parts of Europe on various spatial and time scales. It is a consequence of climate change, but at the same time countries point out an increase in water demand. The drought of 2003 was highly significant for all the Alpine Countries, with a precipitation deficit for the eight driest months between $-20 \%$ and $-60 \%$ of long-term annual precipitation. In recent years many drought events (2002-2017) occurred, even in Alpine areas where previously there were no problems with drought events (e.g. Northern Bavaria in 2015). Effects of droughts (i.e. in 2015) were visible, in varying intensity, in almost all water-dependent sectors. All these findings lead us to focus attention on the importance of adequate drought risk mitigation and response measures, which could become one of the major challenges in water and natural disaster management. We have to be aware that changes in the quality and quantity of our water resources are expected, and without proper adaptation measures there will not be enough water for all requirements in the future.

\section{Green infrastructure for an integrated and sustainable water management}

Green infrastructure is a strategically planned network of natural and semi-natural areas with other environmental features, designed and managed to deliver a wide range of ecosystem services, such as water purification, air quality, space for recreation and climate mitigation and adaptation" (EUROPEAN UNION, Building a Green Infrastructure for Europe, 2013). Specifically in the Alpine metropoles, green infrastructure is indispensable for a sustainable water management and necessary to ensure a high quality of living in the future. Within the scope of this topic, the Platform Water Management in the Alps works also hand in hand with activities of the EUSALP Action Group 6. EUSALP AG 6 has elaborated a document which considers the possibilities for implementing green infrastructure solutions to achieve the objectives of both the EU Water Framework Directive (2000/60/CE) and the Flood Directive (2007/60/CE). As the type of river courses in the Alpine region differ greatly in terms of their environment and specific challenges, recommendations have been formulated for different typologies of Alpine water courses - from torrents in less populated valleys to urban river stretches. Green infrastructure is not a solution for all the situations and all the problems. Sometimes the location of settlements or infrastructure that needs to be protected from floods, as well as some other conditions, limit the use of only green infrastructure solutions. Therefore the combined use of natural and technical measures with so-called grey infrastructure is required. In those cases, it is recommended to base each planning process on a transparent debate of options,

* The $7^{\text {th }}$ Water Conference has been organized by the Platform "Water management in the Alps" of the Alpine Convention and the Subgroup "Integrated and sustainable water management " of Action Group 6 of the EU Strategy for the Alpine Region (EUSALP). 
including all alternatives and climate-change impacts and give priority to the conservation of riparian wetlands and other valuable habitats, as many of them, as flood plain areas, could make a significant contribution to flood risk management. If possible, measures should be considered that have less possible impact on flow dynamics and connectivity.

\section{Common guidelines for the use of small hydropower in the Alpine region}

Alpine countries were faced with increasing numbers of small hydropower projects for approval as a result of economic conditions and political ambitions. In 2011 the Platform Water Management in the Alps of the Alpine Convention prepared common guidelines for the sustainable use of small hydropower in the Alpine region. The guidelines are available at the webpage of the Alpine Convention in all Alpine languages. In the mandate 2017-2018, the Platform Water Management in the Alps will elaborate follow-up activities on the common guidelines for the sustainable use of small hydropower in the Alpine region. It was agreed to assess how the guidelines serve the needs of regional / local administrations, which will be shown in a common report finished by the end of mandate. 


\title{
THE IMPACTS OF AND RESPONSE TO DROUGHTS IN THE ALPINE REGION
}

\author{
CHAIRS: HANNAH BERGER, BAVARIAN ENVIRONMENT AGENCY, \\ GERMAN DELEGATION TO THE WATER PLATFORM \& \\ CHRISTIAN SCHILLING, AUSTRIAN DELEGATION TO THE WATER \\ PLATFORM, BMNT, AUSTRIA
}

The two sessions of Module 2 are aimed at highlighting experiences with and identification of droughts events in different regions of Alpine countries (Germany, Austria, Italy, Slovenia) and to present existing approaches to cope with challenges in different sectors of water resources management. The sessions are dedicated to facilitating knowledge exchange in drought management and to raising awareness of the importance of drought management. One focus will be sharing existing knowledge, which is already available to mitigate impacts of droughts events, which are likely to become more frequent in future in the Alpine area.

\section{INPUTS}

Current developments and challenges in drought management in Northern Bavaria

\section{Andreas Kolbinger}

Bavarian State Ministry of the Environment and Consumer Protection, Germany

Even now, certain areas in Bavaria are heavily irrigated. In 2015 some water resources were overexploited. Irrigation is an important topic in the future and through the dry summer in 2015 the topic was pushed up the agendas. Some groundwater tables in Bavaria have not been filled up sufficiently since 2015. Particularly affected is lower Franconia in the northwest of Bavaria.

Due to climate change and increasing agricultural demands (increase in yield and quality, increase in irrigation-worthy crops, possible frost protection irrigation), some Bavarian regions face increased water needs for irrigating crops.

Water quality and environmental objectives must not be adversely affected by the extraction of large amounts of water for irrigation. In 2016 the Bavarian State Ministry of the Environment and Consumer Protection therefore introduced a pilot programme which funds the preparation of "Concepts for sustainable and environmental friendly use of water resources" by up to $75 \%$. A low flow management guideline for Lower Franconia is in the final phase of development.

Even today, a key factor for sustainably handling water resources in Bavaria are targeted control measures. In addition, the impact of intensified agriculture with irrigation has to be taken into account.

\section{Strategic water resources management and drought \\ Johannes Wiesenegger \\ Regional Government of Salzburg, Austria}

Despite the fact that the region of Salzburg is well known for its extraordinary precipitation called Schnürlregen and for quite a number of rainy days, special hydrological situations, e. g. long dry spells as seen in 2003 , can cause local problems in water supply in the northern parts of Salzburg province.

But drought-related problems can also occur during winter as a result of specific situations and special de- 
mands from tourism, e. g. in Obertauern and Saalbach. Approximately 16 million $\mathrm{m}^{3}$ of water is used every year in 52 skiing resorts to produce technical snow, which is distributed across 4700 ha of ski slopes. Filling the 120 reservoirs, mainly built on the upper part of mountains, needs strategic water resources management, especially in regions where wells and springs are also used for local drinking water supply.

Overnight-stay peaks around Christmas and New Year, in combination with low flow, can also create difficulties in terms of wastewater concentration in Alpine rivers and require special management.

Therefore a multi-pillar approach of operational, strategic and creative solutions is used to solve droughtrelated problems of water supply, tourism and wastewater treatment.

\section{Drought management with negotiated processes in Italy}

\section{Gaia Checcucci}

General Director of Water and Land Protection Direction, Italian Ministry of the Environment, Land and Sea, Italy

In Italy, summer 2017 is ranked as the fourth-driest nationally since 1800 . Relative to the 1971-2000 mean precipitations, the summer 2017 mean precipitations are $-41 \%$ nationally, $-82 \%$ in the month of August.

Anyway, after the frequently recurring droughts of the last two decades, Italy has increased its preparedness, with the Italian Ministry of the Environment that has launched, at the end of 2016, the Permanent Observatories on Water Uses at river district level. These commissions of institutions and stakeholders are called, on the basis of the level of water criticality, to play a role that can range from monitoring activities to acting as a governing body for the management of the water crisis, identifying the measures necessary to reduce the impacts of drought, based on the contents of the Drought Management Plan and on negotiations between sectors. In a second phase, these commissions are going to work with standardized procedures linked to threshold values, with associated measures, such as releasing water from reservoirs and reducing withdrawals (as tested in the 2017 plan licensed by the Adige observatory).

The use of reservoirs for improving water discharge for different uses has been the result of structured negotiations, even if the Italian law establishes that the agricultural sector has got the second highest priority (after freshwater supply) and that the Ministries of Environment and Economic Development (in agreement with District Authorities and Regions) could decide to release water from reservoirs in case of emergency.

\section{New tools for better drought risk management}

\author{
Andreja Sušnik \\ Agrometeorological Analysis Section / Slovenian \\ Environment Agency (ARSO), Slovenia
}

Climate extremes likes drought are becoming more acute and certainly affect farmers in Slovenia. Since 1990, agricultural drought notably occurs more often and more intensely, and has reached the magnitude of natural disaster in 2000, 2001, 2003, 2006, 2007, 2012, 2013 and 2017 (cf. Fig. 20). With a set of free tools, ARSO helps farmers make smarter weather-/climaterelated decisions. In 2017 we developed an agrometeorological forecast application that allows a general and professional public easy access to region-specific warnings, measurements and forecasts of agrometeorological variables. For smart irrigation, tailored products, using water balance model IRRFIB to estimate crop water demand, are prepared for rain-fed agricultural crops, with drought stress also evaluated. Additionally, an interactive Drought User Service (DUS) tool is being developed within the ongoing DriDanube project for better drought characterization and early warning in the Danube region. Available to the public online, it

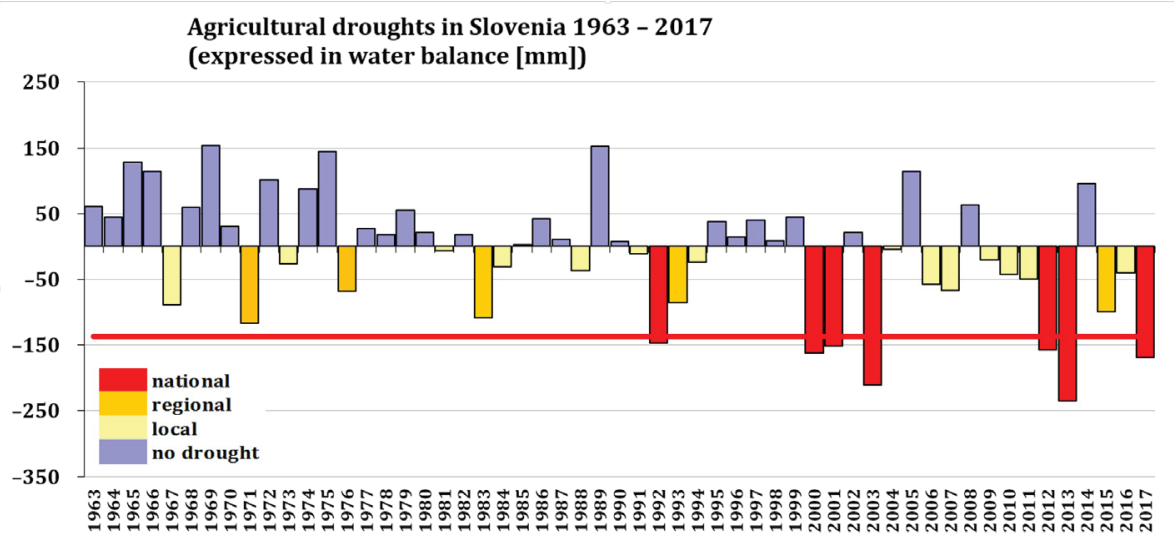

(c) Slovenian Environment Agency
Fig. 20: Agricultural droughts in Slovenia 1963-2017 
includes a range of satellite datasets, further processed into ready-to-use drought information. DUS will also display drought impacts, assessed through newly established national reporting networks, and yield forecast. The project will support the activities of Drought Management Centre for SE Europe hosted by ARSO.

More on:

- Agrometeorological forecast: http://meteo.arso.gov. $\mathrm{si} / \mathrm{met} / \mathrm{sl} /$ agromet/forecast/

- DriDanube project: http://www.interreg-danube. eu/dridanube

\section{Security of drinking water in light of climate change}

\section{Gunther Heißel}

Regional Government of Tyrol, Austria

Tyrol, part of western Austria, is a very mountainous country. Only $12 \%$ of Tyrol is habitable and has to accommodate the roughly 750000 inhabitants and the nearly 50 million overnight stays of tourists.

Most of our drinking water comes from springs in our mountains and a small part from the groundwater of our valley floors. To date, most of our drinking water is native water.

Although most parts of Tyrol receive a comparatively high amount of annual precipitation, due to the geologic setting of the Tyrolean Alps there are only a few areas with big springs (e.g. Northern Limestone Alps). Only some parts of the Limestone Alps are characterized by a low level of karst formation. This means that only these areas have big springs with groundwater with long hydrogeologic residence times of up to years and tens of years.

All other areas of the Tyrolean mountains have smaller springs with groundwater of short residence times. That makes the groundwater of these areas more or less highly vulnerable.

Give these circumstances and conditions, it is obvious that the estimated climate change will influence the security of drinking water supply for our population. We have to expect changes in quantity and quality of our water resources. So we will have to work out strategies to make our supply with drinking water fit for climate change.

\section{Facing droughts in the Alpine region - experiences, approaches and common challenges}

\section{Andrea Bianchini}

Italy, IMELS Consultant, Italian Delegation to the Platform "Water Management in the Alps" of the Alpine Convention

Ministers of the Alpine countries decided to include drought risk management in the 2017-2018 working programme of the platform Water Management in the Alps of the Alpine Convention and EUSALP is now also drafting a ,strategy for water-demand and -supply management to prevent conflicts among sectors and actors also in case of peaks of demand and/or regional droughts".

The drought of 2003 was highly significant for all Alpine countries, with a precipitation deficit for the eight driest months ranging from $-20 \%$ to $-60 \%$ of long-term annual precipitations, with losses in agriculture for hundreds of million euros; but other significant droughts have been recorded in one or more countries in most years of the last two decades, recurring with an alarming frequency and particularly affecting summer months.

An international comparison of plans and strategies that the Alpine countries and regions have put in place in recent years to tackle this ,new" challenge has allowed highlighting the lessons learned, which include: the establishment of commissions of institutions and stakeholders for agreeing on compromises between sectors and introducing procedures linked to threshold values; increasing the resilience of water supply systems (linking networks of distribution, investing in alternative sources, pumping from other regions); improving the efficiency of irrigation and/or limiting agricultural withdrawals; promoting the reduction of drought exposure (crop diversification, sowing more drought-tolerant hybrids, etc.); helping runoff with planned water releases from reservoirs; increasing natural water retention measures. 


\title{
GREEN INFRASTRUCTURE FOR AN INTEGRATED AND SUSTAINABLE WATER MANAGEMENT
}

\author{
CHAIR: LUKA ŠTRAVS, MINISTRY OF THE ENVIRONMENT AND SPATIAL \\ PLANNING, SLOVENIA
}

In the session Green infrastructure for an integrated and sustainable water management, possibilities and potentials of using different kinds of green infrastructure (nature-based) solutions will be addressed in the wider framework of sustainable water management. Issues, challenges and some other hot topics (is there a fully green nature-based solution in the field of the water management?) connected to the green infrastructure theme will be presented and discussed. Experiences in this field from different Alpine countries will be shared.

\section{INPUTS}

Greener Alpine Rivers? Conclusions and Recommendations of the EUSALAP AG 6 Subgroup Water

\section{Elisabeth Sötz}

WWF Austria, for EUSALP AG 6

Over the last centuries, Alpine rivers have been straightened and channeled, longitudinally interrupted by dams, artificial reservoirs and weirs, modified in their lateral connectivity by means of concrete walls and embankments. Even if all these measures have, in most cases, turned out to be successful and effective for their own sectoral scope - land use, flood control, hydropower - they have impacted on other uses of the water courses and in particular on ecological connectivity, hydro-morphological processes and solids transport, leading to reduced flooding of the inundation areas, lower groundwater levels, loss of biotopes as well as less effective protection. Highlighting the effectiveness of green solutions, not least for flood protection, can help to spread green infrastructure solutions across the Alpine macro-region, substantially contributing to an ecosystem-oriented adaptation to climate changes.
The EUSALP AG 6 - subgroup 3 has created a document which considers the possibilities for the implementation of the green infrastructure solutions for achieving both the objectives of the EU Water Framework Directive (2000/60/CE) and the Flood Directive $(2007 / 60 / \mathrm{CE})$. As the types of river courses in the Alpine region differ greatly in their environment and specific challenges, recommendations have been formulated for different typologies of Alpine water courses - from torrents in less populated valleys to urban river stretches (Fig. 21).

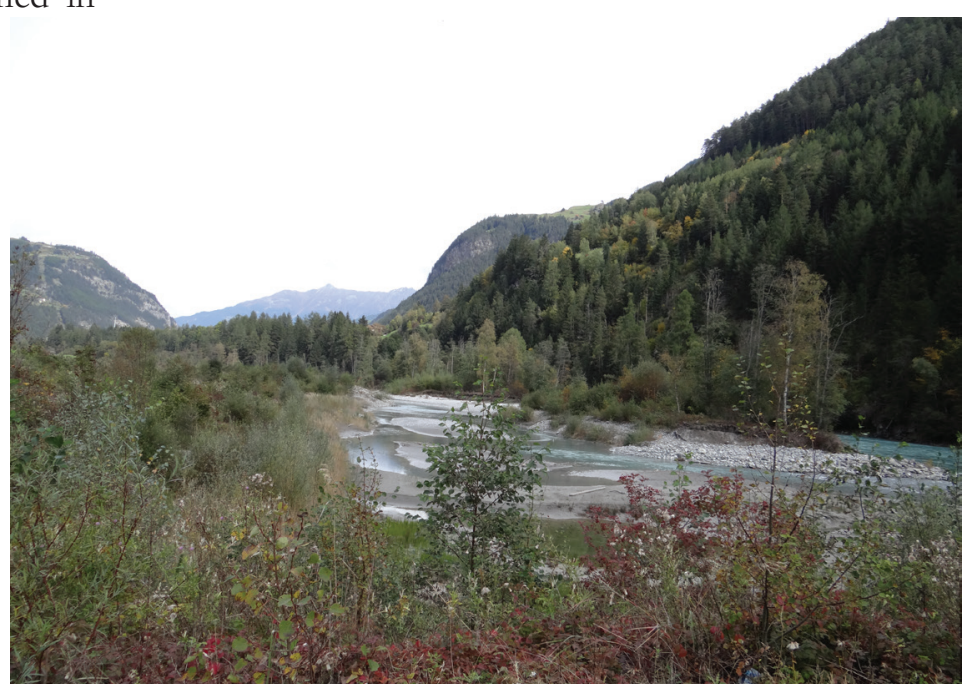

Fig. 21: Riverbed restoration at the River Inn, near Serfaus, Tyrol. Photograph: (C)WWF 


\section{0 shades of Green Infrastructure - experiences from Slovenia}

\author{
Joze Papežl, Mateja Ribnikar² \& Maja Jelen² \\ 'Hidrotehnik, Slovenia \\ ${ }^{2} \mathrm{MOP}$, Slovenia
}

In Slovenia, we strive to meet the demands of green policies which require green approaches and priority treatment of green infrastructure solutions. Therefore, within the framework of the EU co-financing programmes, we started projects in which these measures will be realized - both implemented and established in the environment; for example, the Grevislin project, which was submitted through the INTERREG V-A Italy-Slovenia 2014-2020, in cooperation with neighbouring Italy.

The paper will also briefly present additional naturebased measures and projects in Slovenia (for example, the FRISCO1 project) that are already established, as well as giving some historical insights into the achievements of the environmentally friendly and "close to nature" management of torrential and forest areas in Slovenia.

When designing green infrastructure projects, diverse and complex interpretations present challenges for designing and implementing flood-risk management schemes which contain a combination of "green" and "grey" infrastructure measures. Unfortunately, by solely implementing green infrastructure measures we cannot solve the problems of reducing flood risk. Likewise, some grey measures, in fact, enable the establishment/ preservation of an existing green infrastructure. It is also important how 'green' these grey measures are. How green, then, should a green infrastructure project be for it to rank as such? Which shade of green is enough?

The issue is not purely theoretical, as it also relates to the sources and method of financing these projects.
Alpine Green Infrastructure - joining forces for nature, people and the economy

Michaela Künzl' \& Franziska Drasdo²

'Bavarian State Ministry of the Environment and Consumer Protection, Germany

${ }^{2}$ City of Munich - Department of Urban Planning

Current challenges like climate change, loss of biodiversity or landscape fragmentation require political leadership for sustainably leading the Alpine region into the future - for the benefits of nature, people and the economy. A strategically planned and coherently managed network of Green and Blue Infrastructure (GI) shall aim at securing the continuous provision of the benefits offered in rural and urban settings. This was declared by 27 Alpine states and regions on 2 October 2017 in Munich. As a result of cooperation with the INTERREG Alpine Space Project LOS_DAMA!, mayors of Alpine cities and city regions initiated a GI cities network. Especially in the Alpine metropoles, GI is indispensable for sustainable water management and to secure a high quality of living for the future. Experiences from the cities network provide good examples of the urban dimension of an integrative Alpine water management: Milan creates GI along the river Lambro to serve as recreational facilities for daily visitors. At the same time, consumption by visitors also increases sales for local farmers. In Munich, the near-natural design of the river Isar is also linked to local recreational opportunities and flood protection (Fig. 22). Since restoration, the intensive exchange between various stakeholders has been maintained by regular "river talks". These EUSALP AG 7 activities are strong examples for linking relevant actors in a multi-level approach across borders and bridging urban with rural areas.

Fig. 22: Isar river - Lifeline in the metropole of Munich with origin in the Austrian Alps. Photograph: (c) Klaus Leidorf

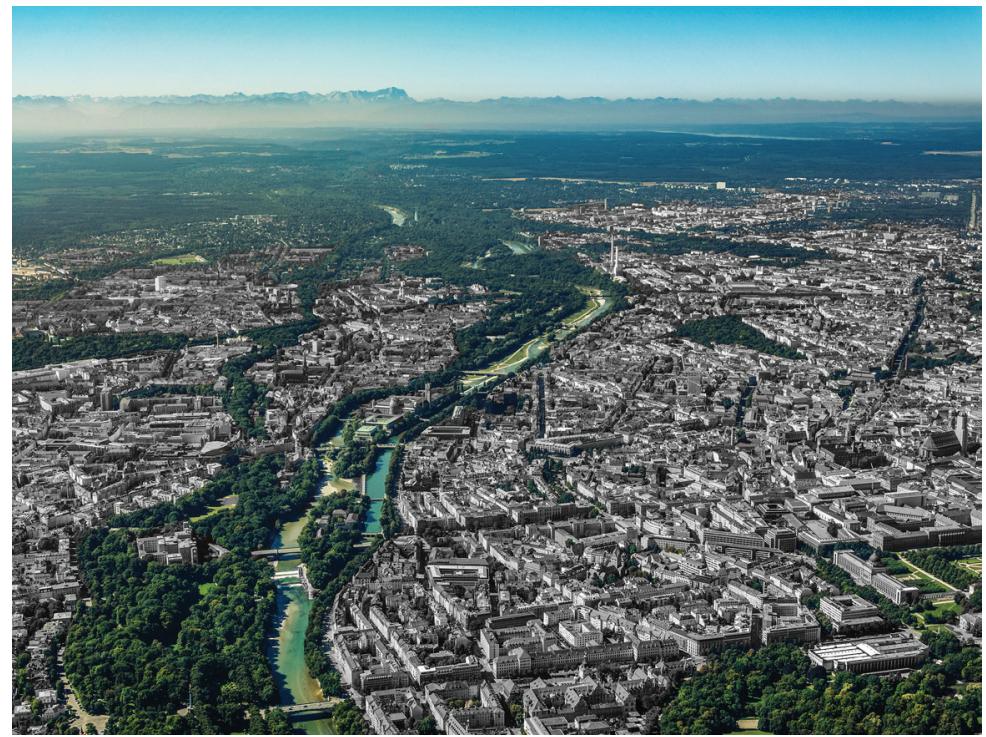




\section{COMMON GUIDELINES FOR THE USE OF SMALL HYDROPOWER IN THE ALPINE REGION}

\section{CHAIR: GIOVANNA DEPPI \& GAIA CHECCUCCI, ITALIAN DELEGATION TO THE WATER PLATFORM, ITALIAN MINISTRY OF THE ENVIRONMENT, LAND AND SEA, ITALY}

In 2011 the Platform Water Management in the Alps of the Alpine Convention developed common guidelines for the sustainable use of small hydropower in the Alpine region, which include good practice examples. The guidelines are available from the webpage of the Alpine Convention in all Alpine languages.

The Water Platform was mandated by the XIV. Alpine Conference to include a follow-up activity on the common guidelines during the mandate period 2017-2018. It was agreed to evaluate how the guidelines serve the needs of regional/local administrations.

The session will highlight the motivation for developing the common guidelines, their content and main objectives for the sustainable use of small hydropower in the Alpine region. A second presentation will be used to present the results of the follow-up activity.

\section{INPUTS}

Hydropower generation in the Alps - the common guidelines on small hydropower of the Alpine Convention

\section{Pietro Colonna}

Italy, Italian Delegation to the Alpine Convention

Based on the mandate from the X. Ministerial Conference of the Alpine Convention (2009), the platform Water Management in the Alps has worked out common guidelines, including good practice examples, on the use of small hydropower, then approved by the XI. Alpine Conference in 2011.

A situation report drafted by the Water Platform showed that of the total electricity production from hydropower, larger plants contribute by far the major share, while stations with a capacity of less than $1 \mathrm{MW}$ make up around $75 \%$ of all HP plants within the Al- pine area, yet contribute less than $5 \%$ to total electricity production.

Even though small hydropower plants often lead to widespread impacts, they can play a crucial role in meeting electricity demand in more remote regions and provide important economic stimulation at local level in less favoured areas.

The key conclusion is that due care and planning on a regional basis is necessary when deciding about new SHP facilities in order to ensure that further development of hydropower is compatible with environmental protection requirements as well as with the targets set for renewable energy. This explains the need for support for decision making and for common guidelines, specifically provide general guidance for the identification of potentially favourable locations for small hydropower plants and for the subsequent authorization decision to consider the principles of sustainable development in the Alps. 


\section{Application of the common guidelines for the use of small hydropower in the Alpine region}

\section{Christian Schilling}

Austrian delegation to the Water Platform, BMNT, Austria

At the X. Alpine Conference in 2009, ministers and high representatives of Alpine countries decided to set up the platform Water Management in the Alps. One of the tasks of the platform was to elaborate recommendations for the sustainable use of hydropower generation, with a focus on small hydropower. As a result, the common guidelines for the use of small hydropower in the Alpine region were published in all Alpine languages and have been approved by the XI. Alpine Conference in 2011. The guidelines include common principles and recommendations, an outline for an assessment procedure as well as a pool of evaluation criteria. The intention of the guidelines is to support authorities in charge of authorizing new hydropower plants and to advise planners to ensure that the further development of small hydropower will happen in a way that is compatible with conservation requirements.

For the mandate 2017-2018, the Water Platform of the Alpine Convention decided to include a follow-up activity on how the common guidelines are being used by the authorities of the Alpine countries. A questionnaire was distributed to the national and regional administrations of the Alpine countries. An assessment report has been drafted based on the information received. It summarizes the feedback and information provided and points out possible further activities. 


\title{
CONFLICTING WATER USE IN THE ALPS
}

\author{
CHAIR: ROLAND PSENNER, EURAC BOLZANO \& GÜNTER KÖCK, ÖAW
}

Water resources play a particular role not only in the Alps, but also in large areas of Europe. They occur in various forms, are highly interlinked, belong to different countries and administrative units and provide habitats for rich and particular diverse groups of organisms. However, changing environmental and climatic conditions as well as growing demand are likely to lead to conflicts in water use and to exacerbate existing disputes over water management strategies. The session will identify hot spots of water use and management, analyse target conflicts, assess their relevance in regional, national and international context, and discuss possible solutions.

\section{Keynotes}

\section{Water-related hotspots in the Alps - Results of the workshops of Module 1 and perspectives Klaus Lanz, International Water Affairs}

Which insights have been gained by the mapping exercise? Which new and surprising issues have come up? In which way can the systematic characterization of water management conflicts help make better decisions? What can we learn from case studies in terms of solution approaches? Are there additional areas of concern which need to be addressed by future water policies? How does personal and professional perspective influence perception? How can we make sure to capture all potential water-related causes of conflict?

\section{Snowmaking - a vital adaptation measure creating conflicts}

\section{Robert Steiger, University of Innsbruck}

Snowmaking has developed from a luxury product placed only at selective exposed areas to a standard equipment covering more or less the entire ski area. Climate change will further increase the use of snowmaking as less natural snow will be available, threatening to shorten and interrupt ski operations. An intensified snow production is likely to fuel conflicts. These include water usage, landscape change and land use, energy consumption and environmental consequences for ski slopes. These conflicts require appropriate attention from both public authorities and ski resort operators. 


\title{
Workshops
}

\section{LOCAL WATER USE: WATER SUPPLY, AGRICULTURE, TOURISM}

\author{
CHAIR: HEIKE ZIMMERMANN-TIMM, GOETHE UNIVERSITY, \\ FRANKFURT AM MAIN
}

\begin{abstract}
While climate change and its effects on the water balance in the mountains have attracted considerable attention, land-use change and water management at the different spatial scales in the Alps have so far received much less attention. In this session, examples will be introduced which aim to bridge the gap between theory and practice, such as in agricultural irrigation. Further, the examples do not tie decisions about water balance to political boundaries and involve the affected parties more actively in decision-making processes. The examples presented will be debated to determine if a paradigm shift is indicated and what role identifying with common objectives plays in a successful outcome.
\end{abstract}

\section{CONCLUSIONS}

Heike Zimmermann-Timm, Oliver Ike, Calianno Martin, Simone Persiano \& Primož Pipan

While climate change and its effects on the water balance in the mountains have attracted considerable attention, land-use change and water management at the different spatial scales in the Alps have so far received much less attention. Even so, both climate change and water-use behaviour will have an important impact on the availability of water resources in the future.

The examples presented in the session showed that the approach taken by Nobel Prize laureate Elinor Ostrom is suitable for the topic of water, because it supports sustainable management and responsible use of water as a resource for the common good (e.g. Montana - example: irrigation network, Čadrg village community - example: drinking water management), while self-interest can promote an overuse of the common resource or an exclusion of communities (e.g. case study Masino). In the evaluation of all the examples, as well as in many practical applications, we often deal with limited data availability: in this context, geostatistical approaches are a useful tool for reliably estimating surface water availability in data-scarce regions (e.g. the Danube and Tyrol regions).
Actions and tools needed:

1. Debate about the crisis of privatization and the return to public ownership

A debate is needed to show that there must be ways that permit at return to public ownership after the neoliberal privatization boom.

2. Platform of the "Promising Practice" examples Promising examples of deprivatization and communalization must be made visible to encourage change and experiential learning.

3. Neutral body for possible collaboration between private and public parties

A regional or even European neutral body should be formed that can propose solutions to conflicting parties upon request when such problems arise.

4. Education and dialogue

There is a need for information and open dialogue involving all interested parties that addresses the needs of the various languages, both the language of the land as well as the specialist language.

5. Monitoring and new approaches

New methodological approaches as well as monitoring programmes to obtain data are needed for reliable estimates. 


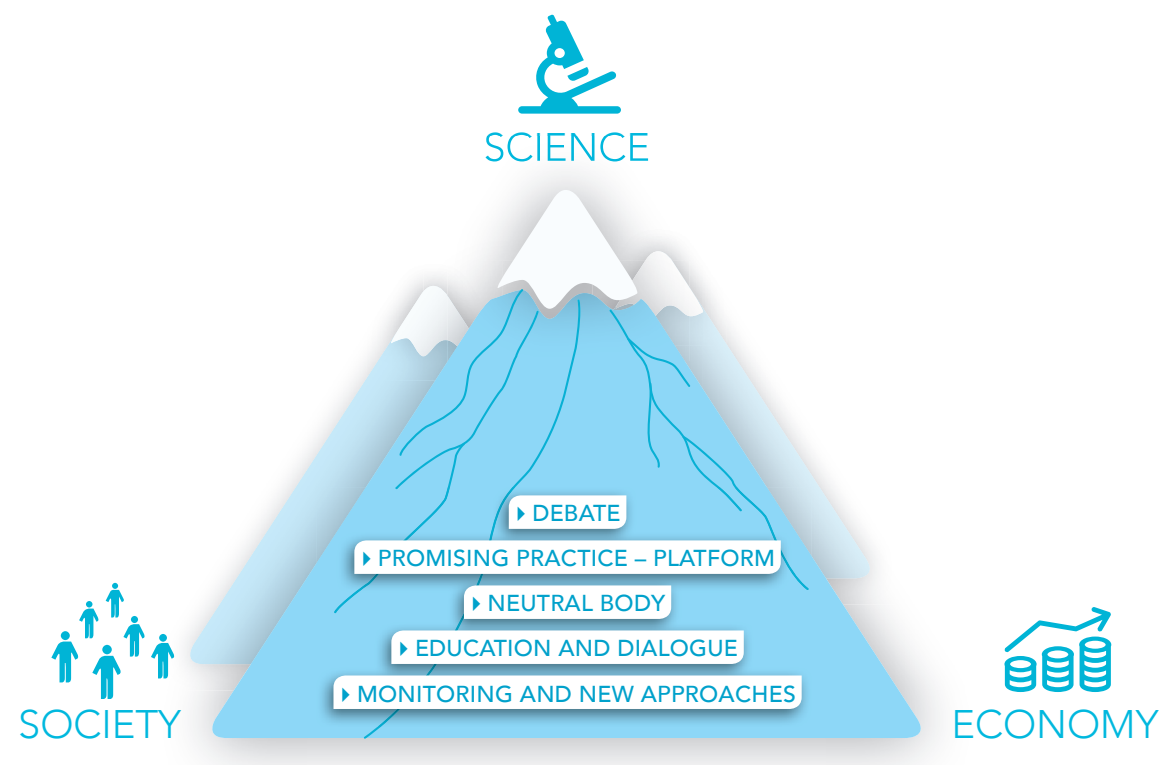

Fig. 23: According to the ongoing dialogue between science, society and the economy, these actions and tools are needed to ensure water availability in the mountains.. Graphics: Heike Zimmermann-Timm.

\section{INPUTS}

Problem of private or public use of water resources: case study Val Masino

\section{Oliver Ike}

Sighignola Luxury Holding

What should be the limit for intervention by the public sector to unblock a situation where the whole tourism of an entire valley suffers from the shutdown of hot-spring water sources owned privately?

The hot-spring water spa of Val Masino dates back to the year 1400 in the Valltelin and is a perfect example of how the public sector has not been able to resolve such a delicate situation. The spa closed in 2014.

What should the time limit be for revoking a public water license from private ownership if the whole tourism industry of a valley is concerned by the wrong decision of a private entity?

Should there be forced management by public authorities to preserve the tourism of the valley, given that the hot-spring spa in Val Masino is the main attraction?

\section{Is Alpine irrigation overestimated?}

\section{Martin Calianno}

University of Lausanne, Institute of Geography and Sustainability

Irrigation is a common water use in Alpine valleys with hot and dry summers due to continental climate and foehn effects. And because irrigation takes place during the peak summer tourist season, conflicts may happen with drinking water uses. While irrigation is usually seen as an important water use, there is little knowledge about water volumes actually used for irrigation in the Alps. As direct field measurements are rare, irrigation demand is estimated mainly by calculating crop water needs or by using withdrawal figures. But withdrawals overestimate the actual demand for irrigation because of losses. Also, not all water withdrawn is demanded by end users. In this work, we make direct irrigation measurements to evaluate irrigation estimates: empirical methods (from withdrawals and from demands, based on local farming practices) and agro-climatic models (CropWat, WEAP-MABIA). Montana (Swiss Alps) was chosen as case study to install monitoring devices (water-, flow-meters) on irrigation networks to measure irrigation distributions to pastures and vineyards (Fig. 24). Results show that withdrawals and agro-climatic models overestimate the observed irrigation by almost ten times, especially for hot and dry seasons. The empirical method, based on local farmers' irrigation practices, also overestimates observed irrigation, but only by a factor of 2.5. This highlights the importance of including actual practices (frequency and volumes of irrigation, management constraints) in the calculation. 
Fig. 24: Sprinkler irrigation in the

vineyards of Montana (Valais, Switzerland). Photograph: (c) Martin

Calianno

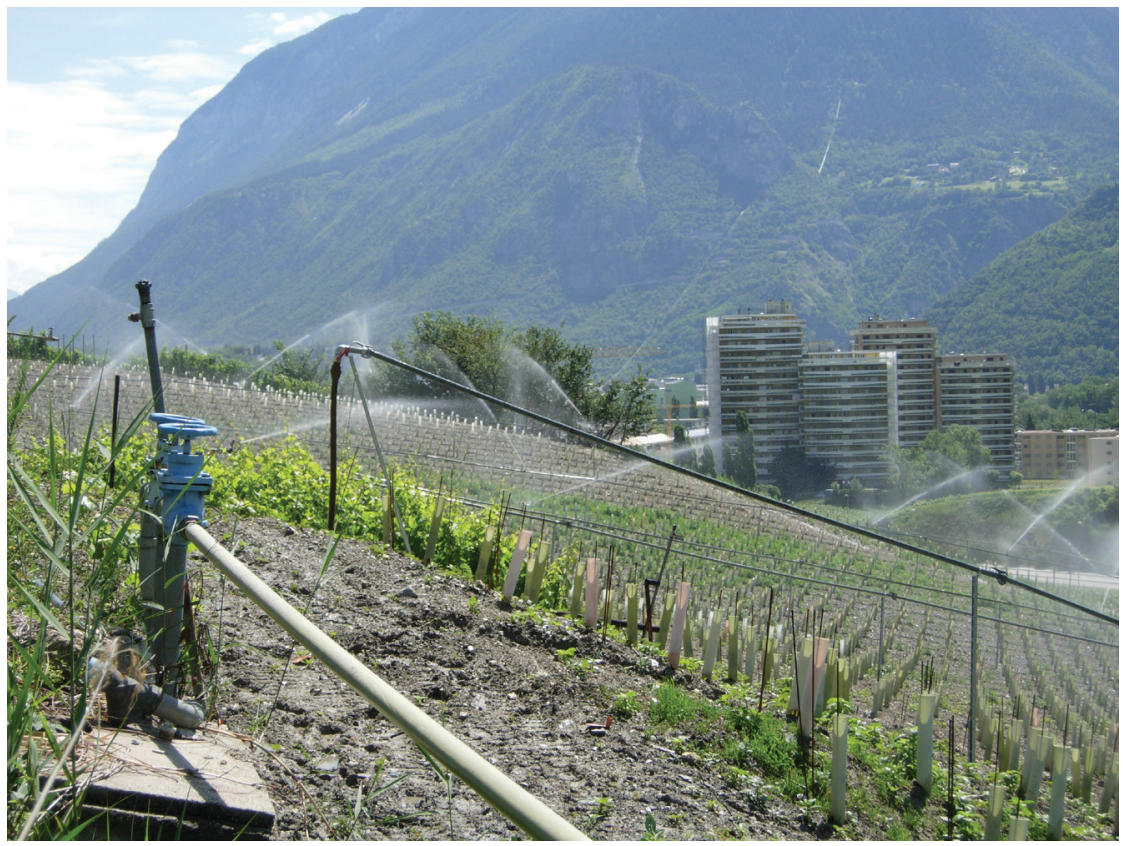

Cross-border water supply assessment of surface water resource availability: application in Danube and Tyrol

Simone Persiano', Alessio Pugliese', Alberto Aloe?, Jon Olav Skøien"2, Stefano Bagli3, Paolo Mazzoli, Juraj Parajka ${ }^{4}$, Berit Arheimer ${ }^{5}$, René Capell ${ }^{5}$, Alberto Pistocchi², Alberto Montanari', Günter Blöschl'4, Attilio Castellarin'

' Department DICAM, University of Bologna, Bologna, Italy

${ }^{2}$ European Commission, DG Joint Research Centre (JRC), Ispra, Italy

${ }^{3}$ GECOsistema srl, Cesena, Italy

${ }^{4}$ Institute for Hydraulic and Water Resources Engineering, TU Wien, Wien, Austria

${ }^{5}$ Swedish Meteorological and Hydrological Institute (SMHI), Norrköping, Sweden

Representing the hydrological behaviour of international watersheds is a fundamental issue for effectively addressing cross-border water resources planning and management problems. On the one hand, macro-scale hydrological models can be used to compute a variety of hydrological signatures along the stream network. Their output can be open-access and freely distributed, providing extremely useful hydrological information across data-scarce regions for the implementation of cross-border policies for water resources management or flood-risk mitigation. On the other hand, geostatistical procedures, such as Top-kriging (TK), have been shown to provide reliable predictions of streamflow, high- and low-flow indices over large study areas.

We consider the latter approaches, focusing on two different problems: 1) the representation of streamflow regime at $\sim 4000$ prediction nodes in the Danube region, producing a GIS data-layer to be made available for a wider use through the Danube Reference Spatial
Data Infrastructure (DRSDI), and 2) the local enhancement of macro-scale runoff simulations, with a focus on Tyrol (Austria and Italy).

Our applications show that geostatistical approaches 1) accurately interpolate observed streamflow regime over large geographical areas and 2) can significantly enhance local hydrological simulations, in areas where macro-scale models fail to correctly reproduce hydrologic behaviour (Fig. 25).

\section{The role of local community in governing water as a common-pool resource}

\section{Primož Pipan, Mateja Šmid Hribar \& Mimi Urbanc \\ Research Centre of the Slovenian Academy of Sciences and Arts, Anton Melik Geographical Institute}

As a fundamental source for life, access for which is difficult to limit and which is subtractable through use, water is often a vulnerable and conflict-prone common-pool resource that demands sustainable governance. Elinor Ostrom won the Nobel Prize for her discovery that people - when facing a limited resource - are able to act and collaborate for the benefit of a common-pool resource. One of the important characteristics of efficient governance is that members have rights as well as obligations or responsibilities, which are counterbalanced. In the presentation, we would like to introduce you to a good practice of water governance and management in a small mountain community in Čadrg village, near Tolmin in Slovenian Alps. The water supply there had long been managed by the village community. In 2010 the reservoir became problematic in terms of drinking water purity. The water 


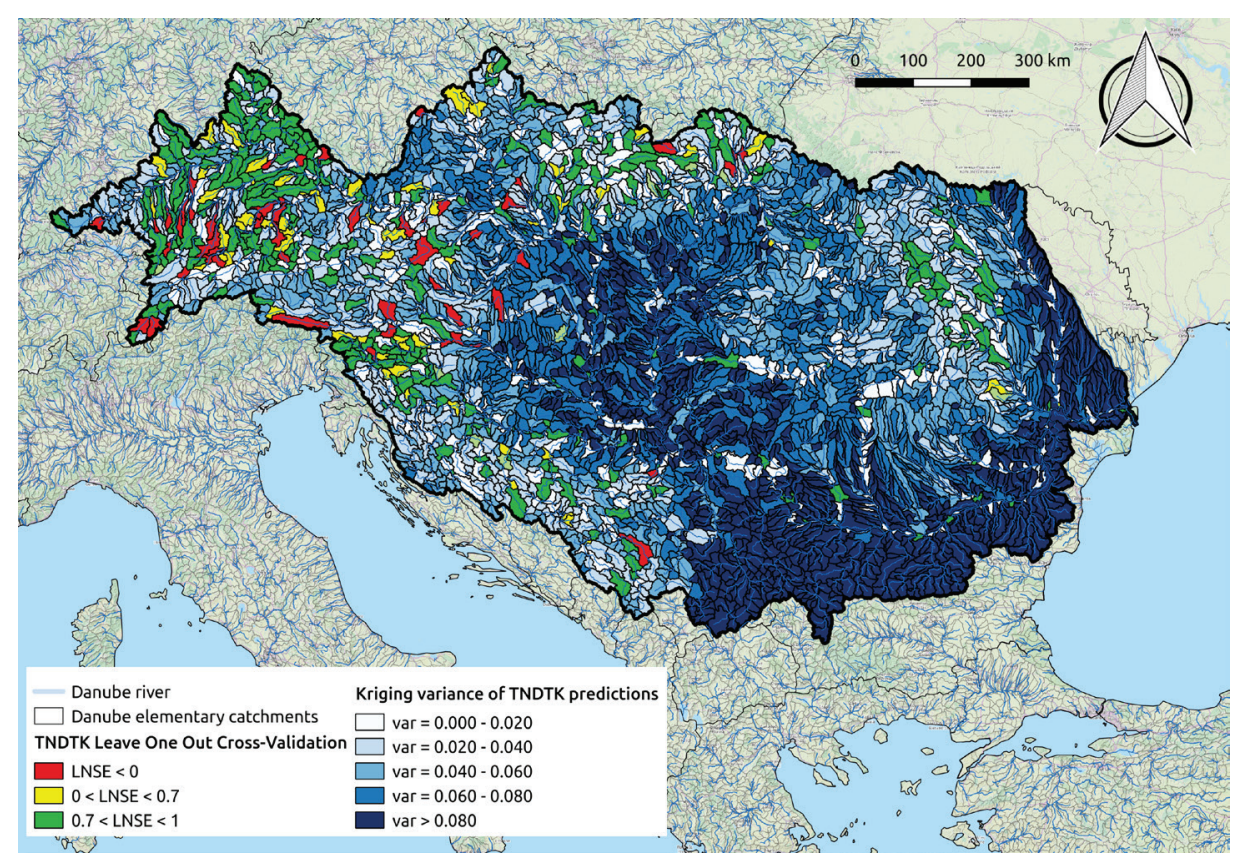

Fig. 25: Prediction variance and local cross-validation LNSE for Danube region elementary catchments: local LNSE values obtained in cross-validation (LPOCV-1 sampling strategy) at 497 $D Q 1+D Q 2$ streamgauges are colour-coded; kriging variance is also illustrated. Source: A. Castellarin, S. Persiano, A. Pugliese, A. Aloe, J.O. Skøien \& A. Pistocchi (2018) Prediction of streamflow regimes over large geographical areas: interpolated flow-duration curves for the Danube region, Hydrological Sciences Journal, 63:6, 845-861, DOl: $10.1080 / 02626667.2018 .1445855$

management could be taken over by the public utility company of the municipality, which would appropriately treat the water with chlorine. However, this approach was not acceptable to locals. The only option for avoiding chlorination was to arrange for treatment with UV radiation by the inhabitants themselves. They defended their right to water, drew up rules for its use and established a transparent management system that they are content with and proud of. We believe that the case study from Cadrg village could be an example to other local communities of how to govern their water sources. 


\title{
ENERGY PRODUCTION (HYDROPOWER)
}

\author{
CHAIR: PETER HANISCH, DONAUCONSULT
}

The presentations reveal the variety of conflicts arising from hydropower generation in Alpine surroundings. They serve as input for the discussion on how much society is ready to 'pay' for the preservation of intact ecosystems or, in turn, for their optimized use. Scale and dimensions taken into account have a significant impact on the result of the evaluation, as well as the need to shift objectives between different spatial, ecological or socioeconomic subsystems.

The objective of the discussion will be to suggest how scientific research, technical practice and economic actors can agree on a common approach for evaluation and implementation of hydropower projects that provides democratic legitimacy for the decision process accepted by the society.

\section{CONCLUSIONS}

\section{Peter Hanisch}

Multi-dimensional conflicts within the water management sector itself, between the framework provided by political decision making, different socio-economic interests and the manifold aspects of the need for conservation of natural resources all point to the need for a cooperative approach. The five case studies presented in this workshop are valid examples for the wide range of conflict situations and the gaps to bridge. The table below tries to give an overview of the different topics, approaches and perspectives:

\section{Case study \#1:}

Wolfram Sparber from EURAC Bolzano presented a study at regional level, covering the province of South Tyrol (Alto Adige). It investigated Possibilities to reduce overall $\mathrm{CO}_{2}$ emissions through substitution of fossil fuels by renewable energy production.

Current energy demand and its expected development had been analysed on an hour by hour basis to find out how future energy production has to be managed to cope with this challenge. The main options available in the region and taken into account were improvement of existing hydro-power plants and an extensive implementation of PV solar energy on ex- isting roof surfaces. The energy demand for heating and air conditioning should be reduced by increasing building efficiency, triggered by incentives set by the government through subsidizing public and private investments. Neither wind energy, construction of new hydro power plants or PV installations on open areas were found to be viable on a larger scale. As traffic is one of the main sources of $\mathrm{CO}_{2}$ emissions, it was found that $50 \%$ of all transport energy in the region would have to switch to electric power. The increase in production of renewable energy should provide enough electricity to cover this additional demand. As long as no other criteria besides reduction of $\mathrm{CO}_{2}$ emissions are taken into account the climate goals could be met by 2030 .

\section{Case study \#2:}

Lutz E. Schlange \& Werner Hediger from HTW Chur $(\mathrm{CH})$ reported about Sustainability assessment of bydropower from a stakeholder perspective.

This presentation showed methods of solving conflicts within and around the water management sector at local (hydro power) project level. In confronting the systemic approach with the stakeholder's views and the scientific view of the problem with 'real' people's perspective and their interests most of the single conflict points and their origins could be identified. Bringing them together for a joint integral assessment, using the 


\begin{tabular}{|c|c|c|c|}
\hline Case Study & Scale & Scenario & Perspective \\
\hline $\begin{array}{l}\# 1: \mathrm{CO}_{2} \text { reduction on } \\
\text { provincial level }\end{array}$ & Regional (province) & $\begin{array}{l}\text { Regional strategy for reducing } \mathrm{CO}_{2} \\
\text { emissions }\end{array}$ & $\begin{array}{l}\text { Energy company / } \\
\text { government }\end{array}$ \\
\hline \#2: Decision making & Project (HPP) & Best practice in project development & All stakeholders \\
\hline \#3: SHPP development & Regional (province) & Future changes in policy making & Environment (NGO) \\
\hline \#4: HPP operation & Project (HPP) & Environmental impact research & Operator, stakeholder \\
\hline \#5: Floodplain flows & River & Environmental regulations research & Environment \\
\hline
\end{tabular}

proposed iterative methodology, it was possible to start a dialogue involving all stakeholders including the energy producer, investors, politicians, public administrations, NGOs, local citizens and other businesses. Their perspectives and the possible trade-offs were discussed until an optimized solution could be found which was eventually accepted by all sides to unlock the decision process. Best practice strategies like these are needed to bring the Swiss Energy Strategy's goals of substituting nuclear power by 2050 closer to realization.

\section{Case study \#3:}

Giovanna Deppi and Lucia Ruffato (Comitato Acqua Bene Comune, Belluno) brought their view on energy strategies, again at regional level, in an Italian province, focusing on Small bydropower plants (SHPP): a critique related to the Belluno area (Italy).

Latest surveys for Italy show that more than 2300 SHPP with less than 1 MW output provide only $6 \%$ of the total hydroelectric production, while $1140 \mathrm{HPP}$ with more than $1 \mathrm{MW}$ are responsible for the remaining $94 \%$ of hydroelectric production.

More than 150 new SHPP projects triggered by government incentives in the field of renewable energy are located in the Belluno province because of its outstanding topography and rich water resources (from $2000+$ all over Italy). The authors show how an originally well-intended strategic goal of supporting renewable energy production, set by the government under the impression of climate change issues, can backfire on other ecologically sensible issues. A lack of coordination between the implementation of the EU Renewable Energy Directive 2009/28/CE and the EU Water Framework directive 2000/60/CE, respectively, was identified as one major source of this misinterpretation of European Community environmental goals.

Different initiatives have been started, supported by established hydroelectric companies as well as by various NGOs, to reshape the permission and subsidy processes for SHPP, considering their environmental impacts versus their share of energy production.

\section{Case study \#4:}

Christian Schlüchter \& Thomas Scheurer (University of Bern) reported about an existing hydropower scheme including two reservoirs at the river Spöl in the Engadin valley. The research area covers the local, project level.

The remaining river stretch, located in a national park, was put under investigation to find out more about the hydro-ecological pressures overlapping with other environmental issues, such as sediment flows from the reservoirs and increased organic load from insufficient wastewater treatment in the catchment area.

The setup of the hydropower scheme allowed for technical flooding of the low flow river stretch between the two reservoirs and for close monitoring of the impacts of technically controlled flows. Additional events originating only partly from within the water management could be investigated in-depth, using this kind of a 1:1 outdoor lab. Valuable findings were made about tolerance and resilience of water habitats and more research questions are to be answered at this specific location in the future.

\section{Case study \#5:}

Julia Brändle (WWF Switzerland) and Daniel Hayes (University of Life Sciences, Vienna) presented their research initiative to Preserving Alpine floodplain rivers through functional floodplain flows.

Alpine floodplain rivers come under multiple pressure. Providing sufficient environmental flow slowly became state of the art, while the hydrologic conditions of the related floodplains became poorer and poorer. The pressure on land use and the demand for flood protection did not leave many river stretches where a major part of the flow regime is able to develop its near-natural impact, putting floodplain biodiversity under serious threat.

The research project identified criteria describing ecologically relevant functional floodplain flows which should be able to provide the seasonal variability, flow magnitude, frequency, event duration, and rise and fall of the hydrograph for near-natural conditions. 


\section{Findings}

Especially the climate-change-induced goals concerning the reduction of $\mathrm{CO}_{2}$ emissions have put $\mathrm{Al}-$ pine rivers under increased pressure by boosting the development of new and the improvement of existing hydropower facilities. Additional stress to the natural river-related habitats comes from conflicting land use in Alpine regions, where in general less than $15 \%$ permanently habitable land is available, which has to be shared among settlement, commercial use, traffic, infrastructure, agriculture and tourism, just to name the more common stakeholders.

The case studies presented in the workshop show how much potential is opened up by an in-depth analysis and the pursuit of "both this and that" strategies, compared to the rather obvious classic "either - or" exclusive solutions. Because of the complexity of the target systems, an in-depth examination of the individual criteria and aspects is required to recognize and understand the total impact. By explaining and using these findings, it is possible to identify the essential criteria to be addressed both in the public debate and in the decision-making process. The outcomes have to be made publicly available to stakeholders as a basis for their decision making.

The analysis of decision-making processes described in existing administrative guidelines highlights the importance of an open socio-political debate, not only on the individual project but also on the underlying framework conditions.

Today's state of the art in technical water management systems offers opportunities for controlling the impacts on affected ecosystems in a wide range. Investigation results show that there are methods and tools available to achieve a high benefit for the ecosystems concerned with a relatively low impact on the original use.
The conflicts presented around the resource 'water' in Alpine settings provide the impulse for the discussion on how much exclusivity society as a whole is ready to 'pay' for the preservation of intact ecosystems or, in turn, for their optimized use. The scale selected for the comparison can have a significant impact on the result of the evaluation. In addition, the effects of relocation and the need to shift between different spatial, ecological or socio-economic subsystems must also be taken into account. Best practice examples based on dynamic trade-offs in space and time between opposing goals become more and more available. These strategies just have to be carefully analysed and adapted to each new conflict.

\section{INPUTS}

Energy transition in Alpine regions - what does it mean for water use and water management?

A view from South Tyrol on dynamic regional energy modelling and ongoing refurbishments of large-scale hydro power plants.

\section{Wolfram Sparber}

Eurac research, Institute Renewable Energy, Bolzano

The EUSALP EU strategy Alpine region has set the target to make "...the Alpine Space a model region in energy efficiency and renewable energy applications...". Many regions within the Alpine Space have set ambitious climate and renewable energy targets to be met until 2020, 2030 and 2050.

But with which energy system can such targets be met? What technology combination, to which extent, has to be applied to reach the target in a most cost-effective way? Can the targets be reached under technical, social, environmental and economic constraints?

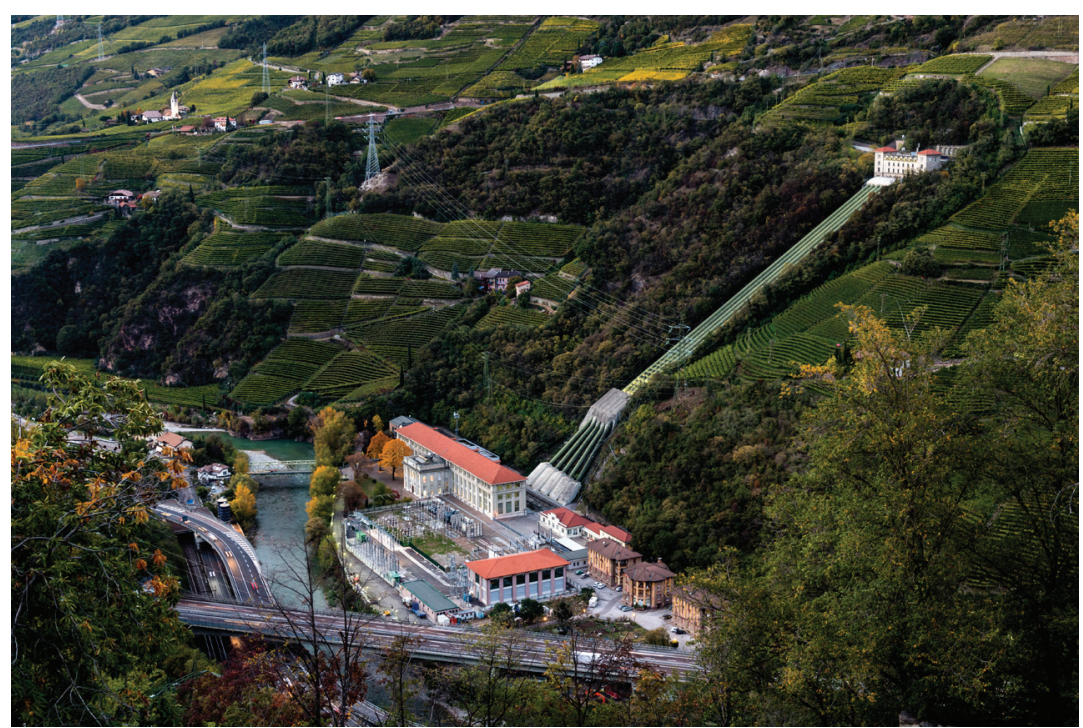


Within Eurac Research, a method has been developed that provides answers to these questions considering the hour by hour energy consumption for a reference year. The region of South Tyrol with its energy consumption, building stock, landscape and natural resources, transportation mix and its climate plan (target 1.5 ton CO emissions/capita until 2050) was taken as a demo model. Technical, social and environmental constraints were taken into account in terms of the possible expansion of renewable energy sources for electricity and heat production. The energy efficiency potential was considered, especially with regard to the existing building stock, as well as the mobility sector and its transition to zero emission transport.

The main results of this model are presented, taking into account the important investments going on by the energy utility Alperia in the local hydropower infrastructure (Fig. 26). Alperia is investing in massive refurbishment of existing large-scale hydropower plants in terms of safety, efficiency and environmental aspects.

\section{Sustainability assessment of hydropower from a stakeholder perspective}

Lutz E. Schlange', Werner Hediger', Gianluca Giuliani2 \& Marc Herter $^{2}$

1 University of Applied Sciences Chur, Department of Entrepreneurial Management

${ }^{2}$ University of Applied Sciences Chur, Department of Living Environment

Hydropower being the most important domestic energy resource and backbone of regional economies across the Alpine region, it also affects the environment and thus poses a major challenge for sustainable development. The purpose of this research is to advance sustainability assessment of hydropower projects, in particular regarding its integrity, flexibility and transdisciplinarity. To this end, the iterative methodology proposed integrates a systematic assessment, on the one hand, and a human-centred dialogue focusing on the semantics and priorities of stakeholders, on the other. To comprehensively evaluate the complex effects of hydropower plants, an integrated impact and sustainability assessment is applied to case studies in selected Swiss Alpine regions in the construction and operation phases. In order to foster a critical dialogue

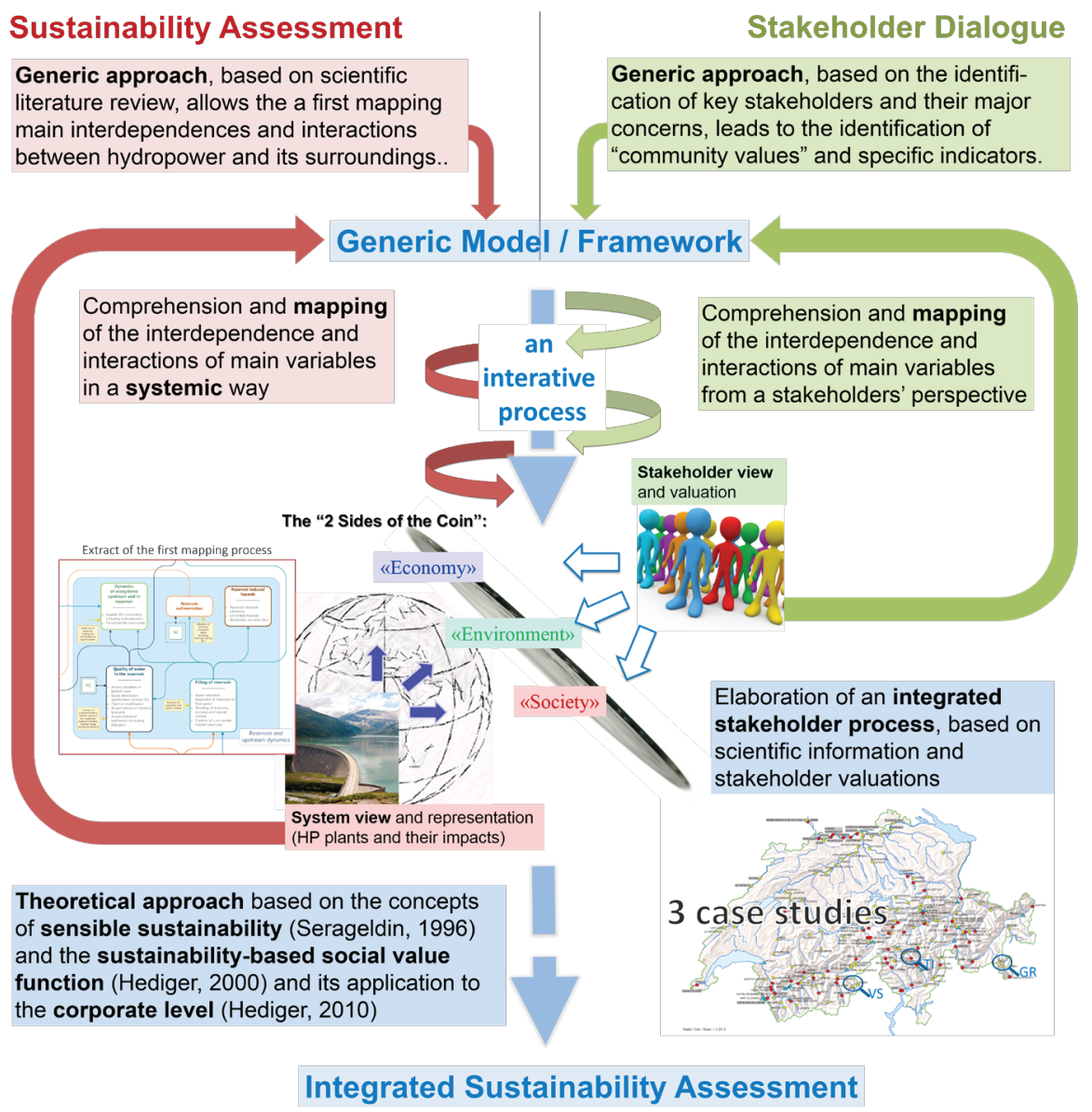

Fig. 27: Two Sides of Integrated Sustainability Assessment. Graphics: @ Zentrum für wirtschaftspolitische Forschung ZWF, Hochschule für Technik und Wirtschaft HTW Chur 
about and higher acceptance of the projects under evaluation, trade-offs between sustainability goals are evaluated by stakeholders, including energy companies, investors, politicians, public administrations, NGOs, local citizens, and businesses.

\section{Small hydropower plants: a critique related to the Belluno area (Italy) \\ Monica Camuffo 1,2, Giovanna Deppi³, Luigina Malvestio $^{2}$ \& Lucia Ruffato 2 \\ ' Università Ca'Foscari Venezia, Department of Environmental Sciences, Informatics and Statistics ${ }^{2}$ Comitato Acqua Bene Comune Belluno \\ ${ }^{3}$ Coordinamento Nazionale tutela fiumi Free Rivers Italia}

Small hydropower plants (SHPP; Fig. 28) are widely criticized by research communities from many countries. As early as 2011, the Alpine Convention highlighted SHPP-associated risks for pristine environments and small profits in terms of energy production. Despite the questionable benefits of SHPP, Italian government still considers hydropower (and mainly small plants) as one of the ways to energy autarchy. In 2009 the Italian government approved measures to implement the Direttiva 2009/28/CE without considering their viability and impact on preexisting environmental directives (Habitats and Water Framework directive). Local institutions were not ready to manage the speculative stress induced by the incoming government's economic incentives (state aid) in the absence of adequate territorial planning and regulations and ended up with unprecedented exploitation of unspoiled streams. More than 2000 new SHPP projects have been presented in Italy, mainly in the Alpine region; 150 of them in the Belluno area that sadly witnesses this threatening circumstance. We focus on the community reactions to the new wave of hydroelectric projects, conflicts, networks and solutions that emerge in the locality. We will show how local communities are able to resist and to invest time, energy and money trying to improve inadequate policies established at national regional and provincial level.

\section{Impacts and risks of reservoirs: the case of reservoirs along the river Spöl}

\section{Christian Schlüchter' \& Thomas Scheurer ${ }^{2}$ \\ 'University of Berne, Institute of Geological Sciences ${ }^{2}$ ISCAR}

This presentation illustrates scientific and technical challenges to managing geo-ecological impacts of reservoirs for hydropower production. The river Spöl in the Engadin valley was a high-energy Alpine river until it was developed as part of a hydropower scheme in two steps, beginning in 1962: construction of an upper dam to form the Lago di Livigno and of a lower dam to create the Ova Spin reservoir. The remaining river segment in-between the two reservoirs runs in the Swiss National Park. This fact did allow fundamental research into the geological and biological processes of a managed Alpine river with a focus on the nature of the water flow, which has been reduced by regulations and is highly controlled as well as seasonally and daily variable. The technical flooding in 1995 was monitored scientifically and became the starting event of a series of monitored floodings of the river with the result of an overall revitalization of the system to the benefit of all parties involved: plant operators, science community and, above all, nature. However, two events

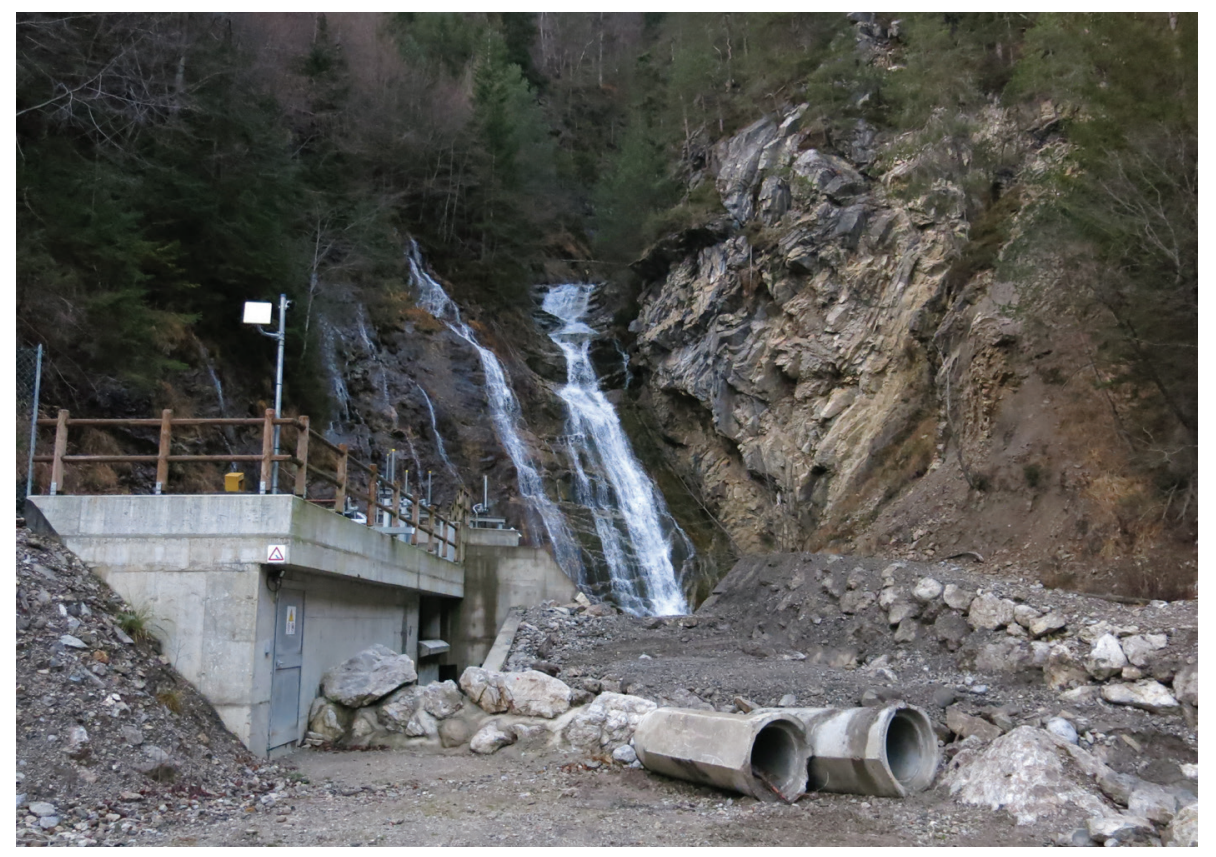

Fig. 28: Small hydropower plant on the Velezza stream in Lozzo di Cadore, Belluno province. Photograph: Giovanna Deppi 

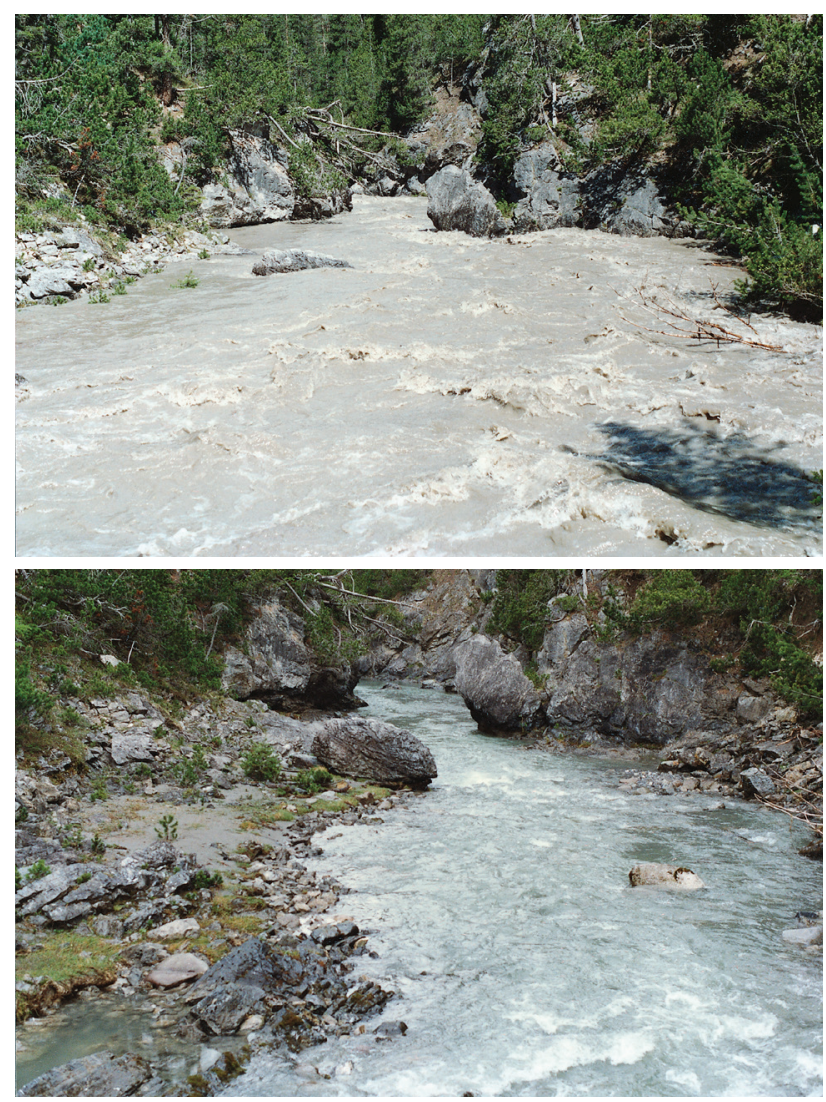

Fig. 29: Artificial flood in River Spöl (Swiss National Park): artificial flood during one day (max. $40 \mathrm{~m}^{3} / \mathrm{s}$ ) above, and residual water $\left(1.5 \mathrm{~m}^{3} / \mathrm{s}\right)$ after the flood. Fotos: Christian Schlüchter

added to the environmental experimental character of the river Spöl (Fig. 29): In 2013 fine-grained sediment from the upper reservoir (Lago di Livigno) produced a muddy, biohostile river and in 2016 a PCP-dust cloud escaped from a maintenance operation in the facilities of the upper dam. In addition, organic sediments were recorded in the Ova Spin reservoir, which were the result of insufficient wastewater treatment from Upper Engadin.

\section{Preserving Alpine floodplain rivers through functional floodplain flows}

Daniel Hayes', Julia Brändle², Carina Seliger', Bernhard Zeiringer' \& Stefan Schmutz'

' University of Natural Resources and Life Sciences, Vienna, Institute of Hydrobiology and Aquatic Ecosystem Management

${ }^{2}$ WWF Switzerland

Alpine floodplain rivers are biodiversity hotspots. As these ecosystems are particularly sensitive to hydrological modifications, water abstraction poses a serious threat to them, if environmental flow (e-flow) management does not consider the requirements of the whole river system, but only chosen instream criteria. Based on essential functions and processes of unimpaired floodplain rivers, we identify fundamental principles that must be adhered to in order to determine truly ecologically-relevant e-flows. Literature emphasizes that the natural flow regime and its seasonal components are primary drivers for functions/processes of abiotic and biotic elements, e.g., morphology, water quality, floodplain, groundwater, riparian vegetation, fish, macroinvertebrates and amphibians. Based on the liaison between central flow regime elements and associated environmental components within and adjacent to the river, we formulate a process-oriented functional floodplain flow (ff-flow) approach (Fig. 30), which offers a holistic conceptual framework for e-flow assessment in floodplain river ecosystems. This approach proposes a dynamic e-flow regime, as it underlines the importance of emulating the natural flow regime with its seasonal variability, flow magnitude, frequency, event duration and rise and fall of the hydrograph. Thus the ff-flow approach can safeguard the protection of Alpine floodplain rivers by establishing ecologically-relevant e-flows and guiding flow restoration measures.

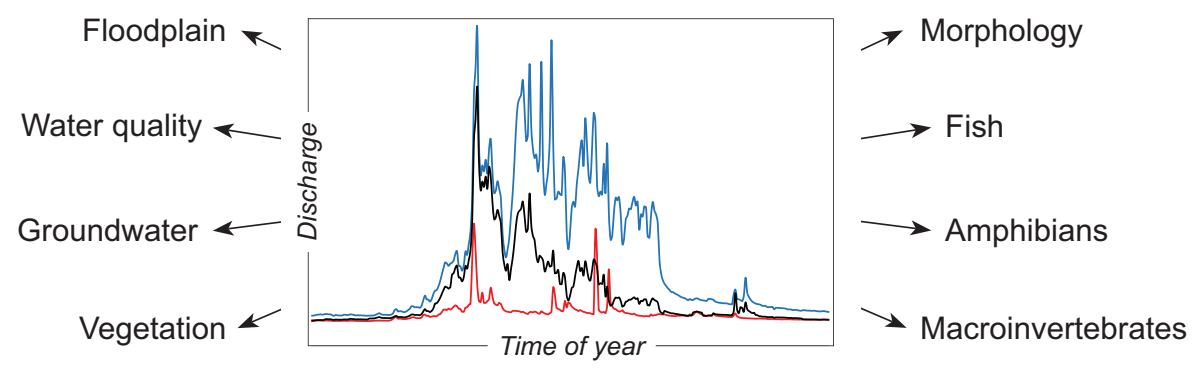

\section{- Natural hydrograph, - Minimum flow, - Functional floodplain flow}

Fig. 30: The functional floodplain flow (ff-flow) approach integrates ecological functions and processes with principal flow regime components and their seasonality. It is understood to be a guide towards key aspects of the annual hydrograph and

their implications for various elements of floodplain ecosystems (Source: Hayes, D.S., Brändle, J.M., Seliger, C., Zeiringer, B., Ferreira, T., \& Schmutz, S. (2018): Advancing towards functional environmental flows for temperate floodplain rivers. Science of the Total Environment, 633, 1089-1 104.). 


\section{TOURISM}

\section{CHAIR: PHILIPPE BOURDEAU, UNIVERSITÉ GRENOBLE-ALPES, INSTITUT DE GÉOGRAPHIE ALPINE}

While water has become a central resource of the summer and winter tourist experience and the economy in the mountains, its increasing uses (sports and leisure activities, well-being, technical snow...) make it a common good faced with the risks of shortage and competition between recreational and utilitarian uses (daily life, agriculture, industry). The workshop will address key questions for the prospect of recreational uses of water in the mountains: What know-how is needed for regulating water uses between the tourism sector and other activities, and vis-à-vis the downstream watersheds? What should governance of water between public and private actors look like? What are the benefits of integrated water management systems?

\section{CONCLUSIONS}

Philippe Bourdeau

Even if the variations in precipitation patterns unlike temperature variations - as a result of climate change are not clearly documented, there is considerable uncertainty about the future availability and quality of water in the face of risks of scarcity and increasing competition between recreational uses as well as between recreational and utilitarian uses (daily life, agriculture, industry), both within mountain regions and between mountain regions and downstream areas.

The two case studies presented in the workshop and the conclusions from the Water \& Tourism Conference 2017 in Sion \& Serre (Switzerland) show that:

1. In rural areas, recreational uses of rivers can help to preserve socio-ecosystems by enhancing them without degrading them, but are likely to compete with hydropower production, whose environmental impacts are much greater. Coordination between local and regional stakeholders must be stepped up to reconcile uses;
2. In Alpine tourist resorts, which are highly artificialized regions, an increasing number of functions are attributed to artificial reservoirs (irrigation, drinking water, artificial snow production, recreational practices), which become ever more numerous and whose management on the scale of catchment areas is becoming increasingly complex. It will not be possible to manage emerging dynamics of recreational hyperconsumption of water (artificial indoor rivers, spas...) by an increase in prices because users are willing to pay;

3. At the local level, the risk of water supply crises is lower than in the past, thanks to the systematic interconnection of water supply sources, even if political fragmentation often makes it difficult to manage the resource. However, there is a risk that the issue of economic and solidarity responsibilities towards downstream areas will come to the fore, requiring mountain regions to assume their role as water towers. 


\section{INPUTS}

Valuation of recreation related ecosystem services on rivers Soča (Slovenia) and Tara (Montenegro)

Jernej Stritih', Matjaž Harmel² \& Klemen Strmšnik²

\section{'STRITIH, Sustainable Development, Bovec ${ }^{2}$ ZaVita d.o.o., Ljubljana}

The rivers Soča in Slovenia and Tara in Montenegro are highly attractive for recreation and tourism in terms of fishing, rafting, kayaking, hiking and experience of nature (Fig. 31). Both river basins are within UNESCO biosphere reserves (Julian Alps and Tara River Basin). The upper Soča river is already much used for recreation, while tourism and recreation on the river Tara are at early stages of development. For the upper Soča river in Slovenia, existing added value generated by recreation and tourism was assessed based on actual revenues generated. On Tara, the potential for future revenues was assessed based on comparison with Soča. Both cases show that the economic value of recreation and tourism, while having very low or even positive effects on river basin conservation, is comparable to the value of energy generation that had been proposed on the rivers previously. But recreation and tourism contribute considerably more to local sustainable development, as they provide a higher number of local jobs and entrepreneurial opportunities based on nonextractive use of nature. Even though not used at the moment, the biosphere reserve or similar communitybased mechanism may provide a good framework for the management of nature-based recreation and tourism, and for trade-offs with other ecosystem services in the river basin.
Integrated Water Resource Management in tourist areas: moving from the hydrological basin to the water use basin

\section{Emmanuel Reynard, Martin Calianno, Marianne Milano \& Christophe Clivaz}

University of Lausanne, Institute of Geography and Sustainability

Integrated Water Resource Management (IWRM) was proposed to enhance sustainable water management. Although organizing water management according to the hydrological watershed limits is interesting, it can be difficult to apply at local level because of anthropic factors that may not fit into these limits (e.g. water derivations). It is particularly noticeable in mountain tourist resorts, where spatial and temporal concentration of water demand induces a high anthropization of hydrological systems. Is watershed management then the best model for such artificialized watersheds? This issue is discussed by studying the Crans-Montana resort (Switzerland), which experienced several phases of intense development leading to situations of water scarcity. Currently it is a large resort, with more than 40000 tourist beds and a large set of competing water uses (irrigation, hydropower, drinking water supply and artificial snowmaking). Management issues are here analysed from the IWRM perspective. We demonstrate that in this resort, straddling several watersheds with multiple artificial derivations of water, the model of watershed management is not the most appropriate. After analysing the historical evolution of the tourist resort and water needs, we suggest three tools the water use basin, water use density and water use regime, to address highly anthropized water systems with a specific approach focused on the water demand side.

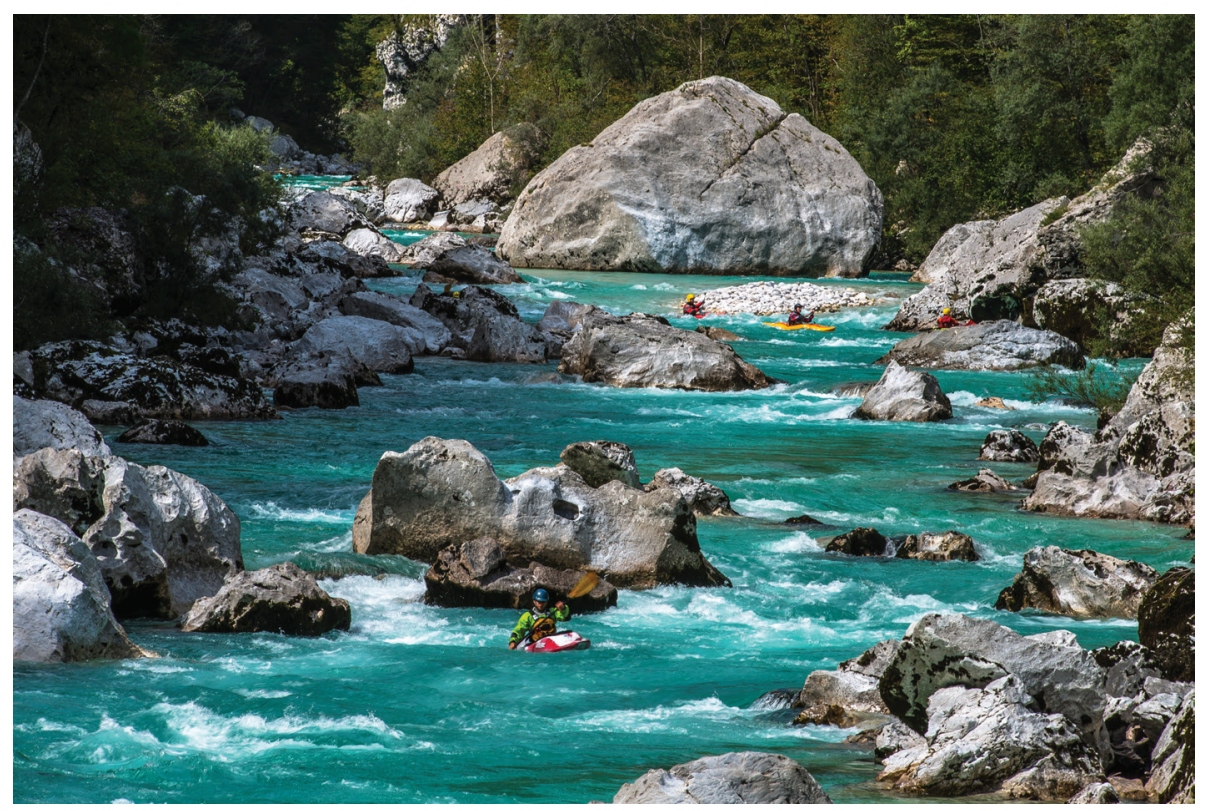

Fig. 31: Kayaking and rafting recreation of Soča river, Slovenia. Photograph: Avelux 


\section{Summary of the Water \& Tourism Conference 2017 in Sion/Sierre (Switzerland)}

\section{Emmanuel Reynard}

University of Lausanne, Institute of Geography and Sustainability

Organized by the Institute of Geography and Sustainability of Lausanne University and the Institute of Tourism, HES-SO Valais-Wallis, the conference Water and Tourism was held in Sion and Sierre (Valais, Switzerland), from 9 to 10 November 2018. It aimed to discuss the relationships between tourism and water and explored three topics: (i) the impacts of tourism on water management; (ii) water as a resource for tourism; (iii) tourism, water and climate change. Around 50 researchers from 10 countries attended the meeting. Three keynote speeches by Prof. Stefan Gössling (Lund University), Melanie Kay Smith (Budapest Metropolitan University) and David Sauri (Autonomous University of Barcelona), 22 oral communications and 5 posters were presented, and the proceedings will be published in Mondes du Tourisme and Journal of Alpine Research. Several topics were discussed during the conference. The attractiveness of water for tourism faces several challenges, including changes in public expectations over time, as experienced by thermalism, the privatization of the banks of Alpine lakes, or the difficulties of tourism promotion of hydraulic heritage. Tourism also has significant impacts on water resources. The water footprint is often underestimated because it does not take indirect consumption into account. Seasonality of use is also a major issue for integrated mountain water management. Finally, water management in tourist regions faces major challenges related to global warming.

\section{On the recent variation of the Snow Reliability Line in the south-eastern Alps}

\section{Massimiliano Fazzini}

The response of the recent nivological signal to climate change is very difficult to quantify in the Alps, bordered by the Mediterranean Sea to the south and continental domains to the north and east. However, at altitudes between 1500 and $2000 \mathrm{~m}$, despite observation for 90 years, a greater inter-seasonal variability in the nivometric sums is evident but with no trend. A shorter duration of snow cover on the ground is clear, closely dependent on the strong increase in temperature. At lower altitudes there has been a reduction in the total amount of snowfalls and a strong reduction in the snow duration on the ground, while above 2000 $\mathrm{m}$, there is an evident increase in the sum of fresh snow fallen, in close connection with the greater amount of available energy during the passages of low-pressure systems. Through the daily analysis of data, for about 40 monitoring stations located in some of the most important ski resorts in the south-eastern Alps, for the timespan 1985-2017, we calculated the average altitude at which the seasonal thickness of the snow on the ground was more than $30 \mathrm{~cm}$ for at least 100 days. This limit is called Snow Reliability Line (SRL); below it, the survival of a ski resort is not economically guaranteed. The first results would not show an clear trend - with an average that currently stands at around $1800 \mathrm{~m}-$ affected by the strong negative nivometric anomalies that occurred in the last two winter seasons 2015-16 and 2016-17. 


\title{
ECOLOGICAL INTEGRITY OF RIVERS
}

\section{CHAIR: LEOPOLD FÜREDER, UNIVERSITY OF INNSBRUCK, INSTITUTE OF ECOLOGY}

\begin{abstract}
Alpine rivers play a particular role in the Alps, their surroundings and over large areas of Europe. They occur in various forms, are highly interlinked, cover surfaces involving different countries and administrative levels, provide habitats for a rich and particular biodiversity, but also suffer from multiple demands and use. A wide spectrum of anthropogenic impacts has resulted in an alteration of catchments and discharging rivers, sometimes even in a complete disruption of river systems. Several national and international directives are in place for their protection and sustainable use, as well as for improvements of their ecological status, and these contribute to the high conflict potential. Here we discuss a) the ecological status of rivers in the Alpine regions, b) look at conflict scenarios and key management measures, and c) propose innovative projects and concepts towards a sustainable ecological integrity.
\end{abstract}

\section{CONCLUSIONS}

Leopold Füreder

The ecological integrity of Alpine rivers, in its current status, mirrors alarmingly the effects from a variety of anthropogenic impacts. Ever-increasing demands in land use, water abstraction for energy, snow production and irrigation, water resource alterations, organic and inorganic pollution, as well as engineering activities for flood protection and erosion control, have changed the structure and function of river systems. River management faces multi-dimensional conflicts as pressures continue and key legal frameworks are coming into play more strongly. We invited five presentations to the workshop in order to a) provide an overview of the ecological status of rivers in the Alpine regions, b) learn from different conflict scenarios and key management measures, and c) present innovative projects and concepts towards a sustainable ecological integrity.

The first presentation provided an overview on the environmental conditions of Alpine rivers. In order to meet the requirements for sustainable development and management of rivers, a priority framework for halting the loss of intact rivers and biodiversity was deemed useful, emphasizing the importance of a "panAlpine perspective". This large-scale consideration was seen as crucial for a well-balanced implementation of protection and restoration measures against river-type loss and their importance and/or representation.

Later presentations introduced different approaches for awareness-raising towards recognition of intact rivers (The Wild River Site Labe), for holistic decision guidance in river management programmes (The $W W F$ Austria - River Restoration Concept) and for a better understanding of cause-effect relationships on a regional (Clean Water Project - San Giovanni Torrent) and supraregional level (the ALFFA project).

Given all these examples, we can conclude that strong and further effort has to be dedicated to a multi-spatial and multi-dimensional understanding of river systems and their management. Factors and processes act over several dimensions (spatial and temporal connectivity), impacts and problems do not stop at national borders and management measures have to pay more attention to past, recent and future framework conditions and integrate conservation efforts, flood protection measures and sustainable use. 


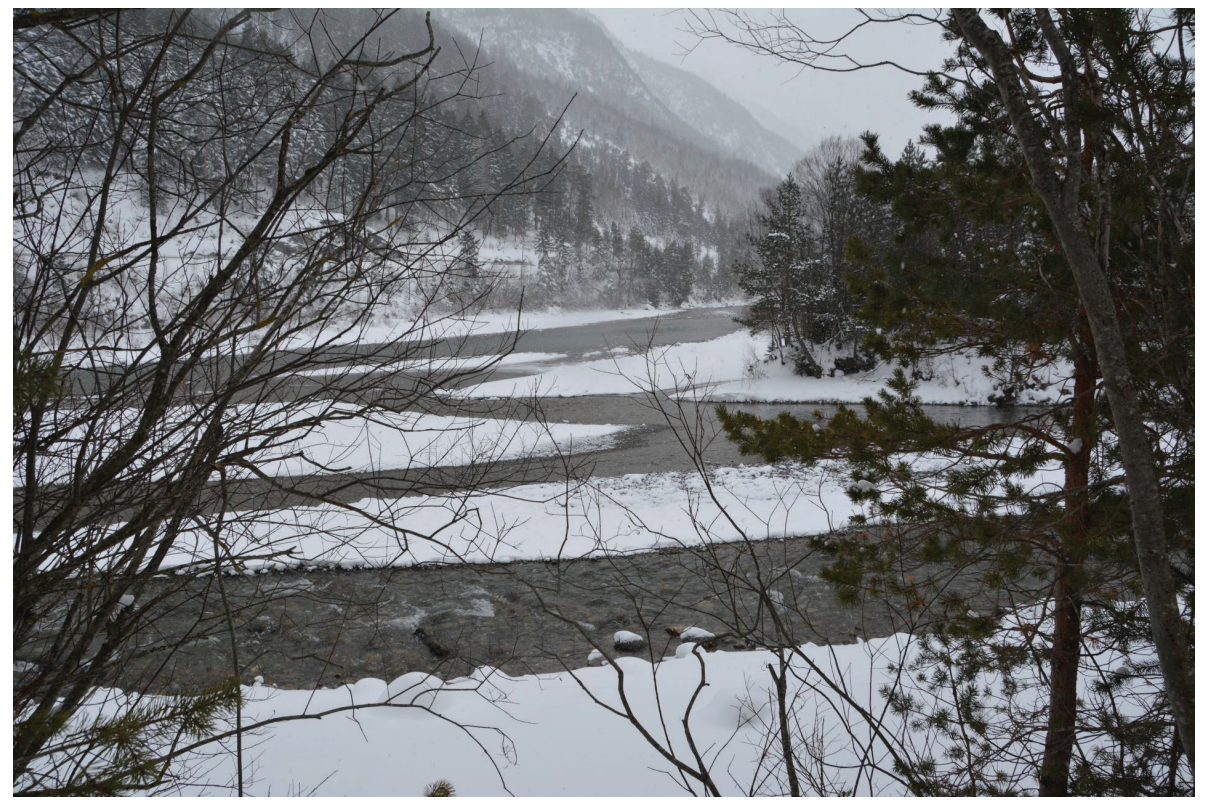

Fig. 32: The natural status of most Alpine rivers has been dramatically altered by human activities. High-quality rivers like the Austrian sector of the River Lech therefore are valuable reference systems for understanding ecosystem function and structure, especially the effects from human impacts. Photograph: Leopold Füreder.

\section{INPUTS}

\section{Overview of the environmental conditions of the rivers of the Alps}

\section{Susanne Muhar \& Carina Seliger}

University of Natural Resources and Life Sciences, Vienna, Institute of Hydrobiology and Aquatic Ecosystem Management

The major river systems of the Alps are under strong pressure from the ongoing exploitation of their water resources. However, healthy rivers and their multiple functions receive increasing awareness and appreciation by people as well as by representatives of administration and policy. That goes hand in hand with key legal frameworks, which require ecologically intact rivers and/or their biodiversity to be maintained and the status of degraded aquatic ecosystems to be improved.

Based on our investigations and the establishment of a pan-Alpine data base, an overview of the environmental status of Alpine rivers can be provided. The results help to establish a prioritization framework to halt the loss of healthy rivers and their biota by appropriate conservation strategies. Emphasis is put on this "panAlpine perspective" because the scope of most existing conservation activities rarely goes beyond national borders. This is crucial for a sustainable implementation of protection and restoration and helps to avoid shortterm, single-case decisions without knowledge of the Alps-wide context.

\section{The Wild Rivers Label - an effective tool to conserve Alpine river landscapes?}

\section{Roberto Epple}

European Rivers Network

Rivers and streams that have remained untouched and have escaped any major changes to their natural shape (for example, with flood barriers, changing river channels, embankments, various alterations) and maintained crystal clear water are extremely rare in France and Europe. They should all be protected. However, current regulations, mainly those that stem from the European Water Framework Directive, are not sufficient. To counter the threats to wilderness rivers, WWF and ERN France initiated the Wild Rivers Programme (programme riviéres sauvages) and an associated certification scheme. The label is a high-level instrument for the protection and development of the region that acquires it, strengthening its image among various populations. It is certified by Afnor Certification, after a technical audit of the application file and a visit to the site of the river basin to ensure that the assessment criteria for wilderness and governance (the Chart) are respected by the applicant (regional nature park, local authority, river association, etc.). The label is awarded on condition that a conservation actions plan is established and applied over a period of time. Today it consists of three levels, with a fourth envisaged that would correspond to optimum wilderness across all European rivers. A recent feasibility study discusses the options and changes for developing an equivalent label on a pan-Alpine level. 


\section{WWF Austria - River Restoration Concept \\ Gebhard Tschavoll \\ WWF Austria}

Austria's major rivers have lost much of their original characteristics over the past 150 years. Although water quality could be improved due to targeted remediation programmes, economic pressure and over-exploitation have led to a general deterioration of the ecological quality of the riverine natural areas. This is accompanied by an increasing risk of damage caused by flooding as settlements and infrastructure have moved closer to the rivers. Climate change, with a higher probability of extreme precipitation events, adds further to this situation. In its first module, the WWF River Restoration Concept uses reference routes distributed across all river systems in Austria to show which habitats have been most affected by loss and projects the development into a medium- and long-term future. A scenario called WWF river vision compares this development with a nature-compatible variant. In its second module, the River Restoration Concept uses the link and evaluation of data on flood risk, population distribution and ecology to show in a masterplan in which river sections the greatest possible synergies for flood protection, biodiversity and recreation can be generated through flood protection and revitalization measures. The River Restoration Concept was developed in cooperation with the planning office Revital Naturraummanagement, who carried out the entire GIS evaluation. The results will be made available to the public at the website www.fluessevision.at

\section{Clean Water Project - San Giovanni torrent (Italy)}

\section{Andrea Cottini', Filippo Miotto', Marzia Ciampittiello², Angelo Boggero 2 \& Stefania Cerutti}
' Associazione per lo sviluppo della Cultura, degli Studi Universitari e della Ricerca nel Verbano Cusio Ossola ${ }^{2}$ ISE CNR Verbania
${ }^{3}$ Università Piemonte Orientale

Lake Maggiore basin (north-western Italy) has always provided opportunities for hydroelectric plants. As is generally known, the right balance between the preservation of the ecological quality of rivers and hydropower generation is not easy to maintain, mainly due to lack of further research. The exploitation of water for hydroelectric purposes can alter habitats, inducing their loss, impoverishing biodiversity, with significant effects on the most sensitive taxa and on the ecological quality of the water course.

As a result of these requirements, the Clean Water Project, a pilot study carried out on the river San Giovanni with ISE CNR of Verbania, was launched.

The main aims were: 1) to gain scientific knowledge on the effects on the biodiversity of the different human impacts in the river basin; 2) to verify how the presence of human impacts affects the hydro-morphological, chemical and biological quality of the rivers systems, up and down the infrastructures; 3 ) to set up a best practice to analyse impacts, 4) to verify compliance with the European directives and Italian standards.

The results showed the reduced effect of small hydroelectric plants if proper facilities have been realized to increase river quality, so they can be compared with the effect of other anthropic river structures. A next step is to apply the procedure in a river before and after the construction of a hydroelectric plant to understand the real effect on ecological status.
Fig. 33: Andrea Cottini presenting "Clean Water Project - San Giovanni Torrent (Italy)"

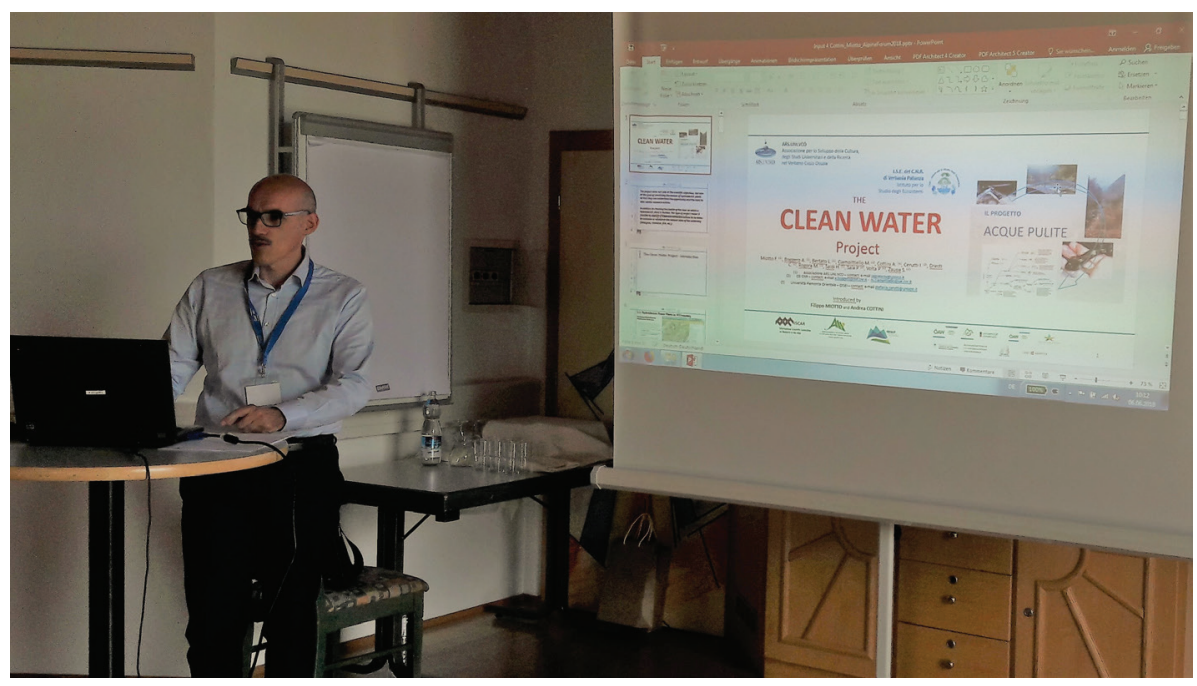




\section{ALFFA - Holistic (multi-scale) analysis of the factors and their effect on the fish fauna in inner-Alpine areas

\author{
Stefanie Oberarzbacher', Roberta Bottarin', Alberto \\ Scotti', Wolfgang Mark², Bernd Pelster', Michael \\ Niederwanger ${ }^{2}$, Josef Wieser ${ }^{3}$ \& Erich Tasser ${ }^{1}$ \\ ${ }^{\prime}$ EURAC Research, Institute for Alpine Environment \\ ${ }^{2}$ University of Innsbruck, Institute of Zoology \\ ${ }^{3}$ Agentur Landesdomäne, Aquatisches Artenschutzzentrum \\ (ITAT104 1 ALFFA, INTERREG Italien-Österreich)
}

River ecosystems are strongly influenced by landform and human activities in their surroundings. Most rivers worldwide have been severely altered by a combination of different anthropogenic interventions, leading to dramatic changes in the aquatic habitat and the organism community. Fish are an established biological indicator. With information about species composition, abundance, dominance and population structure, it is possible to make reliable predictions about the status of the river ecosystem.

The disappearance of species, local decline of populations and the endangering of fish stocks (in general) are evidence for the dramatic change in the fish fauna in Tyrol and South Tyrol. An additional threat is the loss of genetic integrity as a result of stocking with nonnative species and the loss of autochthonous species.

In contrast to most of the previous research, where only individual drivers were examined, in this project we will: 1) determine the impact of (as far as possible) all influencing drivers (incl. land cover in the catchment; agriculture, fisheries, fish-eating birds, pesticides); 2) visualize them through geostatistical and multi-scale models; 3) and incorporate the results into river management plans to provide guidelines for future decision making. 


\title{
MANAGING CONFLICTING WATER USE
}

\author{
CHAIR: VALERIE BRAUN, INSTITUTE FOR INTERDISCIPLINARY MOUNTAIN \\ RESEARCH, ÖAW
}

\section{Keynotes}

\section{WATER AS A CAUSE FOR CONFLICTS}

\author{
MARTIN GRAMBOW, TU MUNICH
}

\begin{abstract}
Water is the most political resource in the world. Every living thing needs water. Every life form is adjusted to a certain amount of water. Water is a gravimetric resource, always flowing top - down. On its way, water collects memories, at least in terms of quality.

When one considers water as a political resource, one might think of major conflict zones like Israel, Jordan or Syria. Any water conflict in our region seems insignificant in comparison. But when we look more closely, we are forced to admit that many of the current political and social challenges in Europe are inextricably linked to the resource water. The Alpine Space is a culmination point in which these effects are magnified: It is the water 'reservoir' of Europe, the high gradient means energy but also forces (hydropower but also erosion). It is home to extreme and therefore always vulnerable systems, in the ecological and the hydrological sense. Climate change will exacerbate things further. The basis for any solution has to be to acknowledge the problem and to place it at the centre of a social and political debate.

Water has one dramatic characteristic: it links things that appear, at first glance, unlinked: irrigation and urban planning - Innsbruck and Budapest - renewable energy and water quality - drinking water and fish populations. As inconvenient as this 'water link' may be, it does provide us with an excellent and integrated indicator for sustainable and socially responsible action.
\end{abstract}

\section{PARTICIPATIVE PROCESSES IN WATER MANAGEMENT}

\author{
KLAUS MICHOR, REVITAL
}

Rivers are multi-functional systems. Stakeholders from the public, private and civil society sector often represent their interests vehemently. Consequently, the demand for participatory planning processes is of great importance. Yet the solutions are often determined by technical, economic and licensing-relevant framework conditions. In addition, the planning processes are getting longer, more complex and unmanageable. Technically and legally complex questions are a special challenge in participatory processes. Experience has shown that it is important and at the same time difficult to communicate planning principles and measures for all persons involved. 


\section{CONCLUSIONS}

\author{
Valerie Braun
}

The growing demand and the availability of Alpine water resources for water provision, energy production and tourism in Europe makes the future of water resources relevant for the local population, the economy and politics. Moreover, the Alps are considered the water tower of Europe, providing the lowlands with water for agricultural, domestic and industrial use. Alpine water resources are threatened by climate change and may lead to social conflicts. The following summary of the two keynotes deals with the multi-functional use of river basins. Martin Grambow, head of the Water Management and Soil Conservation Department in the Bavarian Ministry of the Environment and Consumer Protection, proposes an integral negotiation process of all concerned and an extended risk matrix. Water justice and water as a common good should be the basis for all involved. Klaus Michor from REVITAL is convinced that multi-functional river basins can be achieved through integrative and participative planning approaches by using different methods like the use of narratives. It will be important in the future to find cross-border solutions that include all those involved to provide everyone with good and sufficient water and at the same time preserve ecosystems.

\section{Water as a cause of conflict}

In the Alps, high rainfall and the great storage capacity of frozen water contribute to continuous water storage and distribution. This is why the Alps are also called the water tower of Middle Europe. Yet the differences of the upland and lowland regions are palpable: The upstream riparian sections within the Alps have very high quality drinking water, but are also more dependent on rain for water supply. In contrast, the downstream riparians who need the Alpine water, e.g. for irrigation, complain about poor water quality, reduced or increased discharge through hydroelectric power plants, etc. Rivers and water bodies also have a social function: they fascinate as a habitat but also serve as recreational areas for locals and guests.

Paul Crutzen, a Dutch meteorologist, suggests the term Anthropocene for the current human geological epoch. The Anthropocene is not only a challenge but also offers great opportunities. But the balance of ecosystems on which we depend is endangered by i) the immense use of raw materials and energy, ii) the production of waste, iii) the destruction of habitats, etc.. Yet our strategies for solutions stem from a time when ecosystems were still functional ${ }^{1}$.

1 Ernst Ulrich v. Weizsäcker, Interview WDR, https://www1. wdr.de/wissen/mensch/club-of-rome-interview-100.html
An approach to a solution could be integral catchment area management. Catchment area management serves to coordinate the various interests and requirements of water resources. However, in the core regions of the Alps, a multi-functional use of water bodies is needed and with it extended coordination. Different uses include that

- as leisure, living and economic space;

- for nature and water protection and

- for energy use (hydropower) and water storage.

Conflicts or competition can arise at all levels, from small water withdrawals, brook straightening, etc., to the large river basins. The different interests of protection from natural hazards and the protection of ecosystems as well as the multi-functional use of water bodies need to be incorporated into an extended risk matrix to avoid conflicts and competition. The extended risk matrix has been successfully implemented in the assessment of the Water Framework Directive and the Flood Framework Directive. In addition, an opportunity and risk matrix can be applied to determine the actual costs of an activity. Normative, technical, repressed and hypothetical risks are listed, described and discussed. ${ }^{2}$ The application of an integral negotiation process of all concerned can lead to success. Basic values, which are decisive, should be water justice, water as a common good and hydro-diplomacy.

It must be possible to mitigate future water conflicts. Therefore it is important to ask the essential question, what kind of world we want to live in and who decides this. Nature has become a rare commodity. In order to achieve a better link between ecological and human needs, a supplementary indicator system would have to be established. A functioning democracy, in which majorities are behind reasonable paths, could lead to reasonable solutions.

\section{Participation in water protection planning processes}

Agriculture, forestry, nature conservation, industry, trade, tourism, recreation, infrastructure and settlement make great and often overlapping demands on land for their purposes. Moreover, the population in Alpine areas is increasing, especially on the fertile valley floors. The growing demand for space poses a special challenge for spatial planners.

Over the last 150 years, there has been an almost $25 \%$ increase in land use for settlements and infrastructure next to rivers at the expense of grassland, arable land, open land, forests, gravel, sand and still waters. Yet space for retention areas is needed for flood protection. These large inundation areas have to be redeveloped and will also contribute to improving the morphology of the river. Climate change also causes a

2 Wilderer, P.A., Renn, O., Grambow, M., Molls, M., Mainzer, K. (eds.) 2018. Sustainable Risk Management. 
high degree of forecasting uncertainty and is projected to significantly alter river flow regimes and so modify their ecosystem processes. Integrative and participatory planning approaches for the development of Alpine river basins will become increasingly important. Multifunctional river basin corridors that take on different spatial needs could be a solution. For example, at one river stretch many different uses, such as soil stabilization for flood protection, spawning grounds for fish, a canoeist's paradise, groundwater recharge and selfpurifying capacity need to be realized.

Participatory processes interact with formal participation and are defined as codetermined, with decisionmaking power and with some decision-making competence. Within a participatory process concerning the spatial development of a river basin, different demands need to be included: fishing, hydropower, recreation, traffic, groundwater, nature conservation, self-purification, climate change, flood protection, settlements, accessibility, forestry, agricultural use, recreational facilities, etc.

The participants of the process itself have many different objectives and interests, are either directly or indirectly affected and have to discuss technically complex issues within a short timespan and with few resources. They need to have an awareness of natural hazards and need to develop medium- to long-term perspectives. Participation can therefore be described as follows: One must be able to identify with the topic and must be legitimized. Personal responsibility, conflict prevention, awareness-raising, local knowledge, mutual trust and the introduction of ideas should ideally be included in the process.

The methods used by the process management should be applied at an early stage; there are many instruments for this purpose which are appreciative, integrative, fact-based, and need to be understandable.

The challenges of participatory processes are manifold and complex and occur on the institutional level as well as on the level of perception.

First of all, there are the conflicts at the standards level and the conflicts of interest with internal and external administrative actors. Often the instruments to address certain problems are lacking. The lack of financial scope also makes it hard to operate efficiently.
Second, there are challenges on the level of perception. Perception is determined by a judgement already made and information is interpreted to confirm one's opinion. Known things are rated better, which makes change difficult. Hence the challenges for the project team are as follows:

- project partners are engaged in goal-oriented cooperation;

- project partners have no contractual ties;

- project partners have a cross-organizational cooperation for a limited period of time;

- project teams controlled by the influence of the line organization;

- project partners have different corporate cultures;

- communication effort is very high;

- project duration can last a long time, with interruptions;

- results might not be feasible.

High social skills and technical competence of the project management are necessary; since participative processes can easily be dismissed and perceived as a risk.

The overall strategy in the spatial development of the river basin and hydraulic engineering projects is the development and evaluation of scenarios which should also address emotions. The overall policy is to use narratives as a method. Participants are asked to say what is important to them and why. The narratives focus on synergy effects and have a positive assignment. Another positive effect is that they can easily be memorized and are not binding. The pictorial representation can help to focus on the compatible uses in the river basin and as such help to find a possible solution. The development and the evaluation of scenarios can be achieved by using rounds of reflection to evaluate criteria and find results through discussions.

Multi-functional river corridors can only be achieved through integrative and participative planning approaches. The focus is on finding strategies and develop scenarios. An important objective is to further develop new integrative and participative evolutionary planning tools. 


\title{
Workshops
}

\section{LEARNING FROM THE PAST FOR THE MANAGEMENT OF PRESENT AND FUTURE WATER-RELATED CONFLICTS: DEALING WITH FLOODS AND FLOOD RISK IN HISTORICAL ALPINE SOCIETIES}

\author{
CHAIR: PATRICK KUPPER, UNIVERSITY OF INNSBRUCK, INSTITUTE OF \\ HISTORY AND EUROPEAN ETHNOLOGY
}

Conflicts over water use and water management have affected historical societies in the Alps at least since the Middle Ages. As water had been a common good in many Alpine regions, people had to find solutions for sharing the costs of water supply and flood protection and how for avoiding significant disadvantages for the one party caused by initiatives of another party. This workshop wants to shed light on historical adaptation and coping strategies for floods in the $18^{\text {th }}$ to the $20^{\text {th }}$ century in Austria and Switzerland and will point out why learning from the past will also help dealing with conflicts over water and flood management today and in the future.

\section{CONCLUSIONS}

\section{Christian Rohr, Patrick Kupper}

The three papers of the workshop focused on historical conflicts in river use and flood management but could show that several conflicts today can be explained with reference to a long-time development. In the course of changes in socio-economic structures and needs, conflicts related to the transport of tree trunks and timber in general have mostly vanished, but the groups involved in present-day conflicts have not changed too much. Again, big industrial complexes, like the historical saltern of Hall in Tyrol, which were the biggest consumers of firewood in the past, but also smaller enterprises dependent on waterpower, dominate the way the river is used. The question of who is responsible for the costs after floods, both in the course of a catastrophic event and for long-term prevention, is still an eminent issue today.

A long-term perspective on the flood protection of the river Gürbe (Canton of Bern), with ongoing work for more than 150 years, can show the continuities of conflicts related to those efforts. The regional adminis- tration responsible for flood protection, the water corporations, the anglers, the farmers with agriculturally used properties close to the river, the increasing local population looking for relatively cheap plots of land for building, the environmentalists trying to defend biodiversity and the people that use the riverine zone for recreation have to find compromises. The historical perspective can enable those conflicting parties to see which kinds of compromises might work and which will apparently fail from the beginning.

The acceptance of renaturation, of flood protection, and of any changes to the course of the river as well as to the land use close to the water relies on broadly spread local knowledge of the past. Flood memory, besides written and oral traditions, had mostly been preserved by flood marks. Those 'signs of a memory culture' have not been restored in many places since the $20^{\text {th }}$ century, and in some cases, they have even vanished completely. However, new types of a flood memory culture are currently replacing them using contemporary media: an online blog exists, for instance, on the 2005 flood in the Matte quarter of Bern. The Mobiliar Lab for climate risk studies has released a platform for the memory of floods in Switzerland (see box below). 


\section{INPUTS}

The 1789 Flooding of Innsbruck: human induced disaster, social conflict and contemporary challenges

Reinhard Ferdinand Nießner

University of Innsbruck, Institute of History and European Ethnology

One of the most serious floods in the history of the city of Innsbruck took place on 10 October 1789. To contemporaries, it was the 'greatest flood' in remembered history. The authorities of Innsbruck had to cope with the two rivers in the city, Inn and Sill. Whereas the river Sill caused most damage to begin with on 9 October, the water level of the Inn increased rapidly overnight on 10 October, virtually putting the entire city under water. Even though the water level rose, the river by itself was not to blame. Humans were equally, if not primarily, responsible for the disastrous dimension of the flooding. Wood for the salterns in Hall and the silver mine in Schwaz was traditionally stored for rafting on the banks of the river Inn upstream of the city. With increasing water levels, the river washed away thousands of cords of wood - directly downstream towards the city's main bridge. There, the wood got stuck under the bridge and formed an artificial dam. As a result, the water masses were directed to the city, putting most of it under water, until the bridge was no longer able to withstand the water's pressure. This humaninduced flood consequently destroyed other bridges downstream. The flooding also led to social conflicts: Who was to blame? Who should bear the costs of the reconstruction of buildings and bridges? Moreover, who should sanction the owners of houses if they did not clean their cellars as a municipal decree ordered shortly after the flooding? A detailed analysis of this extraordinary flooding of Innsbruck can help us sharpen our awareness of flood risk management and coping strategies in the early modern period, which are not as different from today's challenges as one might assume.

Taming the torrent? Flood control and conflicts of interest at the river Gürbe (Canton of Bern) from the $19^{\text {th }}$ century until today

Melanie Salvisberg

University of Berne, Institute of History

The Gürbe valley, located south of Bern, is very prone to floods due to hydrological and geological circumstances. After heavy thunderstorms, the river Gürbe carries huge amounts of water and bed load and often causes inundations. Large-scale flood control measures have been taken since the mid- $19^{\text {th }}$ century: The flat lower course of the river was channelled and the steep upper reach was consolidated by a large torrent control (Fig. 34). These efforts allowed intensified use of the riverine zone, which created a vicious circle: The more the land was used, the more important the flood protection became. Therefore big hydraulic engineering projects were implemented without interruption and the flood control system grew bigger and bigger. In the last decades of the $20^{\text {th }}$ century, the protection philosophy slowly began to change: Instead of hard engineering, passive measures should now be preferred

Fig. 34: Check dams at the Gürbe River. (C) Melanie Salvisberg

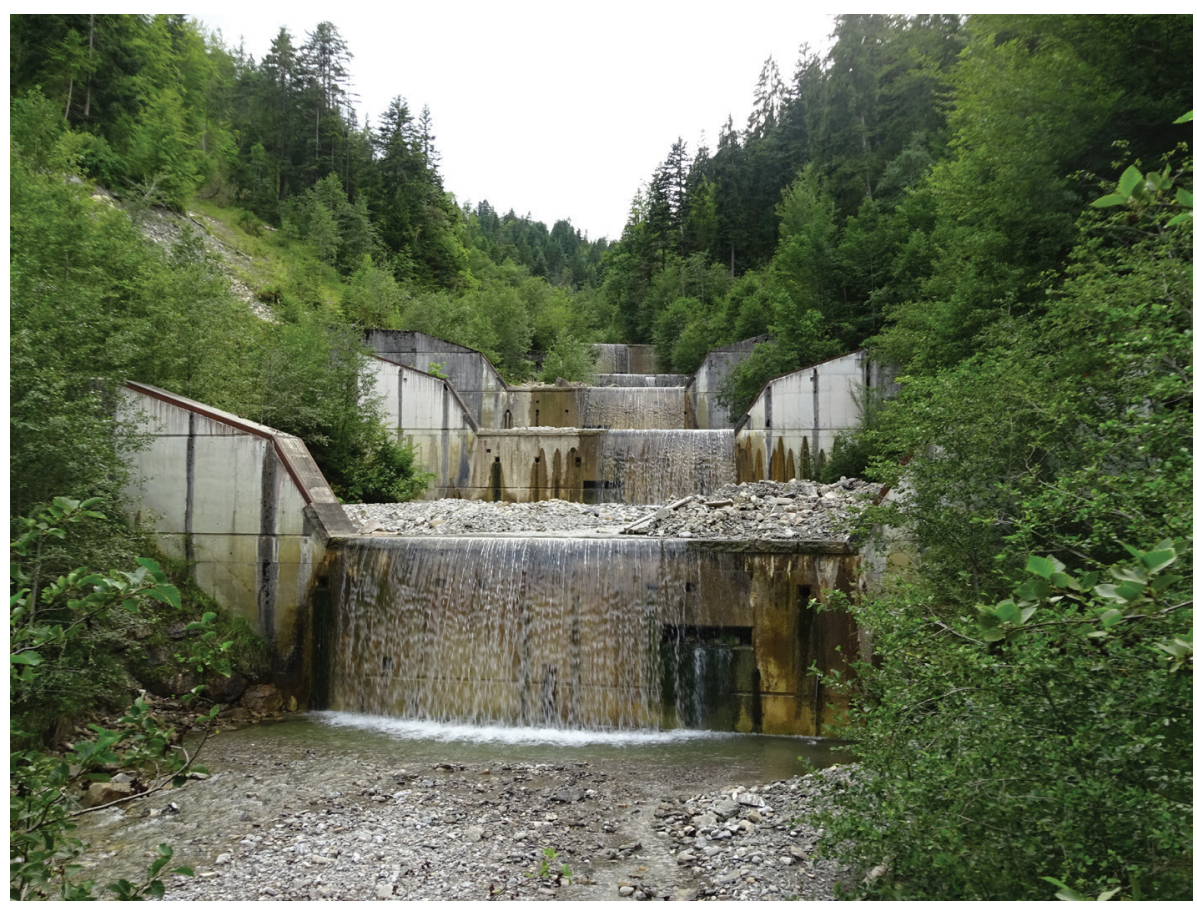


and the watercourses should be ecologically improved. At local level along the river Gürbe, the new principles were hesitantly discussed from the 1980s but only realized after a heavy flood in 1990. The diverse land use made the implementation difficult and conflicts of interest arose. Extended negotiation processes delayed the projects for years.

The input aims to discuss the history of flood protection at the river Gürbe and to answer the following questions: How did flood protection change within the last 200 years? When did the respective conflicts of interest arise and how were they solved?

\section{Avoiding conflicts by revisiting historical experience? Flood marks and their use for disaster memory past and present \\ Christian Rohr \\ University of Berne, Institute of History}

In historical societies in Central Europa, flood awareness and flood management was mostly based on local knowledge, on adaptation concerning settlement areas and on disaster memory. As the German cultural historian Arno Borst argued as long back as 1981, this memory culture has mostly vanished today and was followed by a 'culture of banished memory' (Verdrängungskultur). Flood marks constitute one of the most visible types of flood memory until today. This information on a specific flood event could be just a simple line with the corresponding year, but also a marble tablet with a short description of the events (Fig. 35). They were fixed on public buildings, town gates or houses prone to the river and constituted a permanent warning. The building techniques and the use of the endangered houses were in many cases adapted to the flood risk.

After the large-scale river regulations in the second half of the $19^{\text {th }}$ century, however, people became less cautious about flood risk, because small and mediumsize floods were not threatening any longer. Major destructive floods were too rare to keep up a culture of flood memory. Eventually, more and more flood marks vanished and were in some cases even banished on purpose, for instance because houses with flood marks might lose value for resale. This paper will highlight why learning from the past and reintroducing a culture of flood memory will also help dealing with conflicts over water and flood management today and in the future.

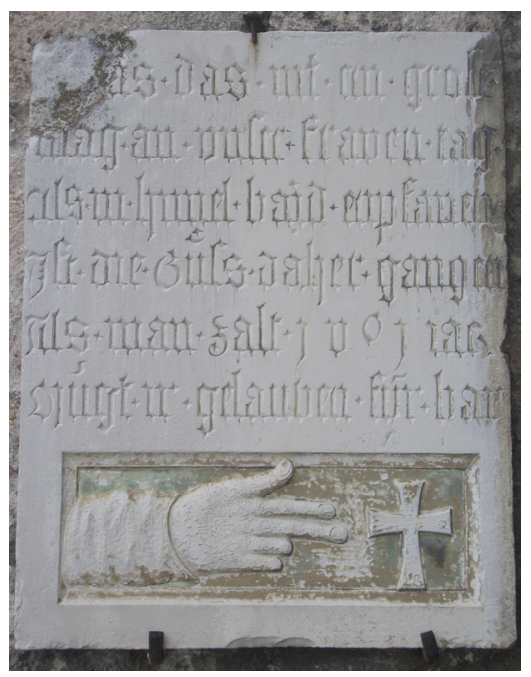

Fig. 35: Traditional flood mark with inscription related to the "millennium flood" of 1501 in Mittich am Inn (Lower Bavaria). Photograph: Christian Rohr.

\section{New types of flood disaster memory}

Flood marks to commemorate inundations have become rare in recent decades. However, new means of flood memory have emerged via social media and online platforms. One of them released in May 2018 is Kollektives Überschwemmungsgedächtnis (collective flood memory) provided by the Oeschger Centre for Climate Change Research at the University of Bern and property insurance company Mobiliar. Anyone can upload photographs of recent and historical floods in Switzerland. The geo-referencing is as exact as possible, so that the users can check the flood risk of their living places easily. https://veberschwemmungsgedaechtnis.hoch wasserrisiko.ch/de/home 


\section{INTEGRATED RIVER BASIN MANAGEMENT}

\section{CHAIR: SUSANNE MUHAR, UNIVERSITY OF NATURAL RESOURCES AND LIFE SCIENCES, VIENNA, INSTITUTE OF HYDROBIOLOGY AND AQUATIC ECOSYSTEM MANAGEMENT \&} PRIMOŽ SKRT, INTERREG ALPINE SPACE, JOINT SECRETARIAT

The Interreg Alpine Space project SPARE aims to harmonize the protection and development of Alpine river ecosystems. After more than two years of intensive work, SPARE shares some first results: An interactive workshop will be held to present, test and discuss an online database of reference cases, which shall support practitioners and decision makers by introducing existing solutions of Integrated River Ecosystem Management (IREM). Also, one of the five SPARE pilot areas will present itself and the participatory process that was started to develop long-term solutions to balance the use and protection of the Inn river basin in the Engadin valley.

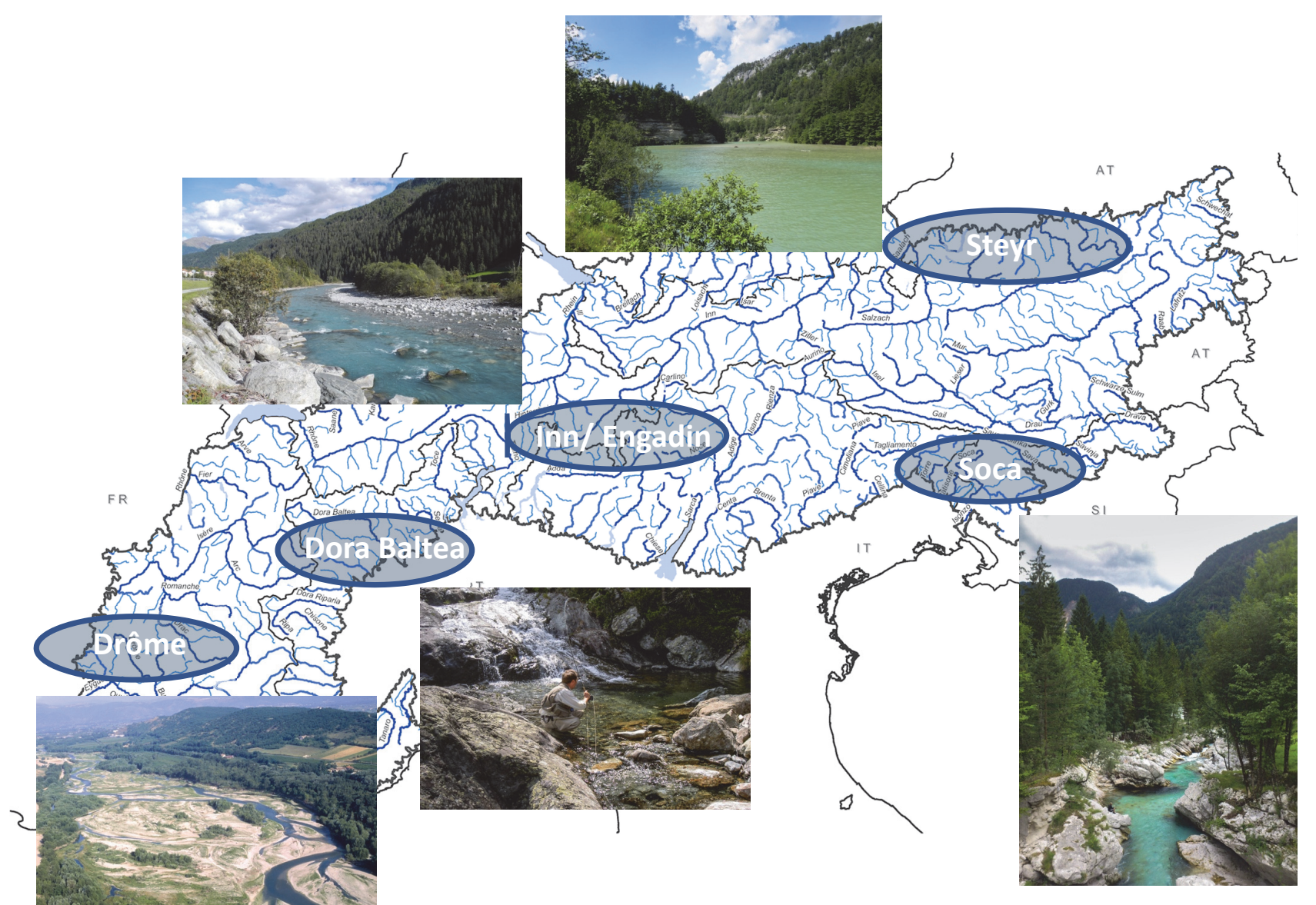

Fig. 36: Pilot Case study areas - SPARE. (C) Soca: Andrej Bašelj; all other rivers: SPARE 


\section{INPUTS}

\section{SPARE - Strategic Planning for Alpine River Ecosystems Integrating protection and development}

Susanne Muhar \& Kerstin Böck

University of Natural Resources and Life Sciences, Vienna, Institute of Hydrobiology and Aquatic Ecosystem Management

The Interreg Alpine Space project SPARE aims at contributing to an improved harmonization of human use requirements and protection needs of Alpine rivers. Project partners from six Alpine countries collaborate to show how strategic approaches for the protection and management of rivers can be enhanced across different spatial and governance levels. A central element to reach this goal are five different pilot areas across the Alpine space that are committed to integrative river and catchment management and engaged in participatory processes (Fig. 36). The manifold SPARE project activities lead to the development of a range of different outputs. This includes a pan-Alpine overview of priority rivers with high protection needs, a collection of river management challenges and best solutions in the Alps, a set of governance tools that shall enable river managers to plan, apply and evaluate integrated and participatory river management approaches and a guidance on innovative river protection and management processes. An additional core output of the project is the Action and Policy Support Service SPARE-LIVE, an interactive platform of knowledge exchange that will provide synthesized knowledge and experiences for policy and decision-making. The SPARE project activities and outputs aim to contribute to capitalizing and improving strategic river management approaches and increasing awareness and knowledge about the functions, services and the vulnerability of healthy rivers.

\section{A reference database to support practitioners toward Integrated River Ecosystem Management}

\section{Sašo Šantl \& Urška Kocijančič}

Institute for Water of the Republic of Slovenia

One of the aims of the Interreg Alpine Space project is to support practitioners and decision makers with existing solutions or reference practices about the coordination and integration of river ecosystem protection objectives within a river basin management. If this process is based on the principle of sustainable development, integrates different spatial levels and policy sectors and involves a wide range of stakeholders, it can be called Integrated River Ecosystem Management (IREM). To facilitate this support, the project envis- ages the creation of an online platform. Services that this platform will provide include a searchable reference database that collects numerous practices with different levels of compliance with IREM. To provide efficient pre-identification of relevant practices we developed a quick assessment tool, which follows the principles of IREM by introducing relevant criteria and supporting scoring methods. To establish a usable reference database, a sound testing and validation is required. The workshop aims to support this process and will also provide the opportunity for a broader discussion on the topic.

\section{Integrated River Basin Management in the Inn river basin $(\mathrm{CH})$ \\ Angelika Abderhalden \\ Stiftung Pro Terra Engiadina, WWF Switzerland}

Integrated River Basin Management is a cross-sectoral approach to managing water resources, rivers and water-related infrastructure. In a participatory process, a long-term plan regarding water supply, use and protection of and from water is developed. A set of actions is defined to guarantee high efficiency in the use of water for all sectors involved. These decisions enjoy higher acceptance as they are developed by the affected stakeholders themselves. The Engadin is an inner-Alpine dry valley. As the Engadin faces a change in discharge (amount and seasonality) due to climate change within the next decades, existing conflicts between the sectors energy, tourism, agriculture and public water supply might increase. To avoid this, an Integrated River Basin Management Plan is developed within the project IEM Inn. The aim of this project is to develop a long-term solution to balancing the different uses as well as the protection of water in a sustainable way, using different participatory methods. This project is a part of the Interreg Alpine Space Project SPARE (Strategic Planning for Alpine River Ecosystems) that aims to gather, analyse and adapt strategic planning approaches in the management of rivers within the Alpine region, to test innovative participatory methods (Fig. 37) within selected pilot case areas and to develop and adapt different tools for balancing use and protection of water. 
Planning participation for integrated river basin management Inn (CH)

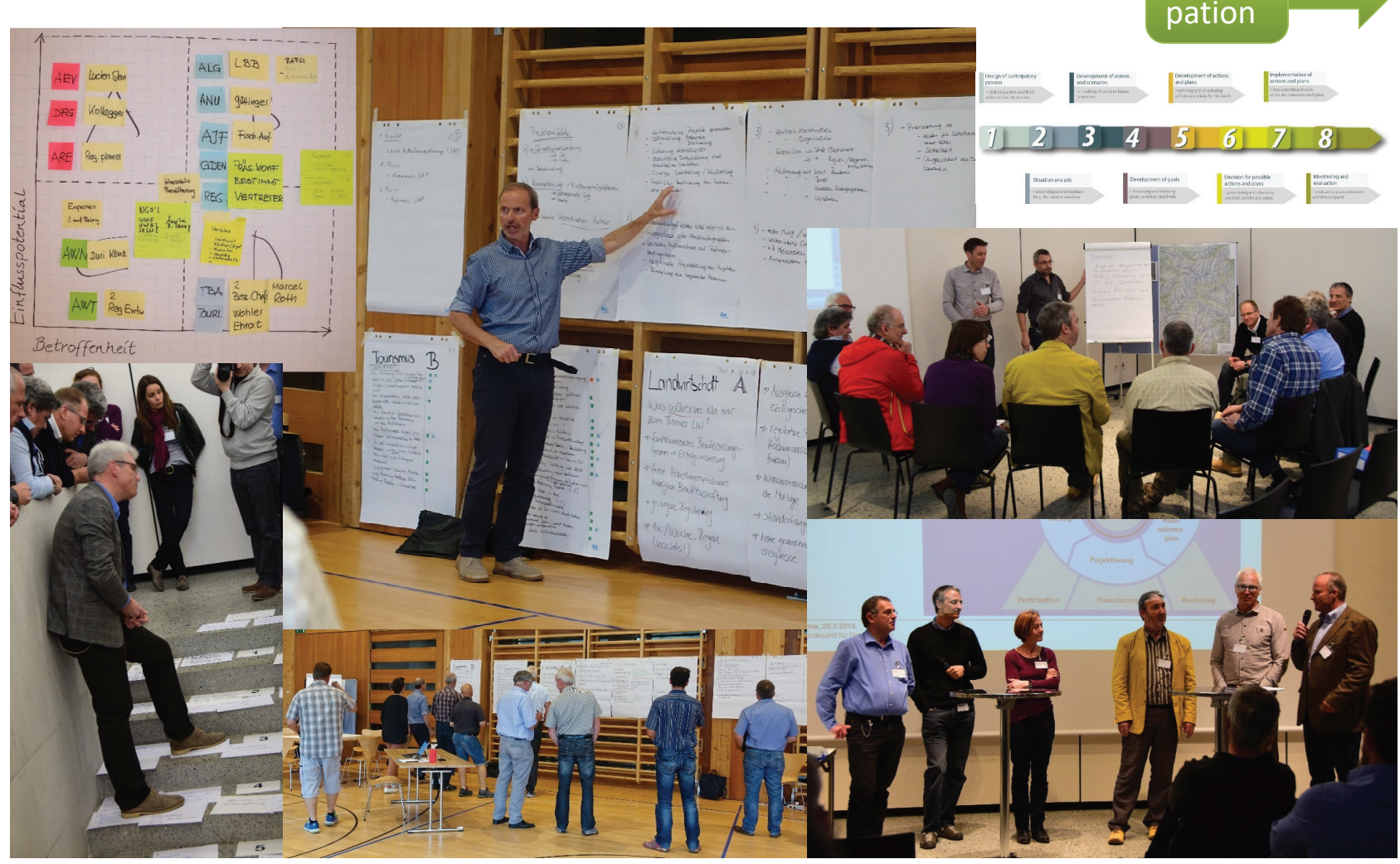

INN

SPAR̂.

Fig. 37: Planning participation for integrated river basin management Inn (CH)

Current programmes and networks - Poster and network presentation

Integrated river basin management in the Alpine Space - Lessons learnt from past projects

Primož Skrt, Interreg Alpine Space, Joint Secretary

Interreg Alpine Space is an EU-funded programme (ERDF) that supports transnational cooperation in the Alpine region. Water is one of key priorities of the programme.

A special focus is given to the rivers - landmarks of the Alps. Rivers have unmeasurable importance from the ecological and biodiversity perspective. They provide several ecosystem services as well as direct economic benefits. Alpine rivers are also one of the fundamental landscape elements for tourism development.

Combining so different, sometimes conflicting, interests (especially between protection and development) is a challenge that does not stop at borders and requires an integrated and transnational approach. This need has resulted in several projects that have achieved important results and provided solutions for river basin management.

The SHARE project focused on balancing river ecosystems with hydropower requirements. It developed and tested an integrated decision-support tool which combines both perspectives. Alp-water-scarce advanced management strategies against water scarcity in the Alps. The project surveyed the different users in the pilot river basin to find joint solutions. The project SedAlps helped reducing sediment-related risks and conflicts by promoting integrated approaches to river sediment management. AIM capitalized results on renewable energy production to optimize hydropower exploitation and the conservation of ecosystems.

These projects have also proved the need to address challenges at transnational level and the added value of an integrated and holistic approach. This was an important lesson that resulted in new (currently ongoing) projects, such as SPARE, HyMoCARES and EcoAlpsWater. 


\section{MITIGATING FUTURE WATER CONFLICTS}

\section{CHAIR: SUSANNE BRANDSTETTER, AUSTRIAN FEDERAL MINISTRY FOR SUSTAINABILITY AND TOURISM}

The River Dialogue format in the strict sense was developed by the Austrian Federal Ministry, responsible for Environment and Water Management, and the regional government of Upper Austria. In a wider sense it is about stakeholder involvement and dialogue processes in Water and integrated River Basin Management (IRBM). At the Forum Alpinum 2018, there is a parallel workshop on IRBM. So the present one will focus on the following topics (while embracing the submitted inputs): 1) Main obstacles for a successful dialogue, and how to prevent/ mitigate them. 2) Defining the scope - how to take the river basin system into account, while not neglecting the local perspective? 3) How to make sure all stakeholders can participate in an equitable and fair way? 4) The role of brokers and facilitators. 5) The specific challenge of cross-border dialogue processes.

\section{CONCLUSIONS}

\section{Susanne Brandstetter}

In the workshop, the topic Mitigation of future water conflicts was presented from three perspectives:

- Forestry (importance for source protection)

- NGO - Strategic Planning for Water Management, focus EU legislation

- Floods and their effects on affected persons

The discussion on the content of the three lectures related mainly to the flood problem described and how the population deals with it. Here, legal framework conditions were discussed, as well as how to deal with the aftermath of a disaster (including psychological problems). There was a great deal of interest in the topic in the workshop and many examples were brought from personal experience. "All agreed that these risks had to be communicated more widely to the population and that everyone had to make a contribution". The examples of Upper Austrian settlements were discussed with empathy.

The discussion on strategic water management planning was based primarily on Austrian examples such as the Water Framework Plan for the river Inn (WWF) and the contribution of NGOs in shaping the future EU Water legislation - Fitness Check Water
Framework Directive. Possible contributions and cooperation were discussed. The importance of ecology was underlined.

For the forestry sector, it was once again emphasized that good forest management is important for securing drinking water supplies for the population. Examples discussed here were the water supply of Vienna with the spring protection areas in the Hochschwab area and a model case from Waidhofen/Ybbs.

The conclusion that can be drawn from my point of view as a communications expert is the following:

The conference as such and the contributions in the keynote speeches and workshops placed a clear emphasis on technical, scientific and administrative aspects. Very little attention was paid to the communication of the contents and of key results to the interested public.

This results in significant gaps concerning the preparation of specialist content for the public. The described measures - statements such as, "there is a website anyway, a report will be published anyway", are not up-to-date measures in a contemporary public relations work in this form. For all publicly funded projects, it is a legitimate claim of the population to be informed about important results in an understandable language and to receive appropriate messages clearly and well.

In recent decades, not only has there been a lot of technical and scientific development, there have also been these rapid and important developments in communication. 


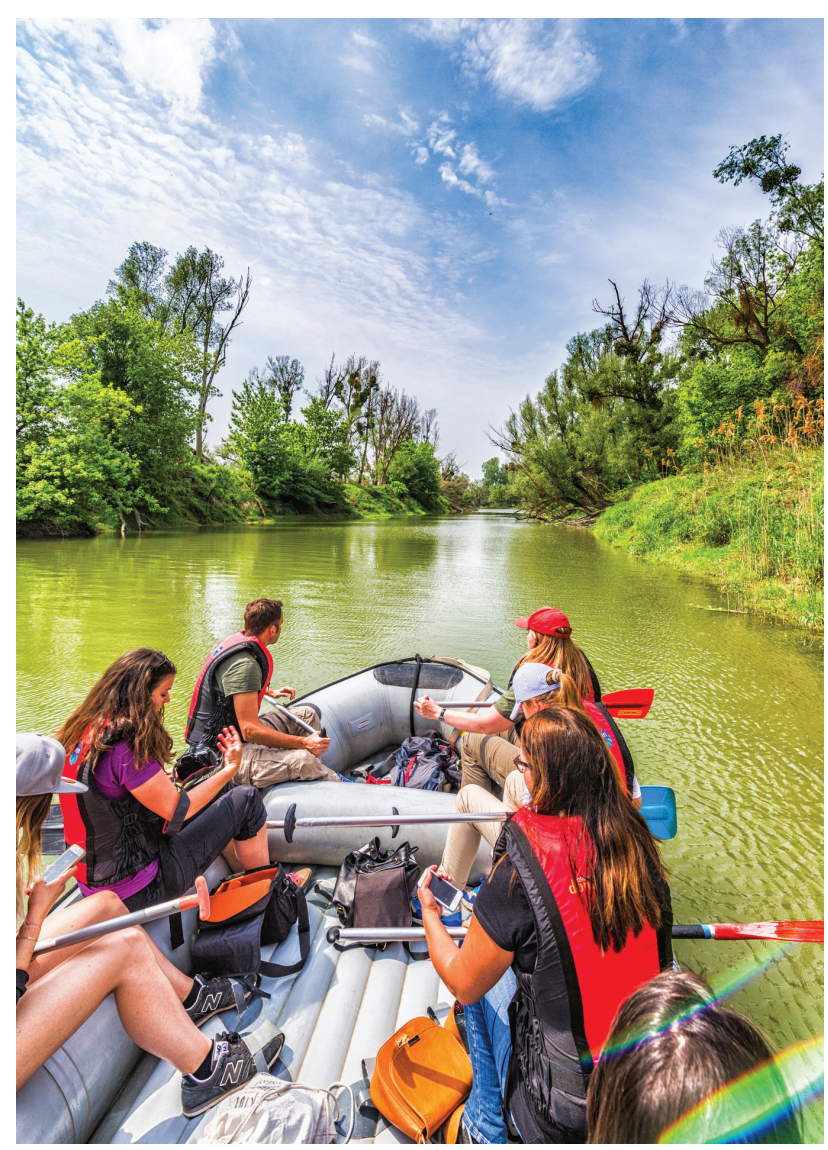

Fig. 38: Instawalk von Wasseraktiv 2018. Photograph: Wasseraktiv, Johannes Marschick.

The communication strategy of the European Commission (including the EU Green Spider Network) focuses on the communication of environmental issues to the population and the corresponding emotionalization and integration according to the latest technical possibilities. The Federal Ministry for Sustainability and Tourism also has a clear focus on these challenges and on a clear language to address broad target groups.

Especially in the water sector, a lot of know-how is also available in platforms and through activities - all accompanied by social media activities - with a wide range, for example:

- www.wasseraktiv.at - water platform for the participation of the interested public

- www.generationblue.at - Generation Blue - youth platform on water

- www.neptun-wasserpreis.at - Neptune Water Prize 2019

- River Dialogue format (13 dialogues were carried out, implementation afterwards also in Bavaria and Baden-Württemberg).

These measures are aimed at knowledge transfer, animation, stake, creation, and confidence building.

The activities of the International Commission for the Protection of the Danube River (ICPDR) should also be mentioned in this context, where a working group of experts under the Austrian chairmanship of the Public Participation is dealing with many projects (Danube Day, Danube Watch magazine, reports for the public, web, etc.).

For the future it would be important to increasingly incorporate the state of knowledge and the working methods of professional, up-to-date communication into the concrete project implementations (national and international), to cooperate with communication experts from the very beginning and to accompany the projects professionally right up to disseminating results in various formats, while striving for synergy effects with already established projects/measures, see above.

Increased water awareness of the population is the goal and the projects must include sufficient capacities and know-how to attain that goal. As regards the topic of this workshop, Mitigation of future water conflicts, a wellinformed public will be able to make a significant contribution here and will also be an indicator of successful solution strategies for the future.

\section{INPUTS}

\section{Best Management Practices within forested drinking water protection zones}

\section{Roland Koeck', Hubert Siegel2 , Elisabeth Gerhardt ${ }^{3}$ \&} Eduard Hochbichler'

'University of Natural Resources and Life Sciences, Vienna, Institute of Silviculture

${ }^{2}$ Austrian Federal Ministry for Sustainability and Tourism ${ }^{3}$ Austrian Research Centre for Forests

Within the Austrian Alps several legally decreed drinking water protection zones (DWPZ) exist which provide the source for the water supply of the majority of Austrian citizens. Forest ecosystems as dominant land cover in the Alps are seen as adequate for DWPZ, since forestry in general does not involve the application of chemical fertilizers or pesticides. Despite this fact, forest management can create adverse impacts for water supply security. In order to guarantee the high quality of drinking water resources in a sustainable way, it is necessary to adapt forest management according to the overall purpose of water protection. A catalogue of Best Management Practices (BMP) was drawn up in the course of EU-funded Interreg projects to achieve this aim. The BMP catalogue should secure or re-establish the water protection functionality of forest ecosystems. BMP for the land-use category forestry include the creation of stable forest ecosystems through natural tree species diversity, prevention of clear cuts, limitation of timber extraction, application of small-scale regeneration techniques, conservation of strong, old and stable tree individuals or the establishment of continuous cover forest management concepts (Fig. 39). The implementation of the BMP catalogue requires profound knowledge transfer to stakeholders. 


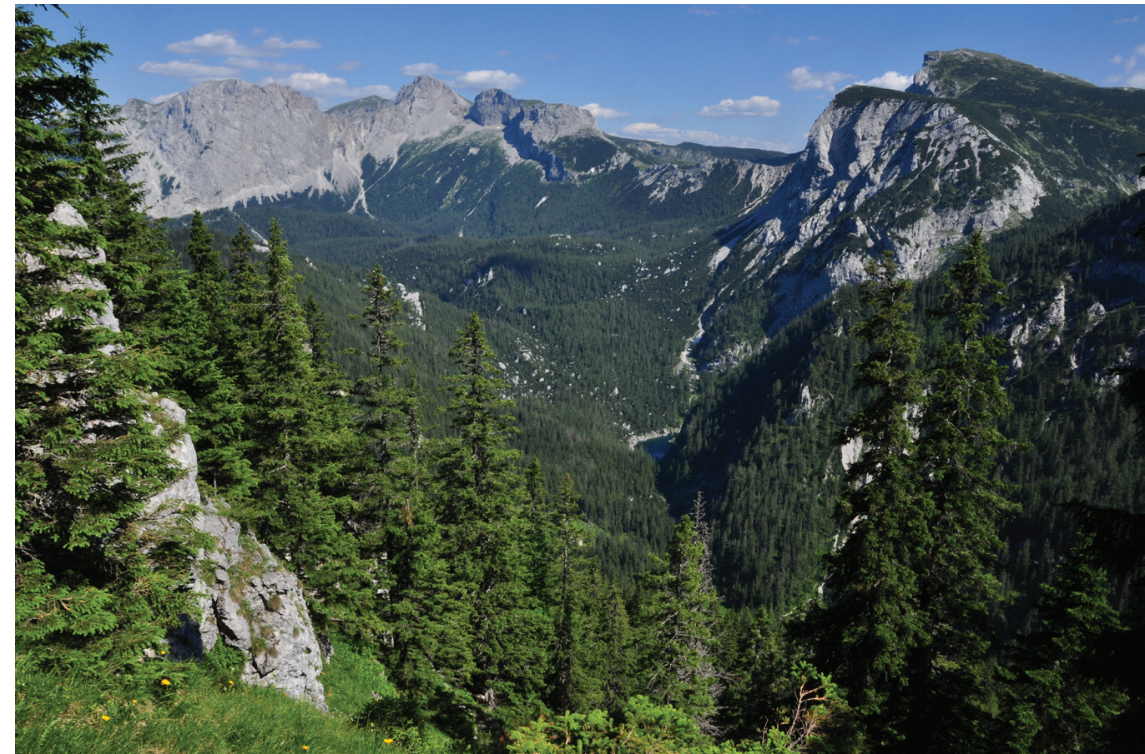

Fig. 39: Stable natural forest ecosystems within a karstic alpine drinking water protection zone. Photograph: (c) Roland Koeck
How NGOs can contribute to water governance on different levels: from EU Water Framework Directive to regional management planning

\section{Bettina Urbanek WWF Austria}

When discussing water governance, the focus in most cases stays on governments - at national, regional or local level - and public administration, while the role of non-state actors is often underestimated. Nevertheless non-governmental organizations can offer valuable contributions: they allow a view from a different angle, and act more independently of personal, political and economic interests than, for instance, land owners or local majors. Through their networks, they can facilitate the exchange between public authorities and local citizens, or between people/organizations in different countries who might be concerned about the same issue. This presentation will highlight the potential roles on two specific examples: 1) The current review process of the EU Water Framework Directive and the respective public consultation process. 2) The Austrian Water Act allows for submission of regional water management plans by everybody interested in water management goals. The WWF took this opportunity to submit a proposal for a river management plan of the Inn valley to the national ministry.
Planned retreat as an option for the European Alps? Who do we need to talk to, when and what about?

Thomas Thaler \& Sebastian Seebaver

'University of Natural Resources and Life Sciences, Vienna, Institute of Mountain Risk Engineering

2 LIFE - Centre for Climate, Energy and Society, JOANNEUM RESEARCH Forschungsgesellschaft $\mathrm{mbH}$, Austria

Disaster risk management has developed a large inventory of adaptive responses to natural hazards. From this wide array of measures, managed retreat of at-risk residents is usually only taken into account if other adaptation strategies are ineffective or unavailable. Despite its potential to permanently reduce vulnerability, managed retreat is highly contested in the public risk discourse. Households consider a wide range of risk assessments, economic consequences and emotional aspects when deciding to move or stay. Many residents infer their future flood risk from prior flood experiences. Households contrast the offered compensation with the current and future value of their property. Personal circumstances, such as recent family formation, retirement or the prospects of one's children play into their economic assessment. The emotional appraisal is shaped by the personal attachment to the residence or farm and by the extent to which the available coping options threaten one's self-identity and way of life. Some households fear stigmatization, e. g. those who remain in the flood plain are concerned about receiving less public support during future flood events. Throughout, households lacked opportunities to contribute their individual perspectives to the design of the relocation scheme. The paper addresses questions of who to talk to, what to talk about and when to talk and will illustrate how to navigate common pitfalls in communication and implementation. 


\title{
ALPINE MULTI-PURPOSE RESERVOIRS: FUTURE POTENTIAL AND RELEVANCE
}

\author{
CHAIRS: ASTRID BJÖRNSEN GURUNG, SWISS FEDERAL INSTITUTE FOR \\ FOREST, SNOW AND LANDSCAPE RESEARCH \& PETRA SCHMOCKER- \\ FACKEL, FEDERAL OFFICE FOR THE ENVIRONMENT, SWITZERLAND
}

\section{CONCLUSIONS}

\author{
Astrid Björnsen Gurung', Manuela Brunner², Manfred \\ Stähli2, Elke Kellner ${ }^{3}$, Melanie Clivaz ${ }^{4}$, Emmanuel \\ Reynard ${ }^{5}$, Marion Douarche ${ }^{6}$, Gottfried Gökler ${ }^{7}$ and \\ Petra Schmocker-Fackel ${ }^{8}$ \\ Research Program 'Energy Change Impact', Swiss Federal \\ Research Institute WSL, Birmensdorf, Switzerland \\ ${ }_{2}^{2}$ Mountain Hydrology and Mass Movements, Swiss Federal \\ Research Institute WSL, Birmensdorf, Switzerland \\ ${ }^{3}$ Oeschger Centre for Climate Change Research, University \\ of Bern, Switzerland \\ ${ }^{4}$ Institute of Geography and Sustainability, University of \\ Lausanne, Sion, Switzerland \\ ${ }^{5}$ Faculty of Geosciences and Environment, University of \\ Lausanne, Lausanne, Switzerland \\ - CIMEO Agence pour l'eau en montagne, St Chaffrey, \\ France \\ 7 PT Produktion \& Technik, Vorarlberger Illwerke AG, Zentrum \\ Montafon, Vandans, Austria \\ ${ }^{8}$ Federal Office for the Environment, Ittigen, Switzerland
}

To date, concerns about water scarcity and related conflicts are almost absent in Switzerland. Yet both the summer drought of 2003 and the anticipated impacts of climate change on Alpine water resources raise our awareness of the increased probability of local water shortages towards the end of this century. Multi-purpose reservoirs might alleviate the negative effects of runoff regime shifts triggered by rising temperature, reduced snow pack and glacier cover. Ideally, such reservoirs meet various demands, such as electricity production, irrigation, snow-making, drinking water supply, ecological needs, or flood control. Is their potential contribution to alleviating water shortages significant? Can natural and artificial lakes and ponds hold back enough water to compensate for the anticipated natural discharge reductions in summer and fall?
The workshop on Alpine multi-purpose reservoirs was triggered by an ongoing Swiss research project aimed at quantifying storable water resources under present and future reference and extreme conditions. The assessment of both water supply and demand makes management options more tangible and therefore serves as a tool when it comes to the envisaged re-negotiations of water concessions and access rights in Switzerland. The workshop synthesized experiences, mainly from Austria and Switzerland, but also from Italy and France, based on five input presentations and the contributions of participants to three thematic working groups on existing management schemes of multipurpose reservoirs or smart solutions for avoiding conflicts when developing multi-purpose reservoirs. More than 20 participants, half of them scientists, half practitioners, shared knowledge and experience on existing and planned multi-purpose reservoirs in the Alps, as presented below.

A survey on existing multi-purpose reservoirs has shown that most examples of such reservoirs include the use of water for hydropower production. Hydropower production is usually combined with irrigation, drinking water supply, ecology, artificial snow production, tourism or flood protection. In contrast, hydropower production is usually not combined with the provision of water for industry. There are also multi-purpose reservoirs which do not include the use of water for hydropower production. These reservoirs were initially built for artificial snow production and can in addition serve for drinking water supply, tourism and irrigation. The results of the survey contradict the perception that reservoirs in the Alps are mainly operated to fulfil one purpose.

A second working group discussed open research questions on the multiple-purpose use of reservoirs. Knowl- 
edge gaps, limitations in models and methods, and missing data influence our capability to assess potentials, risks and opportunities. It was concluded that the most critical data gaps are related to the current and future water demand (e. g. for irrigation or drinking water) and less to the supply. The resilience of reservoirs to long droughts, the impact of sedimentation and the perception and decision process (rules) of multiplepurpose use were mentioned as important open questions.

A third working group shared experiences of the governance of multi-purpose reservoirs. It was noted that the decision-making process is facilitated if all users share the same goal or have a shared vision on the development of their region. Therefore, appropriate participation processes are needed which involve all relevant actors. Furthermore, experiences about ownership, type and duration of water rights were exchanged. The discussion revealed that the participants were not very familiar with water rights, even though ownership could greatly influence the negotiations on different uses of water. The duration and flexibility of water rights are important in terms of the expected climate and socio-economic changes in the future, which will induce changing demands for water uses.

For multi-purpose reservoirs, the following water conflicts are considered to become increasingly important in future:

- Temporal mismatch: Some uses are difficult to coordinate in temporal terms. It could be that the various water demands occur in the same time period, or that there is no demand below the hydropower plant although turbined water is actually released and would be available for potential other uses.

- Spatial mismatch: Besides hydropower, other uses are often located in distant places, in particular when considering that hydropower reservoirs located in alpine regions.

- Anthropogenic vs. ecological needs: Ecological requirements should be recognized in a similar way as other water demand categories.

To prevent and mitigate potential future conflicts, the following recommendations can be derived from the workshop:

- Foresight: The assessment of future supply and demand allows for the early planning of necessary legal and regulatory measures and infrastructure projects. Such timely planning can prevent and mitigate conflicts, reduce costs and environmental impacts.

- Compensation schemes: Suitable reimbursement schemes for uses besides hydropower and artificial snow production should be developed.
- Beyond water management. Smart solutions in water management are not limited to the allocation of water volumes but should entail visions and strategies going beyond the water sector (e.g. adapted agricultural crops or practices or rethinking winter tourism).

Recommended literature:

Kellner E., Weingartner R. (2018). Chancen und Herausforderungen von Mehrzweckspeichern als Anpassung an den Klimawandel. W asser Energie Luft 2: 101-107.

Jossen L., Björnsen Gurung A. (2018) Möglichkeiten und Grenzen von Mehrzweckspeichern in der Schweiz und ihr Beitrag zur regionalen Resilienz. Wasser Energie Luft 2: 108-112.

Mani P., Monney J., Wehren B., Schwegler B. (2018). Stauseen Oberhasli als Multifunktionsspeicher. Wasser Energie Luft 2: 113-118.

\section{INPUTS}

\section{The Hydro-CH2018 Reservoir project}

Manuela Brunner \& Manfred Stähli

Swiss Federal Institute for Forest, Snow and Landscape Research

A change in runoff from snow-dominated towards rainfall-dominated regimes is expected for Alpine rivers under future climate conditions. Current projections suggest that summer runoff will be reduced while more frequent droughts increase the probability of local water shortages. Reservoirs might alleviate the negative effects of such regime shifts if they are not limited to a single use, such as electricity production, but operated to fulfil multiple needs, e.g. water supply or flood control. Such multi-purpose reservoirs allow for the storage of winter rainfall and for water release later in the year when natural water availability is generally lower and water demand is high, not least due to irrigation requirements. In an ongoing project, we investigate the potential of multi-purpose reservoirs for alleviating water scarcity under a future climate in Switzerland. To do this, we propose a multi-modular framework of three modules: water supply, water storage and water demand. This modular structure allows for the consideration of different scenarios within each of the modules. We apply this framework to a set of 22 large hydrological regions in Switzerland to assess the potential of multi-purpose reservoirs for alleviating water scarcity. 
Evolving polycentric climate governance: the case of multi-functional water use in Oberhasli, Switzerland

\section{Elke Kellner ${ }^{1,2}$, Christoph Oberlack ${ }^{1,3}$ \& Jean-David Gerber ${ }^{1,4}$}

I University of Bern, Institute of Geography, Switzerland ${ }^{2}$ University of Bern, Oeschger Centre for Climate Change Research, Switzerland

${ }^{3}$ University of Bern, Centre for Development and Environment, Switzerland

${ }^{4}$ University of Bern, Center for Regional Economic Development, Switzerland

Many resource regimes in advanced democracies are complex rather than integrated (as a result of sectoral division of labour within public administrations, lack of transversal coordination, competition for resources, strong property rights, etc.), leading to contradictory incentives in resource management. This presentation shows how governance processes are evolving to regulate competing multi-functional water uses under climate change in Oberhasli (BE), in the Swiss Alps.

Our approach combines the frameworks of Institutional Resource Regimes (IRR) and polycentric governance. The IRR framework stipulates that formal institutional rules - public policies and property rights - shape the leeway that is available to resource users for defining localized resource-use modalities. Polycentric governance systems are those in which political authority is dispersed across a range of bodies that operate in overlapping jurisdictions which are not in a hierarchical relationship to one another. Recent scholarship suggests that polycentric organization of governance has a greater capacity to deal with complex challenges arising from climate change. The project aims to analyse under which conditions polycentricity can lead to a better coordination of resource uses.

We performed a detailed case study to analyse governance processes of climate change mitigation and adaptation in Switzerland. Data were collected through 22 semi-structured interviews between 2016 and 2018 and by document analysis. The results show that if the number of regulations increases and if at the same time their coherence decreases, then this constellations promotes polycentric governance. The results further identify the conditions under which polycentric governance improves the coordination of resource uses and when it does not.

\section{Management options for Alpine multi-purpose reservoirs}

\section{Gottfried Gökler}

Vorarlberger Illwerke AG, Austria

Founded in the 1930s, Vorarlberger Illwerke AG now operates 11 hydropower plants with four large reservoirs in the south of Vorarlberg, in the middle of the Central Alps. Altogether, these plants have a total capacity of more than 2000 MW in turbine and $1000 \mathrm{MW}$ in pump mode. The total storage capacity of the lakes Silvretta, Kops, Vermunt and Lünersee amounts to 165 million $\mathrm{m}^{3}$ water and is mainly used for producing peak energy and for pump storage.

But the facilities are also used for touristic purposes, although on a relatively small scale. The development of winter tourism with larger skiing resorts and longer seasons, in combination with the effects of climate change, encourages technical snow production, which has reached a considerable volume by now.

It is also worth mentioning that the existing facilities help to reduce costs for measures of flood protection because of the retention capacity of the reservoirs. Nevertheless, the potential for water retention during a flood event is only of regional use. So, for example, it was possible to save the city of Feldkirch, at about $30 \mathrm{~km}$ downstream, during the flood in 2005 , because the peak of the maximum flood could be reduced by a small amount. There have been proposals for preparing drinking water too, but these have been postponed for economic reasons.

We present some ideas for the future on a few examples, taking into account the developments of tourism and the effects of climate, and will illustrate how far multi-purpose uses of reservoirs in the Alps can go and what we can expect from these in the future. 


\section{Contribution of dam reservoirs to Alpine society under changing context: socio-economic and ecological trajectories. A case study in Valais} (Swiss Alps)

\section{Melanie Clivaz \& Emmanuel Reynard University of Lausanne, Institute of Geography and Sustainability}

Hydropower reservoirs are a major landmark in the Alpine landscape, both physically and socially. The construction and operation of large infrastructures impact on the territory and the society in many ways. Both positive (benefits) and negative impacts change over the infrastructure lifetime in the wake of socioeconomic developments, changing perception of different values and the evolution of the legal framework. The first objective of this work was to reconstruct socio-economic trajectories of reservoirs. This required the description and assessment of major past contributions of dam reservoirs to Alpine society, including economic, social and ecological impacts. A specific focus was put on the ecosystem services provided by water stored in reservoirs (in particular various water uses). The second objective was to identify economic, social and ecological indicators to describe such trajectories. Three reservoirs, situated on tributaries of the Upper Rhone River (Switzerland), were chosen as case studies: Mauvoisin, $211.5 \mathrm{M} \mathrm{m}^{3}$, in use since 1957; Toules, $20.5 \mathrm{M} \mathrm{m}^{3}$, in use since 1963; and Tseuzier, $51 \mathrm{M} \mathrm{m}^{3}$, in use since 1957 . This study shows that hydropower reservoirs are not only energy production infrastructures but provide society with a wide range of services, which should evolve in the future, in the context of global warming, the need to develop multi-functional reservoirs and the energy transition.

\section{One extraction - several uses: a case study from France}

\section{Marion Douarche}

CIMEO agence pour l'eav en montagne, France

The small ski resort of Saint Leger les Melezes, in the Southern Alps, manages to take advantage of one spring for several uses. The main spring of the commune was first collected for drinking water. As the resource is sufficient, the same spring fills a pool located near the ski slopes. There, water is transformed into snow during winter. In summer, the pool supplies an agricultural network (Fig. 40). This situation was already a good example of sharing uses.

Nevertheless, out of the local context new work progress evolved: In this part of the Alps, with climate change and after several dry and warm seasons, the basin management plan envisages that everybody should take less water in order to leave more for the environment. The water network at Saint Leger les Melèzes was too old and plagued by many leaks and waste. The commune decided to replace the old pipes. As the installation to extract water from the mountain remained the same, the quantity became more important in the network. The spring, located a few hundred metres above the village, could be used for hydropower production if the baffle blocks were replaced by a turbine. When the flow is too strong to be caught, it fills the pool. It helps to mitigate dry seasons as well as artificial snow making, one of the choices of the commune to maintain its touristic economy. So the pool was enlarged (x 1.5). In summer this larger reservoir permits to irrigate more cultures. At the same time, the new network allows abandoning other, more ancient, structures and to leave other springs to go free, without hu-

Fig. 40: Multipurpose reservoir

(snowmaking, agriculture) and pond to preserve amphibians, at Saint Léger les Mélèzes (HautesAlpes, France). Photograph: Marion Douarche

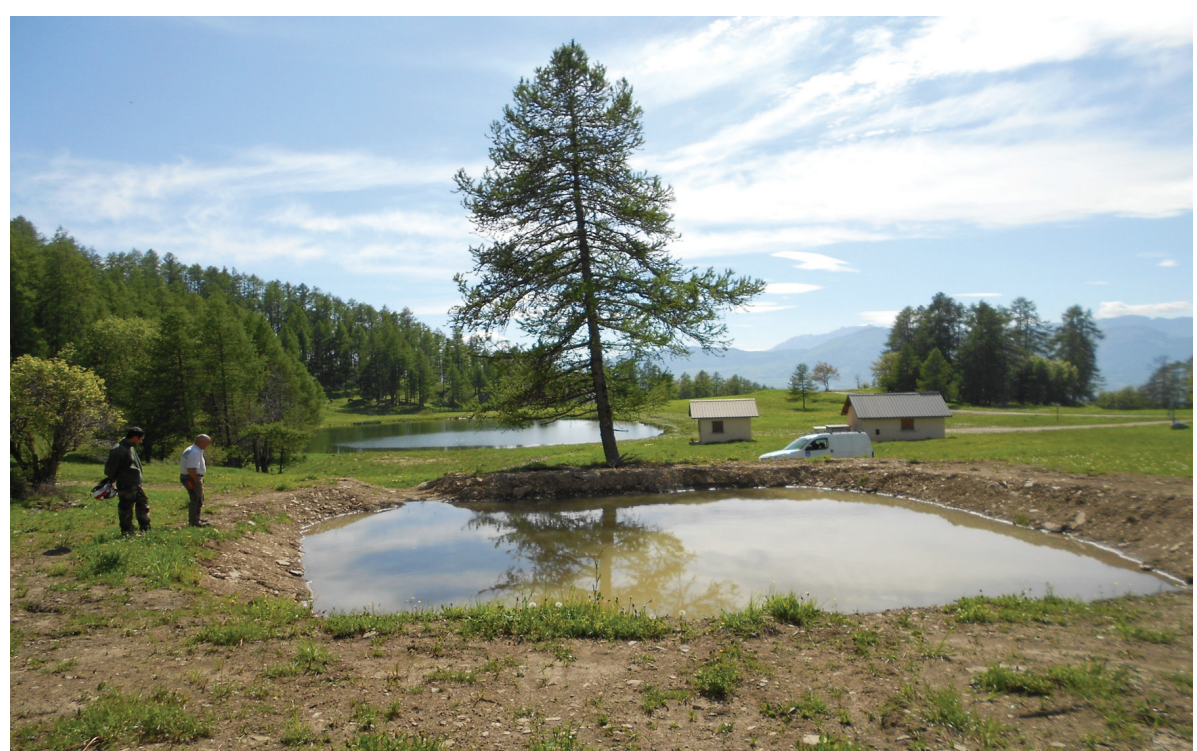


man uses. Last, the pool is designed to be pleasant for the landscape, and the surrounding area is a picnic and recreational place in the mountains. During the construction work, particular attention was paid to toads and newts. Les Ecrins National Park monitors these animals and is very satisfied, as those two populations are growing each year.

Finally, the extraction is the same at the spring, but with fewer leaks and less waste, it permits more uses of the network (to meet the needs of humans and nature) and also it relieves the pressure on other springs.

However, the project was slowed by administrative obstructions about where the excavation material should be deposited, the fees linked to the extraction, the security norms for turbine drinking water, etc.. 


\section{POSTER SESSION: ABSTRACTS}

Fabio Azzolin: The blue gold of lake Parón - Relevance of social capital in the development of a socio-environmental conflict around water management in a micro-basin in the Peruvian Andes

Giacomo Bertoldi: Klimareport Südtirol 2018: impacts of climate change on water resources in South Tyrol

Manuela Brunner: Potential of multi-purpose reservoirs for alleviating summer droughts in the Alps

Enrico Calvo: The function of water protection in the mountain forests of the Alps

Mauro Carolli, Simone Beichler, Sašo Šantl, Martin Pusch: A framework to assess linkages between river hydromorphology and ecosystem services

Marco Di Tullio: Direct close-range photogrammetry as a tool for $3 \mathrm{~d}$ modelling in glaciology: applications in the Alps and in Chilean Patagonia

Massimiliano Fazzini: Recent trends of isotherms 0 and $1{ }^{\circ} \mathrm{C}$ in the south-eastern sectors of the Alps

Leopod Füreder, Thomas Scheurer: The International Scientific Committee on Research in the Alps (ISCAR): commitment, past and future activities

Barbara Grüner, Angelika Abderhalden: Creating an Integrated River Basin Management Plan: IEM Engadin

Johannes Christoph Haas, Steffen Birk: Analysis of different hydrogeological settings along the river Mur (Austria)long-term development and drought conditions

Martin Kainz, Georg H. Niedrist: FORUM WASSER - Water in and around the European Alps: maintaining water availability and high quality in times of global change

Günter Köck, Claudia Köck, Leopold Füreder: Caddisfly larvae as sensitive bioindicators of metal pollution in rivers

Günter Köck, Roland Psenner: Research on water issues funded by the international research programmes of the Austrian Academy of Sciences

Rainer Kurmayer: Innovative ecological assessment and water management strategy for the protection of ecosystem services in Alpine lakes and rivers (EcoAlpsWater)

Rainer Kurmayer, Eugen Rott: Molecular ecology of river cyanobacteria

Peter Mani: The potential of the storage basins in the Grimsel area as multi-purpose reservoirs

Thomas Marke: Potential water scarcity emerging in future water balance simulations with combined land use and climate change scenarios for an Alpine catchment (Brixental/Austria)

Susanne Muhar, Kerstin Böck: Alpine rivers - a book project

Rolando Pozzani: The Interreg Alcotra project 'concert-eaux' 
Alberto Scotti: A 'riverscape' study: effects of Alpine land covers on assemblages and functional traits of stream benthic macroinvertebrates

Anna Maria Urbaniak-Brekke: The adaptive capacity of Norwegian ski resorts

Marc Zebisch, Claudia Notarnicola, Felix Greifeneder, Carlo Marin, Mattia Callegari: Opportunities for monitoring droughts in the Alps with satellite data

\begin{abstract}
The blue gold of lake Parón - relevance of social capitals in the development of a socio-environmental conflict around water management in a micro-basin in the Peruvian Andes
\end{abstract}

Fabio Azzolin

In 2008 the conflict around the water management of an important Andean lake basin, Parón, intensified considerably. The hydroelectric installation, granted to the Duke Energy company, was in fact occupied by peasants of Cruz de Mayo, a Peruvian Andean rural community. This non-violent conflict, after several years of impasse, has seen the recent introduction of various negotiating tables between Cruz de Mayo, Duke Energy, CEAS, a Peruvian Catholic organization, as well as local and state institutions. Our research focuses on social factors that have moved the water conflict towards a process of institutionalization, as well as on social aspects in the community. The concept of social capital can help us to analyse this kind of socioenvironmental conflict and, in turn, could contribute to developing environmental conflict theories that often overlook the social complexity of the involved populations. Social capital, as a social resource embedded in a networks association, gives us a detailed picture of interactions, which in a struggle process can be created within and between social groups. Our hypothesis is that the conflict has been gradually institutionalized, mainly due to the improvement of a specific kind of social capital which has led towards a particular opening of social boundaries in the community. Our findings intend to provide an analytical framework and guidelines that could be used by other social and politic actors.

\section{Klimareport Südtirol 2018: impacts of climate change on water resources in South Tyrol}

\section{Giacomo Bertoldi}

Climate change is already influencing the natural environment, society and economic activities in Alpine regions. It is high time to monitor the impacts and to develop region-specific adaptation and mitigation strat- egies. In 2018 Eurac Research published a report that analysed climate change impacts on the natural environment and on society with a fully interdisciplinary approach, involving researchers of different disciplines, experts and public officials. Moreover, a series of indicators have been identified for quantifying climate change impacts on the different sectors. The report has been written in rigorous but plain language, for a wide audience of stakeholders, interested people, school students and public administrators. In this poster, we present the major impacts of the current climate trends on the water cycle and water resource management in South Tyrol. Results show an increase in water demand for agriculture, with possible increasing water conflicts, which will require changes in current water management policy.

\section{Potential of multi-purpose reservoirs for alleviating summer droughts in the Alps.}

\section{Manuela Brunner}

A change in runoff regimes from snow-dominated to rainfall-dominated regimes is expected for Alpine rivers under future climate conditions. Under a rainfall-dominated regime, summer runoff will be reduced while more frequent droughts increase the probability of local water shortages. Reservoirs might alleviate the negative effects of such regime shifts if they are not limited to a single use, such as electricity production, but operated to fulfil multiple needs, e. g. water supply or flood control. Such multi-purpose reservoirs allow for the storage of winter rainfall and for water release later in the year, when natural water availability is generally lower and water demand is high, not least due to irrigation requirements. We propose a multi-modular framework that allows for the assessment of the potential of multi-purpose reservoirs for reducing anticipated water scarcity. The framework has three modules: water supply, water storage and water demand. This modular structure allows for the consideration of different scenarios within each of the modules. The application of this framework allows assessing the potential of multi-purpose reservoirs to alleviate water scarcity under both current and future climate and socio-economic conditions. 


\section{The function of water protection in the mountain forests of the Alps}

\section{Enrico Calvo}

Under the current Austrian Presidency of the Convention, the Working Group on Mountain Forests of the Alpine Convention investigates the functions and ways in which forests protect drinking water areas and again floods. These two functions are historically fulfilled by mountain forests, but today the ongoing climate changes, socio-economic and territorial changes, and the new sensitivity towards ecosystem services, call for greater attention to the management and conservation of forest ecosystems integrated into the cycle of the waters.

On the basis of the data provided by the representatives of the delegations of the Alpine countries participating in the Working Group, the surfaces, characteristics, functions and distribution of the forests with these particular protective functions will be compared, highlighting specific models and good examples of projects and practices.

The proposed poster intends to inform about the work carried out and to present, starting from the first data collected, the framework of these protection forests and the initiatives that are currently under way in the Alpine countries for their management and enhancement.

\section{A framework to assess linkages between river hydromorphology and ecosystem services}

\section{Mauro Carolli, Simone Beichler, Sašo Šantl \& Martin Pusch}

Alpine river corridors provide a number of key ecosystem services (ES). Nowadays, most Alpine valleys are intensely used, and river networks have been largely modified (e. g. for hydropower production, flood protection). In addition, climate change is profoundly altering the hydrological regime of these rivers. Both trends affect the hydromorphological processes and functions of Alpine rivers, which play a fundamental role in shaping and maintaining river habitats and related ecological functions. As a consequence, many ES have been reduced, which may affect human wellbeing now and in the future. Hence, requests to mitigate the environmental impacts of different hydromorphological alternations also include the improvement of ES availability into the decision-making process. A proper framework may also improve communication among stakeholders. The EU HyMoCARES project develops instruments for the practical application of the ES approach in river and floodplain management, using available knowledge on a) the functional linkages between fluvial hydromorphology and ES, and on b) how management measures may influence those linkages.

\section{Direct close-range photogrammetry as a tool for 3d modelling in glaciology: applications in the Alps and in Chilean Patagonia}

\section{Marco Di Tullio}

Close-range photogrammetry is a technique to generate $3 \mathrm{D}$ models of objects based on overlapping imagery, provided ground control points are available to orientate the imagery. This technique benefited of the fast computer vision algorithmic developments, in which Structure-from-Motion (SfM) plays a special role. Real Time Kinematic (RTK) or very rapid-static GNSS survey techniques are other efficient tools to collect a high number of ground control points.

The aim of the study is to generate 3D models of melting glaciers which are the most important climate change indicator. Our proposal is to merge the benefits of SfM-based close-range photogrammetry and RTK/ very rapid static GNSS surveys to generate 3D models of glaciological interest using the GNSS surveying techniques. Some examples related to the Alps (Forni and Lys Glaciers) and Chilean Patagonian (Exploradores Glacier) are presented.

\section{Recent trend of isotherms 0 and $-1^{\circ} \mathrm{C}$ in the south-eastern sectors of the Alps}

\section{Massimiliano Fazzini}

In the last century, the temperature increase recorded in the Alpine domain was on average twice as high as calculated for the northern hemisphere and is estimated at about $2{ }^{\circ} \mathrm{C}$ and in the last three decades about $1^{\circ} \mathrm{C}$. The effects at high altitudes in the central to eastern Italian Alps and in the Slovenian Alpine region are particularly evident, so much so that the percentage of glacier retreat has increased to $89.5 \%$ and it is likely that most of the glaciers of the Southern Alps will disappear during the $21^{\text {st }}$ century. This study aims to provide a quantification of the increase in temperature in the Tridentine and Slovenian Alps. Thanks to the recent remarkable improvement of meteo-climatic monitoring at high elevations, it was possible to analyse a first study of the thermal - currently temporally generally extended from January 2003 to December 2017 - so as to determine the variation in elevation of annual isotherms of $0^{\circ} \mathrm{C}$ and $1{ }^{\circ} \mathrm{C}$. Twenty-two clusters were identified at elevations between 600 and $3300 \mathrm{~m}$ a.s.l., with meteo-climatic stations located on the valley floor, on slopes and at the peak - so as to calculate these thermal thresholds. The first results of analysis are dramatic; the thermal increase for the short period of study is about $0.3^{\circ} \mathrm{C}$ and the average elevation of annual isotherms $0^{\circ} \mathrm{C}$ and $1^{\circ} \mathrm{C}$ are $2598 \mathrm{~m}$ and $2801 \mathrm{~m}$; finally, the trends show a strong increase in the elevation, estimated at about 32 and $34 \mathrm{~m} /$ year, respectively. 
The International Scientific Committee on Research in the Alps (ISCAR): commitment, past and future activities. 2018

Leopod Füreder \& Thomas Scheurer

The International Scientific Committee on Research in the Alps promotes international cooperation in $\mathrm{Al}$ pine research. In 2000 ISCAR was recognized by the Alpine Conference as an official observer of the Alpine Convention. ISCAR provides a platform for science/ policy interaction on issues concerning the Alpine Convention or EUSALP, and facilitates research cooperation between protected areas. In this respect, ISCAR organizes biannually the ForumAlpinum or (together with Alpine networks ) the AlpWeek on topics of acute interest, and specialized workshops. More information: http://www.iscar-alpineresearch.org/iscar/

\section{Creating an Integrated River Basin Management Plan: IEM Engadin}

\section{Barbara Grüner \& Angelika Abderhalden}

Integrated River Basin Management is a cross-sectoral approach to manage water resources, rivers, as well as water-related infrastructure. In a participatory process, a long-term plan is being developed that covers water supply, the use and protection of and from water. A set of actions is defined to guarantee high efficiency in the use of water for all sectors involved. Such decisions meet with a higher acceptance as they are developed by the affected stakeholders itself.

The Engadin is an inner-Alpine dry valley. Within the next decades, the Engadin will face a change in discharge (amount and seasonality) due to climate change, which might heighten existing conflicts between the sectors.

To avoid this, an Integrated River Basin Management Plan is being developed within the project IEM Inn. The aim of this project is to develop a long-term solution to balancing the different uses as well as the protection of water in a sustainable way, using different participatory methods.

The Integrated River Basin Management in the Engadin (IEM Inn) is a pilot project for integrated river management in the canton of Grisons.

This project is part of the Interreg project SPARE (Strategic Planning for Alpine River Ecosystems) that aims to test innovative participatory methods within selected pilot case areas and to develop and adapt different tools for balancing the use and protection of water.

\section{Analysis of different hydrogeological settings along the river Mur (Austria) - long-term development and drought conditions}

Johannes Christoph Haas \& Steffen Birk

Using standardized hydrological time series we investigate the interaction between groundwater, surface water, precipitation and evapotranspiration in the Austrian Mur valley. We highlight the differences and similarities between different stretches of river and thus hydrogeological settings. In the case of the river Mur, these are an inner-Alpine basin, a narrow valley and wide, pre-Alpine basins. Each shows a distinctive behaviour, ranging from the river as the dominant factor for groundwater dynamics in the narrow and inner-Alpine settings, to the foreland, where precipitation is the most important driver of groundwater level variations. These behaviours are shown by using correlation matrices and by analysing long-term averages of all groundwater measuring stations in a region. In addition to these natural effects and constraints, human impacts greatly affect groundwater levels by various mechanisms, such as groundwater extraction for settlement or industry use or by the construction of run-of-river hydropower plants. However, lack of information on such uses and lack of long-term measurements can make the identification and quantification of such effects difficult. Since a changing climate is likely to increase the occurrence and magnitude of extreme events, we observe the well-known 2003 drought in detail and compare the different aquifer bodies along the river under extreme drought conditions.

\section{FORUM WASSER - Water in and around the European Alps: maintaining water availability and high quality in times of global change.}

\section{Martin J. Kainz \& Georg H. Niedrist}

Water is arguably the most precious resource in the European Alps and its availability and quality of uppermost importance for society. Millions of people in and around the European Alps receive their drinking water from the Alps; and water for commercial use, most importantly for the provision of hydroelectric power, is largely derived from the Alps. It is thus evident that the provision of high water quality and quantity is of top public priority and requires economic, societal and institutional visions, in particular in times of global change. FORUM WASSER is a platform that aims to stimulate debate, backed by science, about current and future water availability and security, with strong interdisciplinary connections. In this presentation, I will identify emerging issues, such as large-scale and longterm consequences of climate-change-induced extreme 
events on water availability, quality and use. The presentation will reflect a variety of risk reduction measures, including precautionary measures, forecasting and early warning, and how such measures are embedded in economic, societal, institutional, and above all scientific, contexts. In particular, I will present selected examples of how climate change may affect water and its ecosystems in and around the Alps; for example, as means of future diet provision, as habitat of decreasing aquatic biodiversity, and as potential contributor to, or withholder of, greenhouse gas emissions.

\section{Caddisfly larvae as sensitive bioindicators of metal pollution in rivers}

\section{Günter Köck, Claudia Köck \& Leopold Füreder}

Monitoring the metal load of rivers by metal analysis of water and sediments is often not sufficient because of fluctuating metal concentrations in the water and delayed responses of sediments. It also provides little information about metal bioavailability in aquatic ecosystems. Thus the abundant caddisfly larvae (Allogamus auricollis) were used to study long-term trends of metal pollution in the rRiver Inn (Tyrol, Austria) over a period of 25 years (1990-2015). Until 1990 a stretch of the river was contaminated by lead- $(\mathrm{Pb})$-containing industrial effluents. Metal concentrations in pooled samples of caddisfly larvae from an upstream unpolluted reference site and a site downstream from the effluents discharge were investigated from 1990 onwards to study short-term and long-term effects of the installation of a "state-of-the-art" industrial waste water treatment plant (WWTP). In spring 1990, concentrations of Pb in caddisfly larvae from the sampling site downstream of the pollution source were approximately 50 times higher than at the reference site. However, after putting the WWTP into operation, $\mathrm{Pb}$ concentrations in caddisfly larvae decreased during the first two years at a constant rate of $64 \%$ per year. In $1992 \mathrm{~Pb}$ burden of the larvae from the downstream site were only $13 \%$ of the $\mathrm{Pb}$ concentrations measured in 1990. From 1992 onward, $\mathrm{Pb}$ concentrations decreased more slowly, reaching $\mathrm{Pb}$ values comparable to larvae from the reference site in 2002. In 2015 the $\mathrm{Pb}$ concentration in larvae from the downstream site were only $1.25 \%$ of the values measured in 1990 with no statistical difference between reference and downstream sites. To conclude, our study shows that caddisfly larvae do reflect metal contamination of aquatic systems at pollution levels hardly detectable by analysis of sediment or water samples. They have emerged as, thus being sensitive bioindicators of metal pollution in freshwater ecosystems.

\section{Research on water issues funded by the international research programmes of the Austrian Academy of Sciences}

\section{Günter Köck \& Roland Psenner}

The research programme Earth System Sciences (ESS) of the Federal Ministry of Education, Science and Research (BMBWF), conducted by the Austrian Academy of Sciences (ÖAW) aims at studying the physical, chemical, hydrological, biological, social, technological and economic processes of the Earth System and their interactions. ESS seeks to fill gaps in the Austrian funding landscape by supporting, for example, interdisciplinary projects, long-term research projects and projects in areas that have hitherto gone largely unexamined and thus can be considered as pioneering. Furthermore, ESS is an interface between Austrian science and international research and is integrated in international research programmes and cooperations (e. g. UNESCO's MAB, IGCP and IHP, LTER, ISCAR) through its three National Committees (NC) Global Change, Geo/Hydro-Sciences, and Man and the Biosphere (MAB). These NCs, made up of renowned scientists and representatives of several ministries and federal organizations, monitor the Austrian research scene, analyse its strengths and knowledge gaps and work out targeted new research foci and the scientific orientation of calls for research projects. Two calls for projects in 2013 and 2015 saw a total number of 32 state-of-the-art research projects (including two projects funded in cooperation with the Belmont Forum), worth more than 8 million euros. About half of these projects focus on topics related to water issues. The new call for projects 2018 will focus on water issues in connection with the UN Sustainable Development Goals (SDGs).

\section{Innovative ecological assessment and water management strategy for the protection of ecosystem services in Alpine lakes and rivers (EcoAlpsWater)}

\section{Rainer Kurmayer}

A new project co-funded through the Alpine Space programme with the aim to improve surface water quality monitoring by i) advanced DNA sequencing techniques that allow meta-barcoding of aquatic biota relevant for the implementation of the EU Water Framework Directive and the Swiss Water Protection Ordinance, and ii) novel technologies in data processing (automation in data processing, data storage, information retrieval).

Along with the identification of gaps in the monitoring approaches across the Alpine regions, the new 
technologies will allow defining improved experimental monitoring protocols to be applied in selected areas (including large peri-Alpine lakes and smaller waterbodies, and key rivers). The transnational approach bridges the scientific divide between academia and governance agencies, putting into practice the EUSALP agenda, i. e. capacity building of research institutions, networks and infrastructure with an Alpine region dimension.

\section{Molecular ecology of river cyanobacteria}

Rainer Kurmayer \& Eugen Rott

Cyanobacteria constitute an autotrophic key component of biofilm on stony substrates in running water that responds to the deterioration in ecosystem integrity. In general, morphological characters have been applied to investigate the species composition of these macroscopic patch-forming cyanobacteria as well as their ecological niche. We apply single cell/ colony genetics to characterize the niche diversification and adaptation potential of abundant cyanobacteria in rivers. The genus Chamaesiphon occurs with a dozen of morphospecies in habitats stressed, for example, through mechanical abrasion (fluctuation in flow regime), desiccation, UV irradiation, or eutrophication. In order to understand adaptation processes, we investigate i) whether the morphological differentiation is influenced by habitat characteristics and ii) whether the physiological adaptations are revealed by functional genes. In the field, individual colonies of cyanobacteria are isolated under the microscope and analysed both morphologically and genetically. In addition to the morphological description, single colony PCR and subsequent sequencing of $16 \mathrm{~S}$ rDNA marker genes and functional genes reveal taxonomic and phylogenetic information. By linking molecular biological characteristics with traditional morphological analysis, this approach contributes to the implementation of high-throughput monitoring tools (meta-barcoding) based on marker DNA sequencing.

\section{The potential of the storage basins in the Grimsel area as multi-purpose reservoirs}

\section{Peter Mani}

Based on a quantitative approach, the potential of the storage basins of the Kraftwerke Oberhasli (KWO) was evaluated. The hydroelectric power production was examined along with the protection against floods and the reduction of drought impacts, taking into account climate change impacts.

In terms of flood protection, the water retention in the storage basins reduces flood risk in the upper part of the Aare catchment considerably. In the lower part, the damping effect of lake Brienz and lake Thun is more effective.

The hotspot of drought lies in the lower part of the Aare catchment. The water in the storage basins in the Grimsel area is far from sufficient to compensate for this.

\section{Potential water scarcity emerging in future water balance simulations with combined land-use and climate-change scenarios for an Alpine catchment (Brixental/Austria)}

\section{Thomas Marke}

The present study analyses the impact of coupled storylines of potential future climate and land-use evolution on the water balance of the Alpine catchment of the Brixentaler Ache in Tyrol / Austria (322 km2). To this end, downscaled and bias-corrected climate simulations for the A1B and RCP 8.5 emission scenarios are combined with three future land-use developments of forest management. Both are later applied as input for the physically-based, distributed water balance model WaSiM. Land-use evolution is elaborated by means of an inter- and transdisciplinary approach, together with local actors, to define plausible and consistent projections for forest management, policy, social cooperation, tourism and economy. i) Ecological adaptation: The forest management consistently applies the political guidelines and the forest cover is dominated by an ecological, place-adapted mixed cultivation with a harmonious age structure. ii) Economic overexploitation and wildness: The forest management focuses on increasing efficiency, cost reduction and short-term results. iii) Withdrawal and wildness: Cultivation in general decreases and the forest becomes vulnerable to natural hazards. The results presented show the impact of the combined climate and land-use evolution on the water balance of the Brixentaler Ache. We demonstrate the effect on the water balance of growing forests on abandoned alpine pastures.

\section{Alpine rivers - a book project}

\section{Susanne Muhar \& Kerstin Böck}

Rivers are characteristic elements of the natural and cultural landscapes of the Alps. To document the manifold significance of Alpine rivers from a natural, cultural and social science perspective, a book with authors from all over the Alpine space will be published. This book aims to raise awareness of the development and functions of Alpine rivers, their ecological, societal and economic significance past and present, the extent and the consequential effects of human use, as well as 
the need for coordination between protection and exploitation interests. It includes technical chapters, river portraits and an atlas section. In the technical chapters, basic knowledge on rivers of the entire Alpine Arc is provided. The river portrait part describes specific characteristics of approximately 50 selected rivers from all Alpine countries. In the atlas section, the environmental status of Alpine rivers is documented in maps, based on the scientific outcome of the Alpine Space project SPARE Strategic Planning of Alpine River Ecosystems. The book intends to stimulate the readers' curiosity and interest to learn more about the diversity and beauty of Alpine rivers. At the same time, it will serve as a reference book with spatially explicit data and maps for future investigations. Finally, awareness of the uniqueness and the value of these rivers and the threats to them from resource overuse should be raised along with readers' motivation to advocate for river conservation.

\section{A 'riverscape' study: effects of Alpine land covers on assemblages and functional traits of stream benthic macroinvertebrates.}

\section{Alberto Scotti}

The term 'riverscape' refers to a riverine landscape that can be studied at different scales, from the single habitat patch to the catchment level. This definition stems from the observation that streams and rivers are characterized by the interaction and the mutual influence of different habitats located both in and outside the water bodies. While several studies have previously assessed the effects of land-cover conversion on the aquatic environment in different parts of the world, very few studies examined these effects in the European Alpine region. Using GIS analysis of the whole Italian Alpine province of South Tyrol (Central Eastern Alps), we selected 15 riverine sites grouped by landcover typology (rocks, grasslands, forests, pastures) and comparable in terms of discharge, altitude, catchment dimension and mean slope. We sampled stream benthic macroinvertebrates on three occasions during spring and summer 2017 at the selected sites. At the same time, we measured a set of water parameters $(\mathrm{pH}$, ORP, EC, nitrate, turbidity, temperature). The typology of land covers in the surroundings of the sampled streams proved to be a crucial driver for the benthic macroinvertebrate communities, being a statistically significant factor in explaining the variation of the samples, both in terms of structure and of functional diversity. This result may represent an important finding with regard to land-use intensification and abandonment currently experienced by the Alpine region as a result of different socio-economic processes. Finally, in addition to climate change effects in mountain regions, this phenomenon may constitute an additional indirect factor influencing structures and functions of aquatic riverine ecosystems in the region.

\section{The adaptive capacity of Norwegian ski resorts}

\section{Anna Maria Urbaniak-Brekke}

Skiing is probably the closest you get to a national sport in Norway, and skiing can be conducted in all parts of the country. However, climate change is leading to less stable winters, creating a need for adaptation or transformation. Despite an increasing body of literature on the impacts of climate change on ski tourism from all over the world, very little is known about the impacts and adaptation options for Norwegian ski resorts. The larger resorts are concentrated in the eastern part of the country, with three large resorts in the western Fjord region, and one in Northern Norway. The large resorts in Eastern Norway are situated in regions that in the foreseeable future will have good opportunities for technical snow production. The climate projections are more worrying for the ski resorts in Western Norway, as these already enjoy a less stable winter climate due to their proximity to the sea. Employing projections for future snow and snow-making conditions, we investigated adaptive responses of ski lift operators, winter sport destinations and winter sport tourists in Western Norway. We developed a framework for assessing the transformative capacity of the destinations, drawing on literature on sources of adaptive capacity.

\section{Opportunities for monitoring droughts in the Alps with satellite data}

Marc Zebisch, Claudia Notarnicola, Felix Greifeneder, Carlo Marin \& Mattia Callegari

In recent years, a series of drought events has affected the downstream regions of the Alps. The 2017 drought in northern Italy led to yield losses and a financial damage of almost two billion euros. One of the main reason for this type of drought is a lack of water from the Alps, which is caused by a combination of a lack of snow and therefore less run-off from snowmelt, along with hot and dry summers with low precipitation and high evapotranspiration losses. Earth Observation can significantly contribute to a continuous and areawide monitoring of water resources in the Alps, such as snow cover or soil moisture, as well as the impacts of droughts on vegetation. Particularly with the latest ESA Sentinel satellites, a constant data stream of high-resolution data is available every few days. From an Earth Observation perspective, droughts and their triggers can be recognized as anomalies in time. For 
instance, snow cover in the Alps (or in a specific catchment) at a given time can be compared to long-term averages to understand if water availability from snowmelt will be below average or below a critical threshold. In combination with meteorological data and seasonal climate forecast, such information can even be used to project water availability within the upcoming weeks or months. In this poster, we discuss the opportunities for monitoring droughts in the Alps by combining Earth Observation with meteorological data and present first results for Alpine catchments. 


\section{PROGRAMME}

\section{MONDAY 4 JUNE 2018}

$13: 00-13: 30$
Tauernsaal*

$13: 30-16: 00$

Tavernsaal*

$13: 30-14: 30$

Tauernsaal*

$14: 30-16: 00$

Tavernsaal*

$14: 30-16: 00$

Saal Fort Claudia

$14: 30-16: 00$

Saal Ehrenberg

\section{Opening, welcome addresses}

Leopold Füreder, Austrian Academy of Sciences \& ISCAR \& University of Innsbruck Markus Reiterer, Secretary General of the Alpine Convention

Ingrid Felipe, Landeshauptmann-Stellvertreterin

Katharina Rumpf, Bezirkshauptfrau

Ronald Petrini, Tourism association Reutte

\section{Module 1: Hydrological and water-driven hotspots in the Alps}

Chair: Rolf Weingartner, University of Bern

Keynote: Analysing alpine water related hotspots: Setting the ground Rolf Weingartner, University of Bern

Introduction to the workshops: What is a water-related hotspot and how can we map it? Klaus Lanz, International Water Affairs

\section{Workshops 1.1. - 1.3.}

Workshop 1.1. Existing water-related hotspots and hazards

Chair: Andreas Schaffhauser, ZAMG; Support for mapping: Kati Heinrich, Inst. for Interdisciplinary Mountain Research (IGF), Austrian Academy of Sciences (ÖAW)

Input 1 - Hydrological scenarios in the Austrian Alps for the next century - first results of the HydroGeM3 project

Ulrich Strasser \& Thomas Marke

Input 2 - The Alps Water tower - an earth observation perspective

Marc Zebisch

\section{Discussion \& mapping}

Workshop 1.2. Emerging water-related hotspots and hazards due to climate change Chair: Andrea Fischer, IGF, ÖAW; Support for mapping: Valerie Braun, IGF, ÖAW

Input 1 - AR Big Data and Google Earth Engine: key tools for glaciers health monitoring Marco Di Tullo

Input 2 - Future lakes - future potentials. New lakes in Austria following glacier retreat Jan-Christoph Otto \& Markus Keuschnig

\section{Discussion \& mapping}

Workshop 1.3. Emerging water-related hotspots and hazards due to socio-economic changes

Chair: Elisabeth Sötz, WWF Austria, Support for mapping: Anna Schöpfer, University of Innsbruck

Input 1 - Fair distribution of risk and benefits - the challenges of social justices in mountain hazard management

Thomas Thaler

Input 2 - The construction of a landscape for tourism. The role of water in the creation of high altitude ski resorts in the French-italian Alps (1950-1980)

Caterina Franco

\section{Discussion \& mapping}



$16: 00-16: 30$
Coffee break
$16: 30-19: 30$
Excursion
Lechtal LIFE project: presentation and excursion to Lechtal, public discussion Presenters: Leo Füreder \& Wolfgang Klien

19:30-22:00 Dinner at Gasthof Klause, visit of the Highline 179 \& entertainment Music: Bluatschink

\section{TUESDAY 5 JUNE 2018}

\section{$7^{\text {th }}$ Water Conference of the Water Platform of the Alpine Convention in dialogue with EUSALP AG 6 Subgroup Water}

Water in the Alps - Management of hydrological extremes and sustainable hydropower use

$8: 30-16: 30$

Tauernsaal* $^{*}$

09:00 - 12:30

Tavernsaal*

$9: 00-10: 30$

Tauernsaal*

$10: 30-11: 00$

$11: 00-12: 30$

Tavernsaal* $^{*}$
Welcome addresses - Official greetings of the Authorities

Markus Reiterer, Secretary General of the Alpine Convention

Stefan Wildt, Regional Government of Tyrol

Paolo Angelini \& Luka Štravs, Co-Chairs of the Water Platform of the Alpine Convention

\section{Module 2: The impacts of and response to droughts in the Alpine region}

Modul 2 - Part I

Chair: Hannah Berger, Bavarian Environment Agency, German delegation to the Water Platform

Input 1 - Current developments and challenges in drought management in Northern Bavaria

Andreas Kolbinger, Bavarian State Ministry of the Environment and Consumer Protection, Germany

Input 2 - Strategic water resources management and drought Johannes Wiesenegger, Regional Government of Salzburg, Austria Input 3 - Drought management with negotiated processes in Italy Nicoletta Diano, Italian delegation to the Water Platform, Italian Ministry of the Environment, Land and Sea, Italy

Debate / interactive section

\section{Coffee break}

Modul 2 - Part II

Chair: Christian Schilling, Austrian delegation to the Water Platform, BMNT, Austria

Input 4 - New tools for better drought risk management

Andreja Sušnik, SI-ARSO, Slovenia

Input $\mathbf{5}$ - Security of drinking water in light of climate change

Gunther Heißel, Regional Government of Tyrol, Austria

Input 6 - Facing droughts in the Alpine region - Experiences, approaches and common challenges

Andrea Bianchini, Italy, Italian Delegation to the Platform "Water Management in the Alps" of the Alpine Convention

Debate / interactive section 
12:30-13:30 Lunch

$13: 30-15: 00$

Tauernsaal*

$15: 00-15: 30$

$15: 30-16: 30$ Tauernsaal*

\section{Module 3}

Modul 3 - Part I: Green infrastructure for an integrated and sustainable water management

Chair: Luka Štravs, Ministry of the Environment and Spatial Planning, Slovenia

Input 1 - Greener Alpine Rivers? Conclusions and Recommendations of the EUSALAP AG 6 - Subgroup Water Elisabeth Sötz, WWF Austria, for EUSALP AG 6

Input 2 - 50 Shades of Green Infrastructure - Experiences from Slovenia Joze Papež, Hidrotehnik, Slovenia, Mateja Ribnikar, MOP, Slovenia \& Maja Jelen, MOP, Slovenia

Input 3 - Alpine green infrastructure - joining forces for nature, people and the economy Manuela Künzl, Bavarian State Ministry of the Environment and Consumer Protection, Germany \& Franziska Drasdo, City of Munich - Department of Urban Planning

Debate / interactive section

\section{Coffee break}

Modul 3 - Part II: Common guidelines for the use of small hydropower in the Alpine region

Chair: Nicoletta Diano, Italian delegation to the Water Platform, Italian Ministry of the Environment, Land and Sea, Italy

Input 1 - Presentation of the elaboration and content of common guidelines Pietro Colonna, Italian Delegation to the Alpine Convention

Input 2 - Application of the Common Guidelines for the use of Small Hydropower in the Alpine region

Christian Schilling, BMNT, Austria

Debate / interactive section

Rapporteur to the Forum Alpinum plenary

Joze Papež, Slovenia

14:00 - 16:00 / 16:30 ForumAlpinum: additional workshops to Module 1-Workshops 1.4. \& 1.5.

$14: 00-16: 00$

Workshop 1.4. Alpine springs under pressure

Saal Fort Claudia

Input 1 - Alpine springs under pressure will Global Change increase present conflicts of interest? Stefanie von Fumetti \& Daniel Küry

Input 2 - Ecological evaluation, conservation and restoration of spring habitats in the Swiss Alps

Daniel Küry

Input 3 - Long-term monitoring of alpine springs to determine climate change impact Gabriele Leonhardt

Input 4 - Collecting biota in spring habitats: A proposal for a sustainable methodology in long-term monitoring studies

Reinhard Gerecke \& Marco Cantonati 
15:00 - 16:30

Saal Ehrenberg
Workshop 1.5. Monitoring and managing European Union species and habitats of alpine rivers

Chair: Norbert Müller, University of Applied Science, Erfurt \& Helmut Kudrnovsky,

freelancer, Kematen

Input 1 - 3230 "Alpine rivers with Myricaria germanica" - actual findings along river Lech Helmut Kudrnovsky

Input 2 - Reintroduction of Myricaria germanica in Italy - an overview

Bruno Michielon \& Tommaso Sitzia

Input 3 - 30 years monitoring and managing Typha minima at the Tyrolean Lech river - a key species of the habitat 7240* "Alpine pioneer formations"

Norbert Müller

Input 4 - Monitoring Bryodemella tuberculata - a key species of the habitats 3220, 3230 and 3240 "Alpine rivers"

Michael Reich

Input 5 - Standardized selections of FFH-species and habitats for protection measures Anna Schöpfer \& Leopold Füreder

\section{6:00 / 16:30 - 17:00 Break}

17:00 - 19:00

Saal Fort Claudia

\section{Current programmes and networks}

Chair: Thomas Scheurer

Programme and networks presentations

Input 1 - NEMOR network / Vision 2030

Bernat Claramunt

Input 2 - Alpine Space Programme: Outlook

Primož Skrt

Input 3 - Network of River Contracts

Massimo Bastiani

Input 4 - Forum Water

Georg Niedrist

Input 5 - Announcement of Young Academics Awards

Aureliano Piva

\section{Poster session}

$16: 30-19: 00$

Meeting of the EUSALP AG 6 Subgroup (closed session)

Saal Ehrenberg

19:00 - 22:30

Tauernsaal*

\section{Conference dinner, entertainment \& water tasting}

\author{
Welcome addresses \\ Roland Psenner, ÖAW \\ Invitation of local politics \\ Hanspeter Wagner, Mayor of Breitenwang \\ Music \\ Landesmusikschule Reutte \\ Water tasting \\ Roland Psenner
}




\section{WEDNESDAY 6 JUNE 2018}

\author{
$8: 30-12: 00$ \\ Tauernsaal* \\ $8: 30-9: 45$ \\ Tauernsaal*
}

$9: 45-10: 15$

10:15 - 12:00

Saal Fort Claudia

$10: 15-12: 00$

Tauernsaal*

10:15 - 12:00

Saal Kreckelmoos

\author{
Module 4: Conflicting water use in the Alps \\ Chair: Roland Psenner, EURAC Bolzano \& Günter Köck, ÖAW
} Keynote 1: Water-related hotspots in the Alps - Results of the workshops of Module 1 and
perspectives

Klaus Lanz, International Water Affairs

Keynote 2: Snowmaking - a vital adaptation measure creating conflicts

Robert Steiger, University of Innsbruck

Keynote 3: Results of the $7^{\text {th }}$ Water Conference (Modules 2 and 3)

Joze Papež, Slowenien

\section{Coffee break}

Workshop 4.1. Local water use: water supply, agriculture, tourism

Chair: Heike Zimmermann-Timm, Goethe University, Frankfurt am Main

Input 1 - Problem of private or public use of water resources: case study Val Masino Oliver Ike

Input 2 - Is Alpine irrigation overestimated?

Calianno Martin

Input 3 - Transboundary water supply assessment of surface water resource availability:

application in Danube and Tyrol

Simone Persiano

Input 4 - The role of local community in governing water as a common-pool resource

Primož Pipan

Workshop 4.2. Energy production

Chair: Peter Hanisch, DonauConsult

Input 1 - Energy transition in Alpine regions - what does it mean for water use and water management? A view from South Tyrol

Wolfram Sparber

Input 2 - Sustainability assessment of hydropower from a stakeholder perspective Lutz E. Schlange

Input 3 - Small hydropower plants: A critique related to the Belluno area (Italy)

Monica Camuffo

Input 4 - Impacts and risks of reservoirs: The case of reservoirs along the Spöl river Christian Schlüchter \& Thomas Scheurer

Input 5 - Preserving Alpine Floodplain rivers through functional floodplain flows

Daniel Hayes

\section{Workshop 4.3. Tourism}

Chair: Philippe Bourdeau, Université Grenoble-Alpes, Institut de Géographie Alpine

Input 1 - Valuation of recreation related ecosystem services on rivers Soča (Slovenia) and Tara (Montenegro)

Jernej Stritih

Input 2 - Integrated water resource management in tourist areas: moving from the hydrological basin to the water use basin

Emmanuel Reynard

Input 3 - Summary of Conference Water \& Tourism 2017

Emmanuel Reynard

Input 4 - On the recent variation of the "Snow Reliability Line" in the south-eastern Alps Massimiliano Fazzini 
10:15 - 12:00

Saal Ehrenberg

8:00 - 12:00

Moserhof

$12: 00-13: 00$

$13: 00-17: 30$

Tauernsaal*

13:00 - 14:00

Tauernsaal*

14:00 - 16:30

Saal Kreckelmoos

14:00 - 16:30

Tavernsaal*
Workshop 4.4. Ecological integrity of rivers

Chair: Leopold Füreder, ÖAW \& ISCAR \& University of Innsbruck

Input 1 - Overview of the environmental conditions of the rivers of the Alps Susanne Muhar \& Carina Seliger

Input 2 - The Wild Rivers Label - an effective tool to conserve alpine river landscapes?

Roberto Epple

Input 3 - WWF Austria - River Restoration Concept

Gebhard Tschavoll

Input 4 - Clean Water Project - San Giovanni Torrent (Lake Maggiore - Verbania - Italy) Andrea Cottini

Input 5 - Holistic (multiscale) analysis of the factors and their effect on the fish fauna in Inner-Alpine space

Stefanie Oberarzbacher

\section{NEMOR Workshop}

\section{Lunch}

\section{Module 5: Managing conflicting water use}

Chair: Valerie Braun, IGF, ÖAW

Keynote 1: Water as a cause for conflicts

Martin Grambow, TU Munich

Keynote 2: Participative processes in water management

Klaus Michor, Revital

Workshop 5.1. Learning from the past for the management of present and future waterrelated conflicts: Dealing with floods and flood risk in historical Alpine societies

Chair: Patrick Kupper, University of Innsbruck, Institute of History and European Ethnology

Input 1 - The 1989 flooding of Innsbruck: human induced disaster, social conflict and contemporary challenges

Reinhard Nießner

Input 2 - Taming the torrent? Flood control and conflicts of interest at the Gürbe River (Canton of Bern) from the $19^{\text {th }}$ century until today

Melanie Salvisberg

Input 3 - Avoiding conflicts by revisiting historical experience? Flood marks and their use for disaster memory past and present

Christian Rohr

\section{Workshop 5.2. Integrated river basin management}

Chair: Susanne Muhar, University of Natural Resources and Life Sciences, Vienna, Institute of Hydrobiology and Aquatic Ecosystem Management

\& Primož Skrt, Alpine Space

Input 1 - SPARE - Strategic Planning for Alpine River Ecosystems Integrating protection and development

Susanne Muhar \& Kerstin Böck

Input 2 - A reference database to support practitioners toward Integrated River

Ecosystem Management

Sašo Šantl \& Urška Kocijančič

Input 3 - Integrated River Basin Management in the Inn River Basin (CH)

Angelika Abderhalden \& Barbara Grüner

Input 4 - Alpine Space: Lessons learnt from past projects

Primož Skrt 
$14: 00-16: 30$

Saal Ehrenberg

$14: 00-16: 30$ Saal Fort Claudia
Workshop 5.3. Mitigating future water conflicts

Chair: Susanne Brandstetter, Austrian Federal Ministry for Sustainability and Tourism

Input 1 - Best Management Practices within forested drinking water protection zones Roland Köck

Input 2 - How NGOs can contribute to water governance on different levels: from EU Water Framework directive to regional management planning Bettina Urbanek

Input 3 - Planned retreat as an option for the European Alps? To whom, what and when we have to talk

Thomas Thaler \& Sebastian Seebaver

Workshop 5.4 Alpine multi-purpose reservoirs: Future potential and relevance

Chair: Astrid Björnsen Gurung, Swiss Federal Institute for Forest, Snow and Landscape

Research \& Petra Schmocker-Fackel, Federal Office for the Environment, Switzerland

Input 1 - The "Hydro-CH2018 Reservoir" Project

Manuela Brunner \& Manfred Stähli

Input 2 - Evolving polycentric climate governance: The case of multifunctional water use in Oberhasli, Switzerland

Elke Kellner

Input 3 - Management options for Alpine multi-purpose reservoirs

Gottfried Gökler

Input 4 - Contribution of dam reservoirs to Alpine society under changing context: socialeconomic and ecological trajectories. A case study in Valais (Swiss Alps)

Melanie Clivaz \& Emmanuel Reynard

Input 5 - One extraction - Several uses: A case study from France

Marion Douarche

\section{Discussions}

$16: 30-20: 00$

Tauernsaal*

$16: 30-18: 00$

$18: 00-20: 00$

$20: 00-21: 30$
Regional products: presentation and tasting

\section{Public Event}

Wasserkonflikte in den Alpen - und in Breitenwang?

Anette Kestler, CEO Tiroler Lech Nature Park

\section{Closing panel}

What is needed to solve (future) conflicts in water use?

Questions to discuss: Which water conflict management is needed for Alpine space? Water availability between individual interests and public good (all scales from local to European)?

\section{Chair: Klaus Lanz}

Leopold Füreder, ÖAW \& ISCAR \& University of Innsbruck

Luka Štravs, Ministry of the Environment and Spatial Planning, Slovenia

Astrid Björnsen Gurung, Swiss Federal Institute for Forest, Snow and Landscape Research Elisabeth Sötz, WWF Austria

Nicoletta Diano, Italian delegation to the Water Platform, Italian Ministry of the Environment, Land and Sea, Italy

Anette Kestler, CEO Tiroler Lech Nature Park

Film presentation \& discussion

„5 Grad plus - Wie das Klima unsere Welt verändert" (ORF Universum) 


\section{PARTICIPANTS}

Abderhalden-Raba, Angelika; UNESCO Biosfera Engiadina Val Müstair, Scuol Adler, Carolina; University of Berne Angelini, Paolo; Ministry for the Environment, Land and Sea, Rome Arduino, Serena; CIPRA International Baver, Christina; Management Authority Alpine Space Programme Berger, Hannah; Bavarian Environment Agency

Berger, Renate;

Bertoldi, Giacomo; EURAC Research, Bolzano

Bettel, Sonja; Journalistin

Bianchini, Andrea; Italian Ministry of the Environment, Land and Sea

Björnsen Gurung, Astrid; WSL

Blattner, Lucas; University of Basel

Böck, Kerstin; University of Natural Resources and Life Sciences, Vienna

Bokal, Sabina; Global Water Partnership Central and Eastern Europe

Böttcher, Heidi; University of Innsbruck

Bourdeau, Philippe; Université Joseph Fourier, Grenoble

Brändle, Julia; WWF Switzerland

Brandstetter, Susanne; Federal Ministry for Sustainability and Tourism

Braun, Valerie; Austrian Academy of Sciences, Innsbruck

Bredenfeld, Thomas; Medienproduzent

Brunner, Manuela; WSL

Bruno, Michielon; Università di Padova, ERSAF

Calianno, Martin; University of Lausanne

Calvo, Enrico; ERSAF Lombardia

Checcucci, Gaia; Italian Ministry of the Environment, Land and Sea, Rome

Claramunt López, Bernat; Autonomous University of Barcelona

Clivaz, Mélanie; University of Lausanne

Colonna, Pietro;

Cottini, Andrea; Associazione ARS.UNI.VCO, Domodosola

Del Barba, Oscar; Delegazione Italiana

Deppi, Giovanna; Italian Ministry of the Environment, Land and Sea, Rome

Di Tullio, Marco; University of Rome La Sapienza

Diano, Nicoletta; Ministry of the Environment, Land and Sea, Rome

Douarche, Marion; Agence Cimeo

Drasdo, Franziska; City of Munich - Department of Urban Planning

Egger, Gerhard; WWF Austria

Engel, Michael; Free University of Bozen-Bolzano

Epple, Roberto; European Rivers Network (ERN)

Fazzini, Massimiliano; University of Camerino

Felber, Agnes; University of Innsbruck

Felipe, Ingrid; Government of Tyrol

Ferjancic Lakota, Taja; Permanent Secretariat of the Alpine Convention

Fischer, Andrea; Austrian Academy of Sciences

Fischer, Mathias; WWF Germany

Franco, Caterina; Politecnico di Milano

Füreder, Leopold; University of Innsbruck

Gaun, Stefan;

Gerecke, Reinhard; University of Tübingen

Giorgi, Annamaria; University of Milan / ISCAR

Girardi, Theresa; I can help!

Goekler, Gottfried; Vorarlberger Illwerke AG

Grambow, Martin; Bavarian State Ministry of the Environment and Consumer Protection

Grüner, Barbara; Pro Terra Engiadina

Haas, Johannes Christoph; University of Graz

Hanisch, Peter; DonauConsult 
Harmel, Matjaz; ZaVita d.o.o.

Hauser, Georg; Plansee

Hayes, Daniel; University of Natural Resources and Life Sciences, Vienna

Heinrich, Kati; Austrian Academy of Sciences, Innsbruck

Heissel, Gunther; Landesgeologie Tirol

Hilz, Christoph; Plansee

Hold, Michael; Plansee

Hrable, Ines; I can help!

Hug, Wolfgang Alexander; WWF Germany

Humer-Gruber, Heidi; University of Innsbruck

Ike, Oliver; SLH Itd

Jelen, Maja; Ministry of the Environment and Spatial Planning of Republic of Slovenia

Kainz, Martin; WasserCluster Lunz

Kellner, Elke; University of Berne

Kestler, Anette; Naturpark Tiroler Lech

Klien, Wolfgang; Government of Tyrol

Köck, Günter; Austrian Academy of Sciences

Köck, Roland; University of Natural Resources and Life Sciences, Vienna

Kohli, Martin; ISCAR, Bern

Kolbinger, Andreas; Bavarian State Ministry of the Environment and Consumer Protection

Kollnig, Christina; Ökologisches Büro Reutte

Kreiner, Daniel; Nationalpark Gesäuse GmbH

Kudrnovsky, Helmut; University of Vienna

Künzl, Michaela; Bavarian State Ministry of the Environment and Consumer Protection

Kupper, Patrick; University of Innsbruck

Kurmayer, Rainer; University of Innsbruck

Küry, Daniel; Life Science AG

Lange, Sigrun; WWF Germany

Lanz, Klaus; International Water Affairs

Lassacher, Felix; Life Lech Monitoringteam

Lechleitner, Sarah; Naturpark Tiroler Lech

Leonhardt, Gabriele; Nationalpark Berchtesgaden

Leoni, Valeria; University of Milan

Lindinger, Helga; Umweltbundesamt GmbH

Lussi, Stephan; BAFU, Bern

Mani, Peter; geo7 AG, Bern

Mark, Wolfgang; University of Innsbruck

Marke, Thomas; University of Innsbruck

Mayrhofer, Wolfger; Permanent Secretariat of the Alpine Convention

Michaeler, Walter; Government of Tyrol

Michor, Klaus; REVITAL Integrative Naturraumplanung GmbH

Miotto, Filippo; Associazione ARS.UNI.VCO

Mitterdorfer, Robin; Kanton Wallis

Muhar, Susanne; University of Natural Resources and Life Sciences, Vienna

Müller, Norbert; University of Applied Sciences Erfurt

Neumaier, Sina; I can help!

Niedrist, Georg; Ingenieurbüro f. Biologie und Gewässerökologie

Nießner, Reinhard; University of Innsbruck

Oberarzbacher, Stefanie; EURAC Research, Bolzano

Otto, Jan-Christoph; University of Salzburg

Pallhuber, Marco; Plansee

Papez, Joze; Hidrotehnik, Planalp, Eusalp AGB

Pecci, Massimo; Dipartimento per gli affari regionali, le autonomie e lo sport, Rome

Pederzolli, Gianfranco; Consorzio B.I.M. Sarca Mincio Garda

Pellegrini, Emilia; University of Padua

Persiano, Simone; University of Bologna

Petrini, Ronald; Tourismusverband Naturparkregion Reutte

Pfister, Jürg; Swiss Academy of Sciences, Bern 
Pipan, Primož; Anton Melik Geographical Institute

Piva, Aureliano; Permanent Secretariat of the Alpine Convention

Polt, Renata; University of Natural Resources and Life Sciences, Vienna

Pozzani, Rolando; Water Platform

Psenner, Roland; University of Innsbruck

Pugliese, Alessio; University of Bologna

Rauch, Jürgen; Metroconsult

Reich, Michael;

Reiterer, Markus; Permanent Secretariat of the Alpine Convention

Reynard, Emmanuel; University of Lausanne

Ribnikar, Mateja; Ministry of the Environment and Spatial Planning of Republic of Slovenia

Rohr, Christian; University of Berne

Salchner, Marlene; Naturpark Tiroler Lech

Salvisberg, Melanie; University of Berne

Šantl, Sašo; Institute for Water of the Republic of Slovenia

Saverwein, Anna; University of Innsbruck

Schaffhauser, Andreas; ZAMG

Scheurer, Thomas; ISCAR, Bern

Schilling, Christian; Federal Ministry for Sustainability and Tourism

Schlange, Lutz E.; HTW Chur

Schlüchter, Christian; University of Berne

Schmid, Julia; Government of Tyrol

Schmocker-Fackel, Petra; BAFU, Bern

Schöpfer, Anna; University of Innsbruck

Schubert, Eva; Landesbund für Vogelschutz

Schural, Manuel; I can help!

Schütz, Stefan; University of Innsbruck

Scotti, Alberto; EURAC Research, Bolzano

Skrt, Primož; JS Alpine Space

Sötz, Elisabeth; WWF Austria

Sparber, Wolfram; EURAC Research, Bolzano

Spiegelberger, Thomas; IRSTEA, Grenoble

Stähli, Manfred; WSL, Birmensdorf

Steiger, Robert; University of Innsbruck

Strasser, Ulrich; University of Innsbruck

Štravs, Luka; Ministry of the Environment and Spatial Planning of Republic of Slovenia

Stritih, Jernej; Stritih Sustainable Development Consulting

Sušnik, Andreja; Slovenian Environmental Agency

Thaler, Thomas; University of Natural Resources and Life Sciences, Vienna

Tolusso, Emiliano; Università degli Studi di Milano

Tschavoll, Gebhard; WWF Austria

Udovc, Andrej; Univerza v Ljubljana

Urbanek, Bettina; WWF Austria

Urbaniek-Brekke, Anna Maria; Western Norway Research Institute (Vestlandsforsking)

Urzi, Alessandro; Consiglio regionale del Trentino Alto Adige e Consiglio provinciale di Bolzano

Von Fumetti, Stefanie; University of Basel

Voraver, Anton; WWF Austria

Weingartner, Rolf; University of Berne

Wenter, Andreas; Free University of Bozen-Bolzano

Wiesenegger, Hans; Government of Salzburg

Wieser, Josef; Agentur Landesdomäne / Aquatisches Artenschutzzentrum

Wildt, Stefan;

Winkler, Charly; Fotograf

Winklmair, Caroline; Naturpark Tiroler Lech

Witty, Stefan; CIPRA Deutschland

Zbinden Gysin, Karin; Berner Fachhochschule

Zebisch, Marc; EURAC Research

Zimmermann-Timm, Heike; Goethe-Universität Frankfurt 


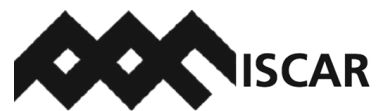

International Scientific Committee on Research in the Alps

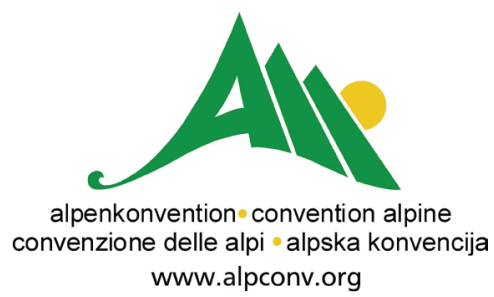

www.alpconv.org

Financial support \& sponsoring

\section{ÖAW
= Bundesministerium Nachhaltigkeit und Tourismus

Akademien der Wissenschaften Schweiz

Académies suisses des sciences

Accademie svizzere delle scienze

Academias svizras da las scienzas

Swiss Academies of Arts and Sciences

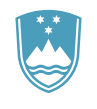

REPUBLIC OF SLOVENIA

MINISTRY OF THE ENVIRONMENT

AND SPATIAL PLANNING
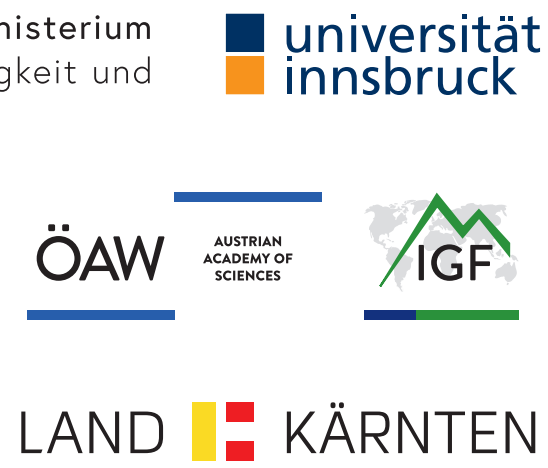
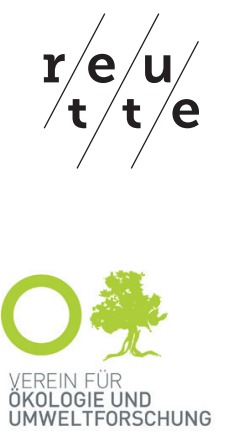

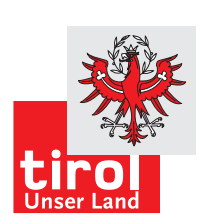

\section{LAND KÄRNTEN}

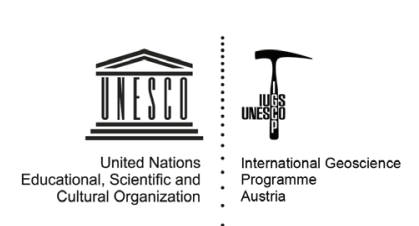

ORF

UNI

VER

SUM

\section{$\mathrm{e}_{\mathrm{m}}^{\mathrm{m}} \mathbf{r}$}

PLANSEE

The Plansee Group
National committee for "Global Change" of the ÖAW National committee for "Geo/Hydro-Sciences" of the ÖAW

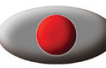

POSCH TV 